\title{
User Guide for VISION 3.4.7 (Verifiable Fuel Cycle Simulation) Model
}

Jacob J. Jacobson

Robert F. Jeffers

Gretchen E. Matthern

Steven J. Piet

Wendell D. Hintze

July 2011

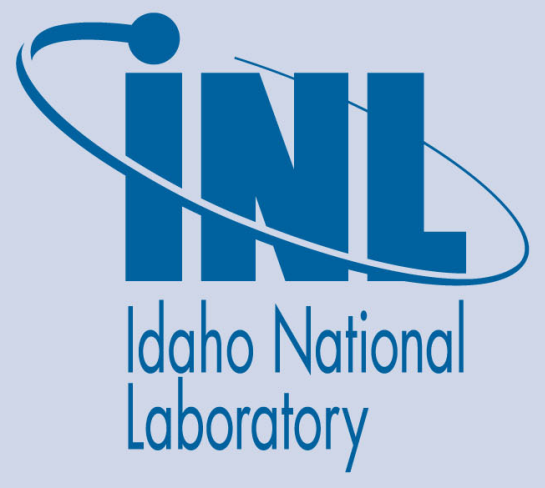

The INL is a U.S. Department of Energy National Laboratory operated by Battelle Energy Alliance 
INL/EXT-09-16645

Rev. 1

AFCI-SYSA-AI-MI-GD-2009-000152

Rev. 3

\title{
User Guide for VISION 3.4.7 (Verifiable Fuel Cycle Simulation) Model
}

\author{
Jacob J. Jacobson \\ Robert E. Jeffers \\ Gretchen E. Matthern \\ Steven J. Piet \\ Wendell D. Hintze
}

July 2011

\section{Idaho National Laboratory \\ Advanced Fuel Cycle Initiative \\ Idaho Falls, Idaho 83415}

http://www.inl.gov

Prepared for the

U.S. Department of Energy

Office of Nuclear Energy

Under DOE Idaho Operations Office

Contract DE-AC07-05ID14517 
DISCLAIMER

This information was prepared as an account of work sponsored by an agency of the U.S. Government. Neither the U.S. Government nor any agency thereof, nor any of their employees, makes any warranty,

expressed or implied, or assumes any legal liability or responsibility for the accuracy, completeness, or usefulness, of any information, apparatus, product, or process disclosed, or represents that its use would not infringe privately owned rights. References herein to any specific commercial product, process, or service by trade name, trade mark, manufacturer, or otherwise, does not necessarily constitute or imply its endorsement, recommendation, or favoring by the U.S. Government or any agency thereof. The views and opinions of authors expressed herein do not necessarily state or reflect those of the U.S. Government or any agency thereof. 


\section{SUMMARY}

The purpose of this document is to provide a guide for using the current version of the Verifiable Fuel Cycle Simulation (VISION) model. This is a complex model with many parameters and options; the user is strongly encouraged to read this user guide before attempting to run the model.

This model is an R\&D work in progress and may contain errors and omissions. It is based upon numerous assumptions. This model is intended to assist in evaluating "what if" scenarios and in comparing fuel, reactor, and fuel processing alternatives at a systems level. The model is not intended as a tool for process flow and design modeling of specific facilities nor for tracking individual units of fuel or other material through the system. The model is intended to examine the interactions among the components of a fuel system as a function of time varying system parameters; this model represents a dynamic rather than steady-state approximation of the nuclear fuel system.

VISION models the nuclear cycle at the system level, not individual facilities, e.g., "reactor types" not individual reactors and "separation types" not individual separation plants. Natural uranium can be enriched, which produces enriched uranium, which goes into fuel fabrication, and depleted uranium (DU), which goes into storage. Fuel is transformed (transmuted) in reactors and then goes into a storage buffer. Used fuel can be pulled from storage into either separation or disposal. If sent to separations, fuel is transformed (partitioned) into fuel products, recovered uranium, and various categories of waste. Recycled material is stored until used by its assigned reactor type.

VISION is comprised of several Microsoft Excel input files, a Powersim Studio core, and several Microsoft Excel output files. All must be co-located in the same folder on a PC to function. You must use Powersim Studio 8 or better. We have tested VISION with the Studio 8 Expert, Executive, and Education versions. The Expert and Education versions work with the number of reactor types of 3 or less. For more reactor types, the Executive version is currently required. The input files are Excel2003 format (xls). The output files are macro-enabled Excel2007 format (xlsm).

VISION 3.4 was designed with more flexibility than previous versions, which were structured for only three reactor types - LWRs that can use only uranium oxide (UOX) fuel, LWRs that can use multiple fuel types (LWR MF), and fast reactors. One could not have, for example, two types of fast reactors concurrently. The new version allows 10 reactor types and any user-defined uranium-plutonium fuel is allowed. (Thorium-based fuels can be input but several features of the model would not work.) The user identifies (by year) the primary fuel to be used for each reactor type. The user can identify for each primary fuel a contingent fuel to use if the primary fuel is not available, e.g., a reactor designated as using mixed oxide fuel (MOX) would have UOX as the contingent fuel. Another example is that a fast reactor using recycled transuranic (TRU) material can be designated as either having or not having appropriately enriched uranium oxide as a contingent fuel.

Because of the need to study evolution in recycling and separation strategies, the user can now select the recycling strategy and separation technology, by year. Recycling strategy means how fuel is routed from used fuel storage into one or more separation facility types. As an example, a separation plant could be designated to use one source of UOX fuel for three decades and then shift to having a combination of UOX and MOX. Separation technology means how fuel is separated into products, which are routed into one of the 10 subsequent fuel types, or waste. So, for example, the user can designate a separation plant type to change efficiency (fraction of TRU into waste) or change from not recovering minor actinides ( $\mathrm{Np}, \mathrm{Am}, \mathrm{Cm}, \mathrm{Bk}, \mathrm{Cf}$ ) to later recovering them. 


\section{CONTENTS}

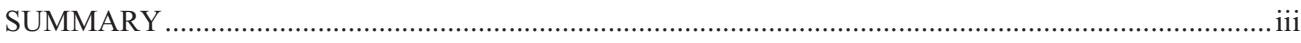

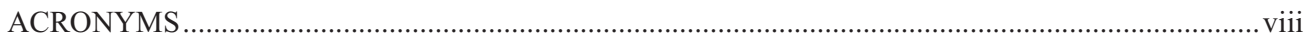

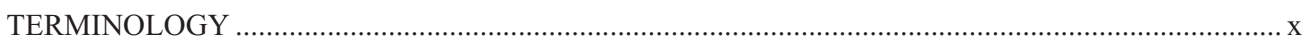

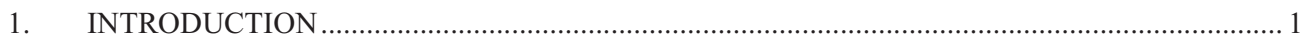

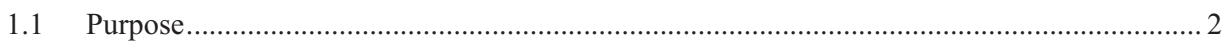

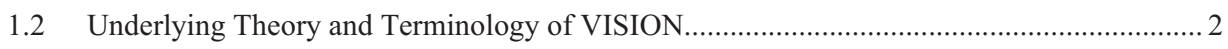

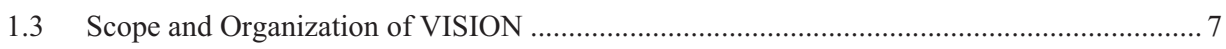

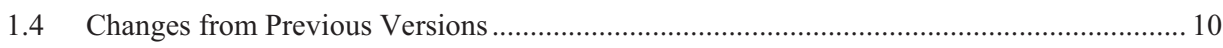

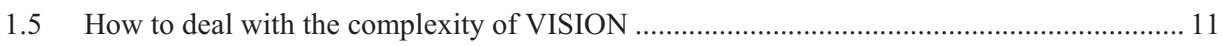

2. KEY ASSUMPTIONS AND INITIAL PARAMETERS............................................................ 13

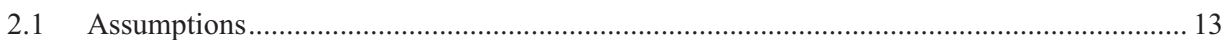

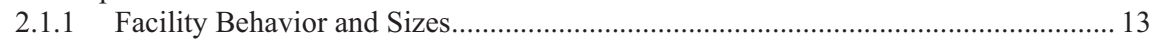

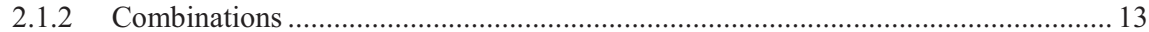

2.1.3 Priority among Reactors, Separations, and Fuel Fabrication Types ......................... 13

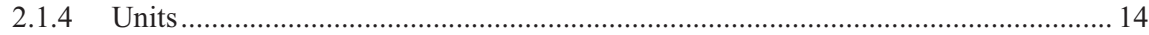

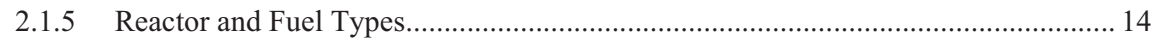

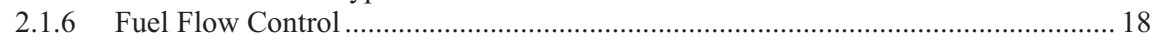

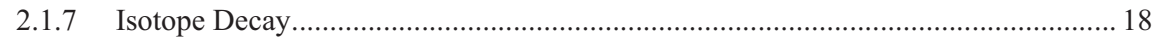

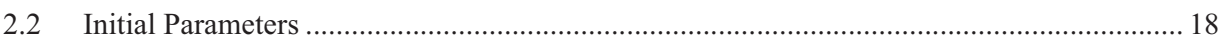

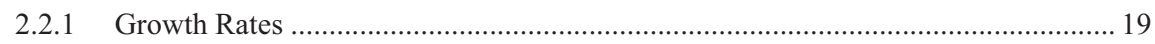

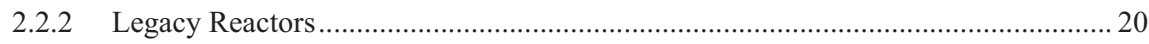

2.2.3 Legacy Fuel..................................................................................................... 20

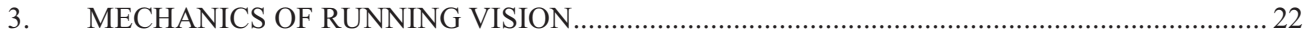

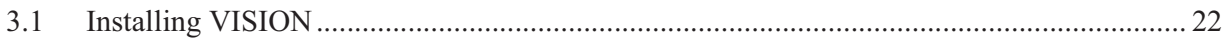

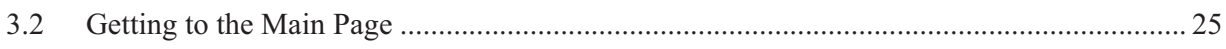

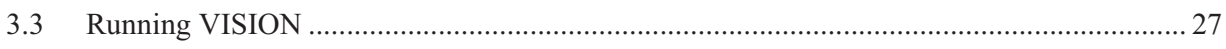

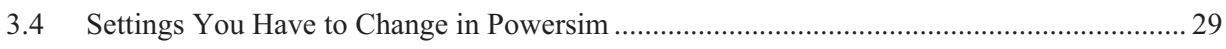

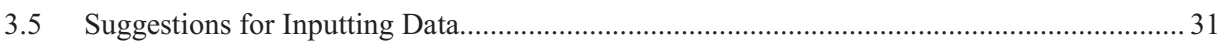

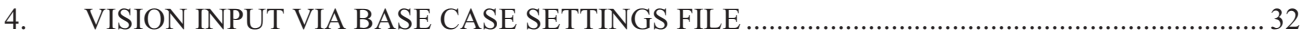

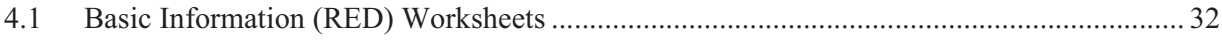

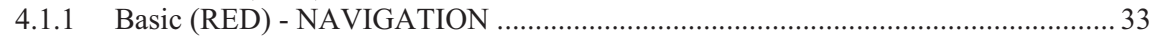

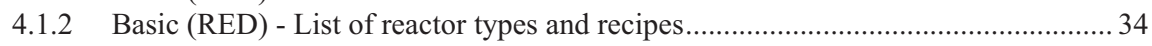

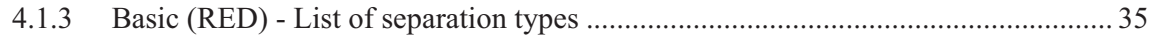

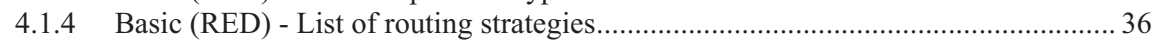

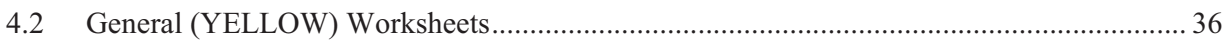

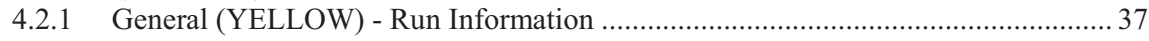

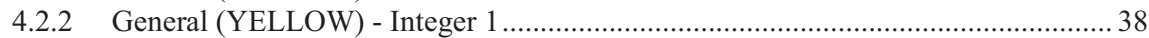

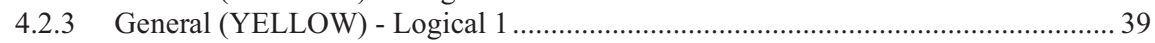

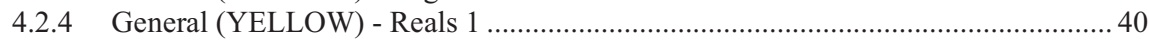


4.2.5 General (YELLOW) - Growth Rate Worksheet and User Help on Growth

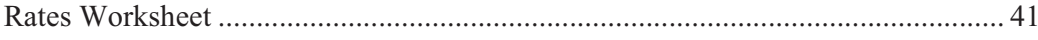

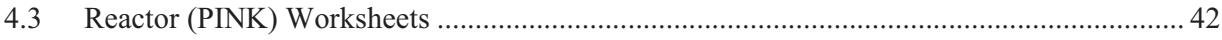

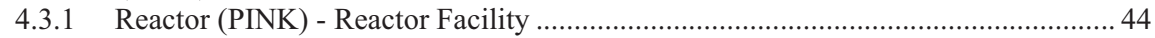

4.3.2 Reactor (PINK) - Legacy Reactor Retirement Rate............................................ 45

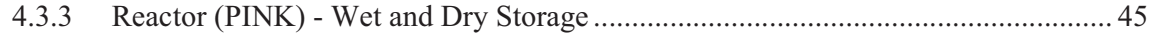

4.3.4 Reactor (PINK) - Reactor \%s and Reactor \%s Total ............................................... 46

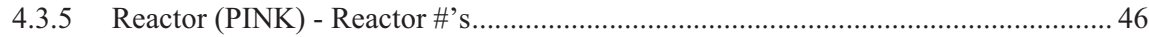

4.3.6 Reactor (PINK) - Reactor Growth \% of Final .............................................................. 46

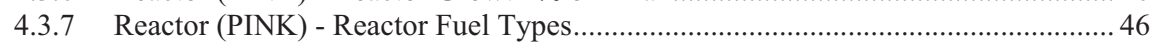

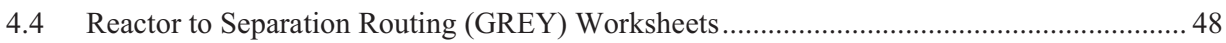

4.4.1 Reactor to Separation Routing (GREY) - Recycle Strategy Option ........................... 49

4.4.2 Reactor to Separation Routing (GREY) - Recycle Strategy Matrix .......................... 49

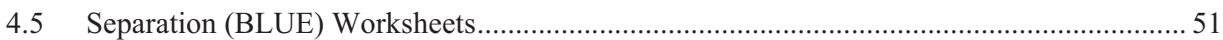

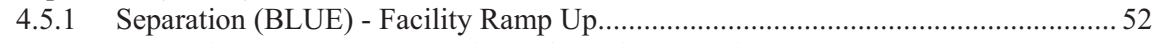

4.5.2 Separation (BLUE) - Separation 1 through Separation 10..................................... 52

4.5.3 Separation (BLUE) - Separation Stream Splits (Separation Efficiency

Matrices)

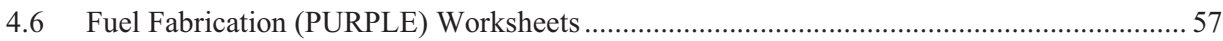

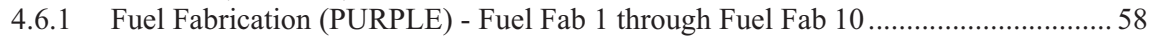

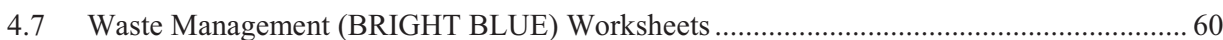

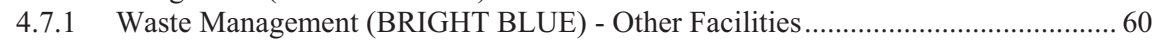

4.7.2 Waste Management (BRIGHT BLUE) - Coflows (Inactive for VISION 3.4) .......... 60

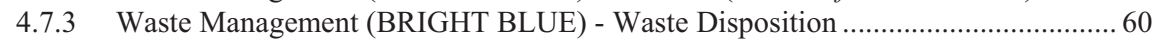

4.7.4 Waste Management (BRIGHT BLUE) - Waste Form and Mass Loading.................. 61

4.7.5 Waste Management (BRIGHT BLUE) - Worksheet for LSF \& SF Waste ............... 61

4.7.6 Waste Management (BRIGHT BLUE) - MRS Flow Capacity ........................................ 61

4.7.7 Waste Management (BRIGHT BLUE) - Repository Holding Capacity …....................61 61

4.7.8 Waste Management (BRIGHT BLUE) - Repository Flow Capacity............................ 62

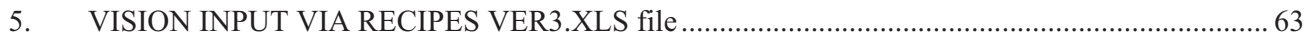

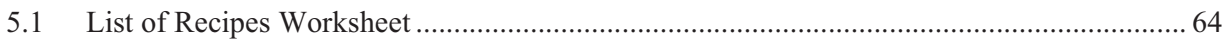

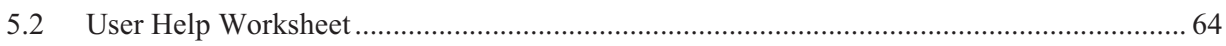

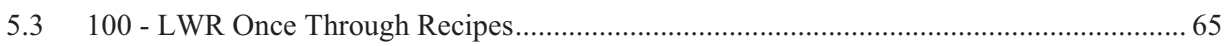

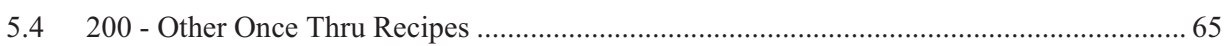

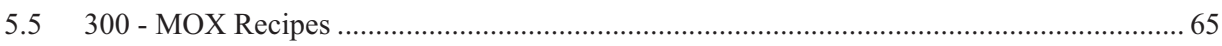

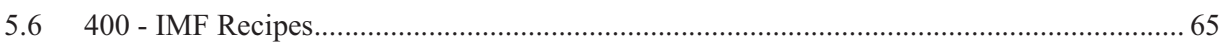

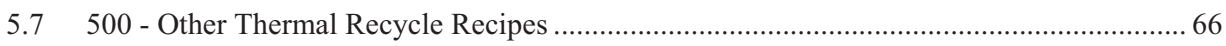

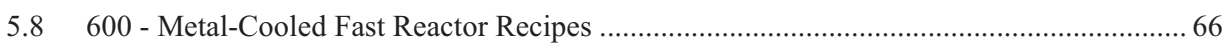

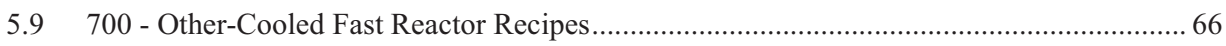

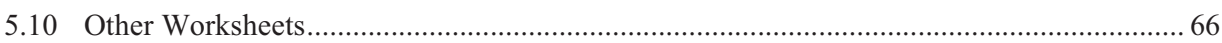

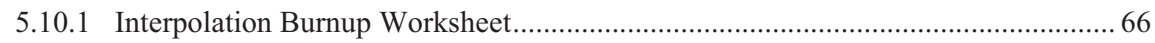

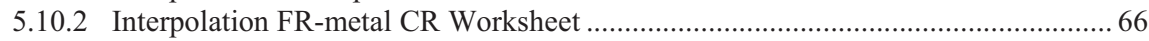

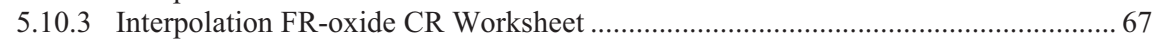

5.10.4 Worksheets Named Yellow, Blue, Green, Nu, VISION k-infinity ........................... 67 


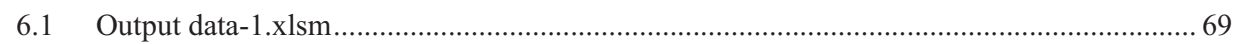

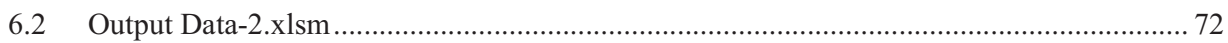

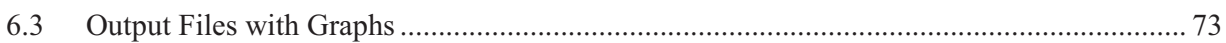

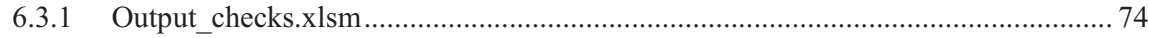

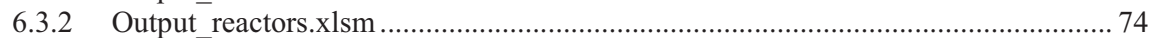

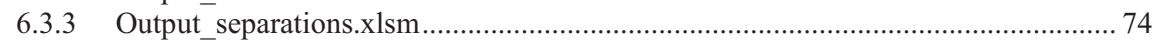

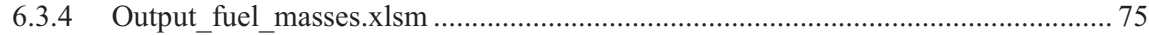

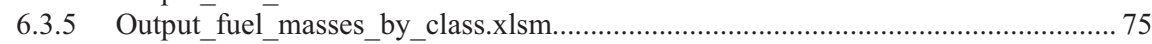

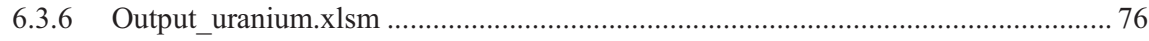

6.3.7 Output_used_fuel_masses.xlsm ................................................................................... 76

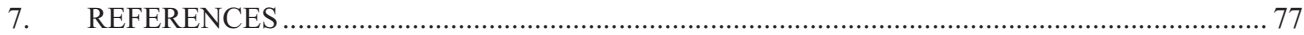

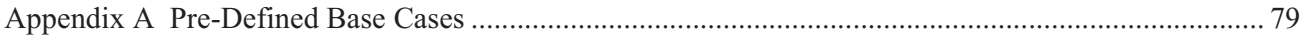

\section{FIGURES}

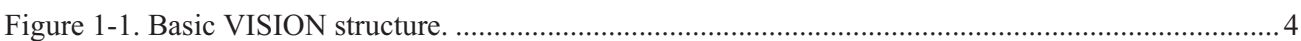

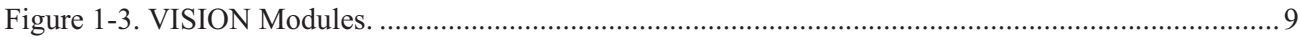

Figure 2-1. Periodic Table as seen from fuel cycle system analysis perspective.[Piet2009].................... 16

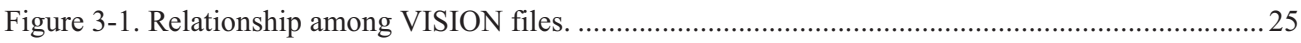

Figure 3-2. VISION main screen in Powersim Studio.................................................................... 26

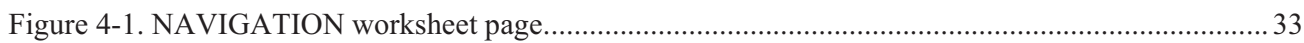

TABLES

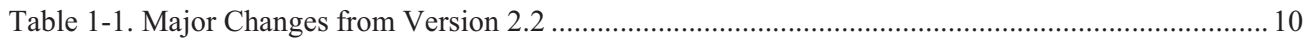

Table 2-1. Tracked Isotopes and Chemical Elements [Piet2009] …..................................................... 17

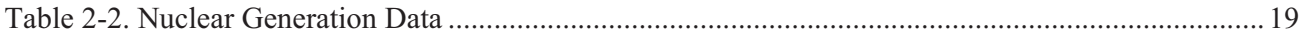

Table 2-3. Thermal Reactor Safety Constraints on MOX/IMF [adapted from M. Todosow] ...................20

Table 2-4. U.S. Used Fuel, Prior to 2000 …........................................................................................... 21

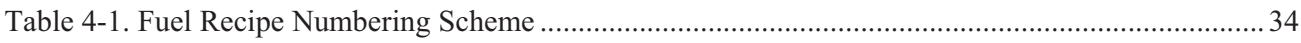

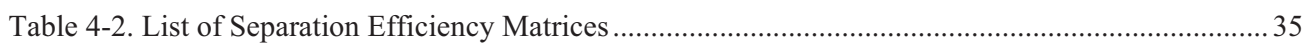

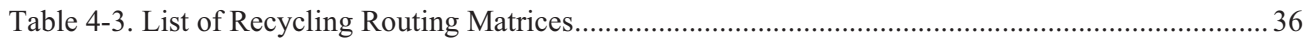

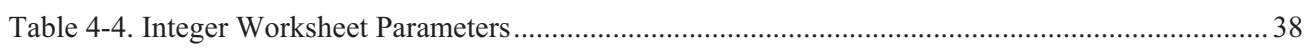

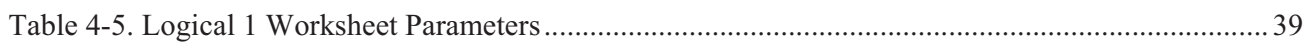

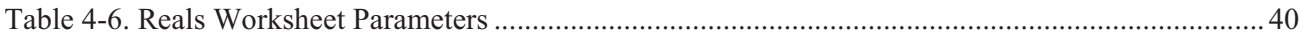

Table 4-7. Reactor Capacities and Transformation Performance in VISION ......................................... 42

Table 4-8. Reactor Capacities and Transformation Performance in VISION........................................... 44

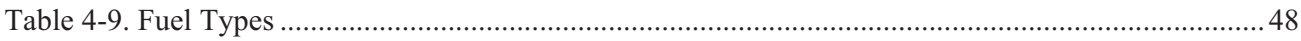


VISION User Guide, Rev 3.4

June 2011

Table 4-10. Separation Facility Capacities and Transformation Performance in VISION.......................51

Table 4-11. Parameters set on the Separation Worksheets ......................................................................... 52

Table 4-12. Definition of Separation Efficiency Matrices .................................................................... 54

Table 4-13. Illustrative UREX+1 Separation Efficiency Matrix .................................................................55

Table 4-14. Illustrative Separation Efficiency for U+UPu+NpPuAm+CsSr+I+Tc Separation of

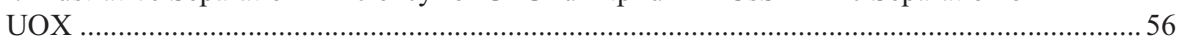

Table 4-15. Illustrative Electrochemical Separation Efficiency of FR Metal Fuel.................................56

Table 4-16. Fabrication Facility Capacities and Transformation Performance in VISION......................55

Table 4-17. Parameters Set on Fuel Fab Worksheets ...............................................................................5

Table 4-18. Parameters Set on Other Facilities Worksheet …................................................................ 60 


\section{ACRONYMS}

\begin{tabular}{|c|c|}
\hline AFCI & Advanced Fuel Cycle Initiative \\
\hline $\mathrm{Aq}$ & Aqueous separation \\
\hline $\mathrm{BC}$ & Base Case \\
\hline $\mathrm{BU}$ & Burnup, sometimes incorrectly used as burned uranium \\
\hline BWR & Boiling water reactor, a type of Light Water Reactor (LWR) \\
\hline CANDU & CANada Deuterium Uranium reactor \\
\hline CFR & Converter Fast Reactor \\
\hline COEX & Co-Extraction producing RU and UPu as products and everything else as a waste \\
\hline $\mathrm{CR}$ & Transuranic Conversion Ratio (TRU produced/TRU destroyed) \\
\hline $\mathrm{CY}$ & Calendar Year \\
\hline DU & Depleted uranium, the low U235 tailings from uranium enrichment \\
\hline E-chem & Electrochemical separation, also known as pyroprocessing \\
\hline EU & Enriched uranium, the high U235 produce from uranium enrichment \\
\hline FBR & Fast Breeder or Burner Reactor \\
\hline FPY & Full Power Year \\
\hline FR & Fast Reactor \\
\hline GNEP & Global Nuclear Energy Partnership \\
\hline GWe & Gigawatt-electric \\
\hline GWth & Gigawatt-thermal \\
\hline HEU & Highly Enriched Uranium \\
\hline HWR & Heavy water reactor \\
\hline IMF & Inert Matrix Fuel (thermal reactor fuel without uranium) \\
\hline INL & Idaho National Laboratory \\
\hline Iso & Isotope \\
\hline $\mathrm{kt}$ & Kilotonne, one thousand metric tonnes \\
\hline LSF & Legacy Spent Fuel, pre-2000 inventory of discharged LWR fuel \\
\hline LTD & $\begin{array}{l}\text { Long-Term Dose, a metric describing the hypothetical dose to the maximally exposed } \\
\text { individual at a specific time after repository emplacement, scaled from 2004-vintage Yucca } \\
\text { Mountain groundwater pathway calculations }\end{array}$ \\
\hline LTH & $\begin{array}{l}\text { Long-Term Heat, a metric describing the heat committed to waste disposal from time of } \\
\text { repository closure to } \sim 1500 \text { years }\end{array}$ \\
\hline LTR & $\begin{array}{l}\text { Long-Term Radiotoxicity, a metric describing the radiotoxicity of isotopes at a specific } \\
\text { time after repository emplacement }\end{array}$ \\
\hline LWR & Light Water Reactor \\
\hline LWR MF & Light Water Reactor Mixed Fuel, LWR that can use multiple fuels, e.g., MOX and/or IMF \\
\hline LWR MOX & MOX fuel in Light Water Reactors \\
\hline MF & Mixed Fuel in a thermal reactor, e.g., MOX or IMF \\
\hline MOX & $\begin{array}{l}\text { Mixed Oxide fuel, a mixture of uranium oxide and one or more transuranic element oxides, } \\
\text { e.g. MOX-Pu or MOX-TRU }\end{array}$ \\
\hline MRS & Managed Retrievable Storage \\
\hline MT & $\begin{array}{l}\text { Montana, sometimes used as metric ton }(1000 \mathrm{~kg}) \text {, but the proper System Internationale } \\
\text { unit would be } \mathrm{Mg} \text { for megagram. Instead, tonne is used here as metric ton. }\end{array}$ \\
\hline PUREX & $\begin{array}{l}\text { Plutonium-Uranium Extraction, producing } \mathrm{RU} \text { and } \mathrm{Pu} \text { as products and everything else as a } \\
\text { waste stream }\end{array}$ \\
\hline PWR & Pressurized water reactor \\
\hline Rxtr & Reactor \\
\hline RU & Recovered uranium from a separation process \\
\hline
\end{tabular}


VISION User Guide, Rev 3.4

June 2011

\begin{tabular}{|l|l|}
\hline SF & Spent Fuel, also called used fuel \\
\hline SWU & Separative Work Unit \\
\hline$t$ & Tonne (metric ton), 1000 kg \\
\hline TR & Thermal Reactor \\
\hline TRU & Transuranics (Plutonium and higher on periodic table) \\
\hline UOX & Uranium Oxide \\
\hline UREX & Uranium Extraction \\
\hline UREX+1 & $\begin{array}{l}\text { UREX producing U, and all-TRU as product streams and several sets of fission products as } \\
\text { individual waste streams }\end{array}$ \\
\hline UREX+2 & $\begin{array}{l}\text { UREX producing U and NpPu as product streams, and several sets of fission products as } \\
\text { individual waste streams. AmCm goes into waste. }\end{array}$ \\
\hline UREX+3 & $\begin{array}{l}\text { UREX producing U, NpPu, and AmCm as product streams and several sets of fission } \\
\text { products as individual waste streams }\end{array}$ \\
\hline UREX+4 & $\begin{array}{l}\text { UREX producing U, NpPu, Am, and Cm as product streams and several sets of fission } \\
\text { products as individual waste streams }\end{array}$ \\
\hline VHTR & Very High Temperature Reactor \\
\hline VISION & Verifiable Fuel Cycle Simulation \\
\hline
\end{tabular}




\section{TERMINOLOGY}

\begin{tabular}{|c|c|}
\hline Base case & A set of parameters in the main input file that defines a self-consistent scenario. \\
\hline Decay products & Decay products of uranium, specifically $\mathrm{Pb}, \mathrm{Bi}, \mathrm{Ra}, \mathrm{Ac}, \mathrm{Th}, \mathrm{Pa}$ \\
\hline Excel & $\begin{array}{l}\text { Microsoft "contribution" to spreadsheet software. } \\
\text { VISION input files are in } 2003 \text { format (xls). } \\
\text { VISION output files are in macro-enabled } 2007 \text { format (xlsm). }\end{array}$ \\
\hline $\begin{array}{l}\text { Fast burner or } \\
\text { converter reactor }\end{array}$ & A fast reactor with transuranic conversion ratio $<1$ \\
\hline Fast breeder reactor & A fast reactor with transuranic conversion ratio $>1$ \\
\hline File & $\begin{array}{l}\text { If extension xls - Excel } 2003 \text { spreadsheet files, file names are in bold in this } \\
\text { document. } \\
\text { If extension xlsm - Excel } 2007 \text { macro-enabled spreadsheet files. } \\
\text { If extension sip - Powersim Studio files }\end{array}$ \\
\hline Fuel recipe & $\begin{array}{l}\text { Either the input or output composition of a reactor fuel, normalized so that the } \\
\text { total recipe equals } 1.00 \text {. Recipes are contained in the file vision recipes ver3.xls }\end{array}$ \\
\hline Group $1 / 2$ & $\begin{array}{l}\text { Alkali/Alkali earths, specifically } \mathrm{Rb}, \mathrm{Sr}, \mathrm{Cs}, \mathrm{Ba} \text {. For fuel cycle management, the } \\
\text { most important radioactive Group } 1 \mathrm{~A} / 2 \mathrm{~A} \text { are } \mathrm{Sr} 90, \mathrm{Cs} 134, \mathrm{Cs} 135, \mathrm{Cs} 137 .\end{array}$ \\
\hline Halogens & $\begin{array}{l}\text { Group } 17 \text { of the Periodic Table, specifically } \mathrm{Br} \text { and I. For fuel cycle management, } \\
\text { the most important radioactive halogen is I } 129 .\end{array}$ \\
\hline Inert gases & $\begin{array}{l}\text { Group } 18 \text { of the Periodic Table, specifically } \mathrm{Kr} \text { and Xe. For fuel cycle } \\
\text { management, the most important radioactive inert gases are Kr81 and Kr85. }\end{array}$ \\
\hline Lanthanides & $\begin{array}{l}\text { Elements La through Lu. For fuel cycle management, the most important isotopes } \\
\text { are Ce144, Pm147, Sm146, Sm147, Sm151, Eu154, Eu155, Ho166m. }\end{array}$ \\
\hline Legacy & $\begin{array}{l}\text { Any reactor or used fuel that exists before the simulation begins, typically the year } \\
2000 \text {. }\end{array}$ \\
\hline Minor actinides & Transuranic isotopes other than plutonium, specifically $\mathrm{Np}, \mathrm{Am}, \mathrm{Cm}, \mathrm{Bk}, \mathrm{Cf}$. \\
\hline Prioritization - order & $\begin{array}{l}\text { A facility capacity is used by a set of incoming flows such that source one is used } \\
\text { first, then source two, etc. until the full capacity of the facility type is used. }\end{array}$ \\
\hline $\begin{array}{l}\text { Prioritization - } \\
\text { percentage }\end{array}$ & $\begin{array}{l}\text { A facility capacity is used by allocating a percentage of the capacity among a set } \\
\text { of potential flows. }\end{array}$ \\
\hline Powersim Studio & $\begin{array}{l}\text { Commercial system dynamic software in which the core part of the VISION suite } \\
\text { is written. }\end{array}$ \\
\hline Routing - pull & $\begin{array}{l}\text { A receiving facility attempts to pull material from a designated set of sending } \\
\text { facilities. Thus, there must be a buffer inventory at each sending facility because } \\
\text { the material may or may not be requested by one or more receiving facilities. }\end{array}$ \\
\hline Routing - push & $\begin{array}{l}\text { Material is sent by a facility independent of whether the receiving facility has } \\
\text { sufficient capability for it. Thus, there must be a buffer inventory at the receiving } \\
\text { facility. }\end{array}$ \\
\hline Transition metals & $\begin{array}{l}\text { In this report, literally the elements not otherwise categorized, including } \mathrm{Se}, \mathrm{Mo} \text {, } \\
\mathrm{Ru}, \mathrm{Pd}, \mathrm{Pd}, \mathrm{Cd}, \mathrm{Sn}, \mathrm{Sb}, \mathrm{Te} \text {. }\end{array}$ \\
\hline Transuranic & $\begin{array}{l}\text { Isotopes above uranium in the Periodic Table, specifically } \mathrm{Np}, \mathrm{Pu}, \mathrm{Am}, \mathrm{Cm}, \mathrm{Bk} \text {, } \\
\mathrm{Cf} \text {. }\end{array}$ \\
\hline TRU Conversion & Ratio of transuranic material created during residence in a reactor divided by the \\
\hline
\end{tabular}


VISION User Guide, Rev 3.4

June 2011

\begin{tabular}{|l|l|}
\hline Ratio (CR) & $\begin{array}{l}\text { transuranic material destroyed. This is related to but different from than fissile } \\
\text { breeding ratio, which is the ratio of fissile material created/destroyed. }\end{array}$ \\
\hline $\begin{array}{l}\text { Separation } \\
\text { efficiency matrix }\end{array}$ & $\begin{array}{l}\text { Also can be described as separation technology matrix or separation partition } \\
\text { matrix. User-defined matrices allocate percentages of each component of used } \\
\text { fuel into fuel product streams, recovered uranium (RU), and/or waste streams. }\end{array}$ \\
\hline VISION & $\begin{array}{l}\text { The suite of Excel input files, Powersim core, and Excel output files that models } \\
\text { the nuclear fuel cycle system. }\end{array}$ \\
\hline Worksheet (or page) & $\begin{array}{l}\text { Worksheets within a spreadsheet file, worksheet names are in bold in this } \\
\text { document }\end{array}$ \\
\hline
\end{tabular}





\section{VISION USER GUIDE}

\section{INTRODUCTION}

This document provides a guide for using the current version of the Verifiable Fuel Cycle Simulation (VISION) model. This is a complex model with many parameters and options; the user is strongly encouraged to read the user guide before attempting to run the model.

VISION is comprised of several Microsoft Excel2003 input files, a Powersim Studio core, and several Microsoft Excel2007 output files. Thus, the user must have Powersim software. We use Powersim Studio 8 Service Release 7 Feature Pack 3. It appears to also work with Studio 8 Service Release 5 and 6, as long as Feature Pack 3 is installed. Studio 8 Expert version works for up to 3 reactor types. After 3 reactor types, then Executive version is required because the number of variables in the model exceed 700,000 . We will work to see if the number of variables can be reduced in future versions.

VISION 3.4 was designed with more flexibility than previous versions, which were structured for only three reactor types - LWRs that can use only uranium oxide (UOX) fuel, LWRs that can use multiple fuel types (LWR MF), and fast reactors. One could not have, for example, two types of fast reactors concurrently. The new version allows 10 reactor types and any user-defined uranium-plutonium fuel is allowed. (Thorium-based fuels can be input but several features of the model will not work.) The user identifies (by year) the primary fuel to be used for each reactor type. The user can identify for each primary fuel a contingent fuel to use if the primary fuel cannot be made, e.g., a reactor designated as using mixed oxide fuel (MOX) would have UOX as the contingent fuel. Another example is that a fast reactor using recycled transuranic (TRU) material can be designated as either having or not having appropriately enriched uranium oxide as a contingent fuel.

Because of the need to study evolution in recycling and separation strategies, the user can now select the recycling strategy and separation technology, by year. Recycling strategy means how fuel is routed from used fuel storage into one or more separation facility types. As an example, a separation plant could be designated to use one source of UOX fuel for three decades and then shift to having a combination of UOX and MOX. Separation technology means how fuel is separated into products, which are routed into one of the 10 subsequent fuel types, or waste. So, for example, the user can designate a separation plant type to change efficiency (fraction of TRU into waste) or change from not recovering minor actinides $(\mathrm{Np}, \mathrm{Am}, \mathrm{Cm}, \mathrm{Bk}, \mathrm{Cf})$ to later recovering them.

So, the user has three major year-by-year ways to control the fuel cycle: fuel recipes, recycling routing matrices that route used fuel to separation types, and separation efficiency matrices, which separate products from waste and also serve to route separation products back to fuel/reactor types.

This flexibility comes with two disadvantages. First, the magnitude of the required input has grown sixfold; the main input file (base case settings ver3.xls) has grown from 4.5 to $30 \mathrm{MB}$. So, we have started to create some Excel macro's to assist in data entry; please comment on their usefulness. In particular, there is a macro for copying the settings of one case into one of the user defined cases. And, there is an "interview" macro for guiding a user through setting up a case. Second, we cannot pre-define most of the output files a user might want, nor anticipate how a user would want them labeled. For example, fast reactors might be reactor type 3 or reactor 6 or not exist. So, we have added a page in the input file that asks users to supply their names for each run, each reactor type, each fuel type, and each separation type; these are used in the various output files. And, we have added "Graph Viewer" and "Graph Builder" 
macros ${ }^{\mathrm{a}}$ into relevant output files so the user can see pre-existing graphs as well as be guided into making new graphs. Pre-existing graphs will generally have to be modified before use, e.g., by deleting reactor, fuel, or separation types that are not used in a particular simulation.

The current model has two limitations in the new algorithm that tells VISION how many fast reactors to order when (a) fast reactors are in the system and (b) fast reactors are not allowed to operate on enriched uranium fuel (they require TRU fuel). The algorithm looks ahead to determine TRU fuel availability and therefore how many fast reactors can be ordered without running into fuel supply later. The user can also run VISION with user-supplied reactor ordering profiles.

1. This algorithm does not account for fuel that is in a permanent repository. i.e., irretrievable. (Retrievable repository is not an issue in this regard.) If your simulation puts fuel into a permanent, irretrievable repository, the algorithm will not account for this fuel having left the available fuel for future separation. This will tend to lead to too many fast reactors, some of which may face inadequate fuel later.

2. For breeder and near-breeder cases (fast reactor TRU conversion ratio $\geq 1$ ), the current algorithm is slightly underpredicting the number of fast reactors that can be ordered. This underprediction tends to be larger the higher the conversion ratio and appears to slowly accumulate during the simulation. This manifests itself with available TRU fuel material accumulating in available material (the "buffer box" from which the fast reactor fuel fabrication draws from).

\subsection{Purpose}

This model is an R\&D work in progress and may contain errors and omissions. It is based upon numerous assumptions. This model is intended to assist in evaluating "what if" scenarios and in comparing fuel, reactor, and fuel processing alternatives at a systems level for U.S. nuclear power. The model is not intended as a tool for process flow and design modeling of specific facilities nor for tracking individual units of fuel or other material through the system. The model is intended to examine the interactions among the components of a fuel system as a function of time varying system parameters; this model represents a dynamic rather than steady-state approximation of the nuclear fuel system.

This is a model that is still being actively developed, and we invite feedback:

Jake Jacobson

Steve Piet

208-526-3071

$208-526-5252$

Jacob.jacobson@inl.gov

Steven.Piet@inl.gov

In this guide, where there are planned features that do not yet work or are in planning, we have denoted them in purple italics.

\subsection{Underlying Theory and Terminology of VISION}

VISION models the nuclear cycle at the system level, not individual facilities, e.g., "reactor types" not individual reactors and "separation types" not individual separation plants. Nonetheless, to avoid repeating the word "types" countless times, this manual will often simply refer to "reactors" and "separations."

a. Graph Viewer and Graph Builder were done by a past INL student intern, Ben Baker, in Excel2003. They have now been updated to work in Excel2007, which no longer supports Office Web Components. 
VISION is more than modeling mass flows, but we have to start there. It models information flows and various types of constraints. Some constraints are provided by the user, in some cases there are different ways the constraints can be expressed, which adds both flexibility and complexity.

Figure 1-1 shows the basic VISION model of the nuclear fuel cycle. The model includes program control and material routing, as well as all the required mass flows. Natural uranium can be enriched, which produces enriched uranium, which goes into fuel fabrication, and depleted uranium (DU), which goes into storage. ${ }^{b}$ (DU) only comes out of storage if used in a reactor. Fuel is transformed (transmuted) in reactors and goes into a storage buffer. Used fuel can be pulled from storage into either separation of disposal. If sent to separations, fuel is transformed (partitioned) into fuel products, recovered uranium, and various categories of waste. Recycled material is stored until used by its assigned reactor type. Note that recovered uranium (RU) is itself often partitioned: some RU flows with recycled transuranic elements, some flows with wastes, and the rest is designated RU. RU comes out of storage if needed to correct the U/TRU ratio in new recycled fuel. Neither RU nor DU is designated as waste.

b. Uranium recovered from separations (RU) can be re-enriched using the isotope-specific separation factors, but the associated amount of separative work units (SWUs) would not be tracked by the model. 


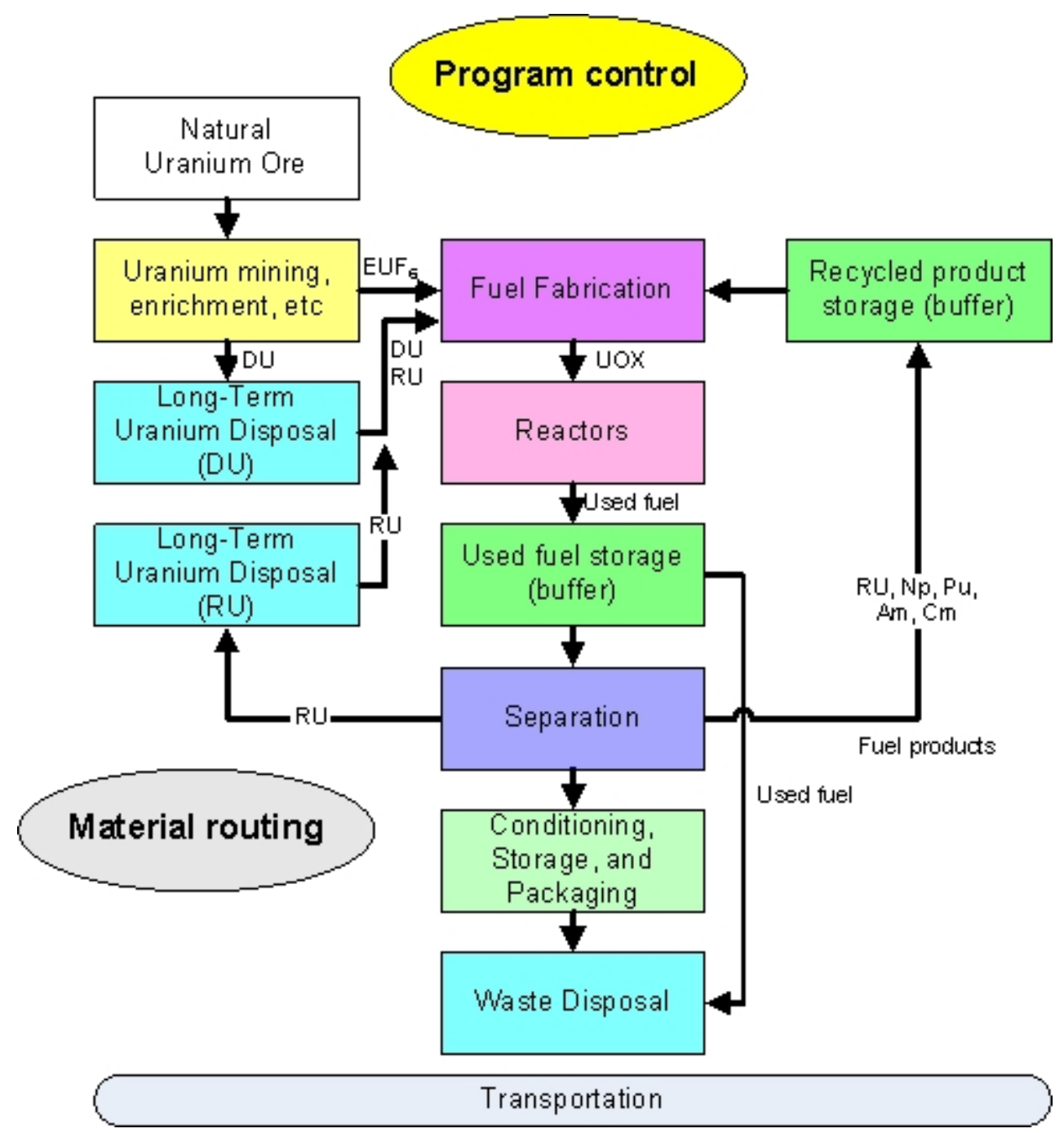

Figure 1-1. Basic VISION structure.

Thus, as fuel moves through the fuel cycle, there are two primary functions - transformation and routing. Transformation occurs at facilities and routing occurs between facilities. Routing does not change the material, it merely moves mass from one place to another. In the parlance of system dynamics, types of facilities are inventories or stocks; routing are flows. Facilities transform material in various ways, e.g.

- Transmutation at reactors,

- Separation (or partition) at separation plants,

- Fabrication at fabrication plants, 
- Waste form creation and waste form packaging at waste processing plants, and

- Isotopic decay at waste storage and all of the above. ${ }^{\mathrm{c}}$

Generally, the performance of each transformation operation is under the user's control. Transformation occurs by user-selected "recipes" that translate an input composition to an output composition. Separation occurs by user-selected "separation efficiency matrices" that partition incoming used fuel into fuel products, recovered uranium, and waste streams. At present, fabrication is not user controlled, material sent to a given fabrication plant always undergoes the type of fabrication appropriate for associated reactor type's fuel, which is itself specified by the fuel recipe selected for that reactor. That is, there is a 1:1 correspondence between fuel fabrication plant types and reactor types.

Routing is also generally under the user's control. The primary exception is again fuel fabrication to reactor. There is no provision to route fuel from one fabrication plant type to a different reactor type.

In principle, routing can be specified either by "pushing" or "pulling."

- Push - Material is sent by a facility independent of whether the receiving facility has requested the material. Typically, there must be a buffer inventory at the receiving facility. Example: Wet fuel storage ejects used fuel to dry fuel storage at the end of its wet fuel storage time.

- $\quad$ Pull - A receiving facility attempts to pull (requests) material from a designated set of sending facilities. Thus, there must be a buffer inventory at each sending facility because the material may or may not be requested by one or more receiving facilities. Example: Recycling request used fuel from dry fuel storage when there is available capacity. Dry fuel storage holds the material until it is requested downstream.

A real fuel cycle system could have both push and pull routing and thus buffers at both sending and receiving facilities. In VISION 3.4, we have chosen to model routing from reactors to separation as "pull", hence buffers are closely associated with reactors, i.e., where used fuel is located such as wet and dry storage. That is, used fuel stays in used fuel storage unless or until pulled by separations or pulled by waste disposal. The routing of separation to fabrication/reactors is primarily modeled as "push", i.e., buffers are envisioned at receiving fuel fabrication plants. Whether push or pull, routing can theoretically be controlled either by priority order or percentage. Priority order means that some capacity is used by a set of incoming flows such that source one is used first, then source two, etc. until the full capacity of the facility type is used. VISION models reactor-to-separation as push/priority-list. Percentage means that material is received or sent to a set of places allocated by percentages. VISION models separation-tofabrication/reactor by pull/percent.

Figure 1-2 shows the routing approach in VISION as well as two of the many alternatives to help differentiate among options. As noted above, VISION uses pull/priority routing from reactors to separation plants and push/percent from separation plants to fuel fabrication (hence reactors). The first alternative shown is pull/priority (reactor to separation) then pull/percent (separation to fuel fabrication). The second alternative is push/percent for both reactor-separation and separation-reactor. All options require at least one buffer between reactor and separation and one between separation and fuel fab; the diagram shows the buffer shifting position. (Here, "position" means in a logical sense, the physical location of buffers is not addressed.)

c. Exception - Isotopes are not decayed once put into a repository as our primary waste management concern is estimating the amount and character of waste forms at the time of emplacement. 


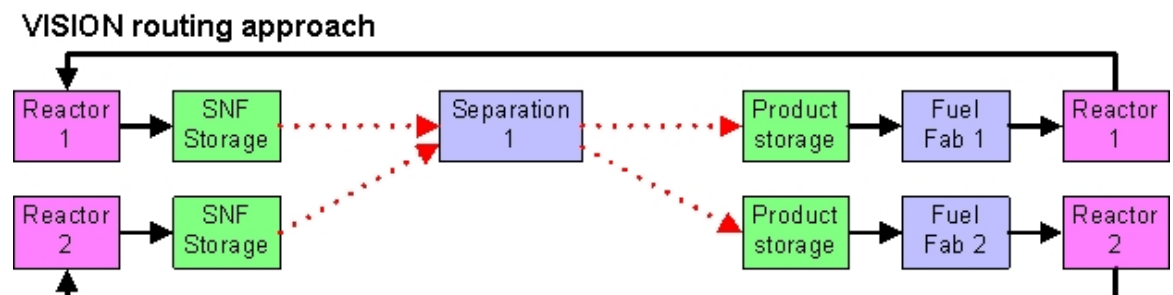

Pull from storage buffer to fill Separation capacity. Separation 1 pulls first, then 2, etc. Fuel stays in storage until pulled.

Priority order - reactor $1 /$ pass 0 , then reactor 2 /pass 0 , etc.
Push from Separation into one product storage for each Fuel

Fab. Products pushed whether Fuel Fab ready to use or not.

Percent allocation - $X \%$ to Fuel Fab 1, Y \% to Fuel Fab 2, etc.

\section{Alternative routing approach}

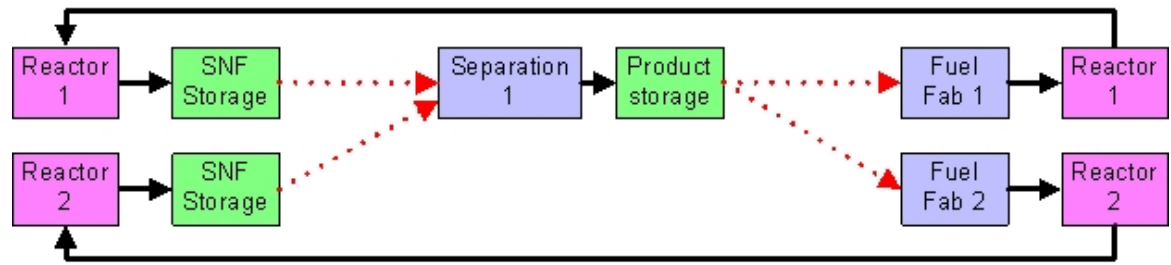

Pull from storage buffer to fill Separation capacity. Separation 1 pulls first, then 2, etc. Fuel stays in storage until pulled.

Priority order - reactor $1 /$ pass 0 , then reactor 2 /pass 0 , etc.
Pull from Separation product storage into Fuel Fab. Fuel Fab 1 pulls first, then 2, etc.

Products stay until pulled.

Percent allocation $-X \%$ pulled from Sep 1, $Y \%$ from Sep 2, etc.

\section{Alternative routing approach}

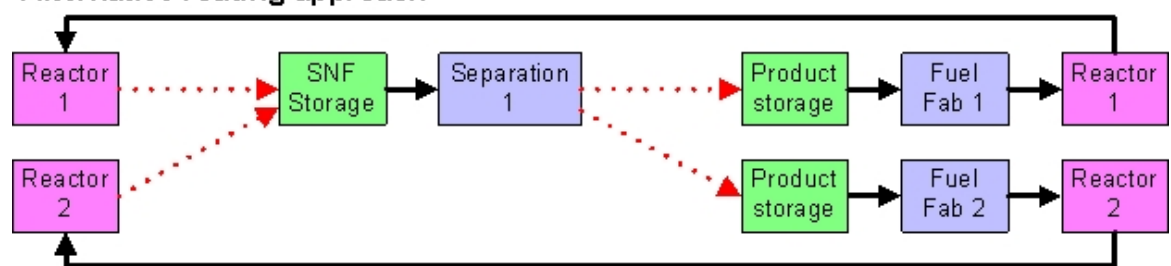

Pus h from Reactors to incoming Separation buffers, regardless of Separation readiness.

Percent allocation - Reactor 1 s ends $X \%$ to Separation $1, Y \%$ to Separation 2 , etc, etc. Reactor 2 sends $Z \%$ to Separation 1, etc.

Push from Separation into one product storage for each Fuel Fab. Products pushed whether Fuel Fab ready to us e or not.

Percent allocation $-X \%$ to Fuel Fab 1, Y \% to Fuel Fab 2, etc.

Figure 1-2. VISION routing approach. 
In addition to the constraints noted above, another type of constraints involve which parts of VISION (previous figure 1-1) are treated as commodities and which are discrete facilities. For our purposes, these are defined as follows:

- Commodity - a function or substance is readily available on demand; multiple suppliers exist (or could exist); the size, lifetime, first operation date are not modeled.

- Discrete facilities - the function in the fuel cycle is only available if an appropriate type of facility is built in the model; the inventory and/or rate the function is provided is limited by the capacity of the facility built.

The best examples of commodities is uranium ore, uranium conversion, and uranium enrichment. VISION calculates how much of these substances and functions are needed, but they are considered readily available.

In VISION, reactors, separation, fuel fabrication, MRS, and geologic repository are discrete facilities. These functions do not exist in a fuel cycle simulation until and unless they are "built".

\subsection{Scope and Organization of VISION}

VISION can be run two ways:

- Pre-defined base cases provide the simplest way to use VISION but the least flexibility. In this mode, the user selects a predefined base case, and the model automatically enters all of the parameters necessary by reading parameters from Microsoft Excel spreadsheets. Currently, when the user selects a predefined base case, they cannot change any of the parameters with the user interface since this would require a complex user interface design within the model. Use of predefined base cases allows the user to select among several dozen different strategies, but the user cannot select any of the parameters for each case.

- User-defined base cases provide the most flexibility but require the user to identify each input parameter. For both predefined and user-defined base cases, VISION reads input parameters from Microsoft Excel spreadsheets prior to running the simulation. The user defined base cases allow the user to access the full flexibility of the model (available without making changes to the code itself) and to easily save those defined cases for repeated runs or varying specific parameters. Once all the parameters for a user defined case are defined in the Excel input files, the user defined cases can be run as simply as the predefined base cases. The user can copy parameters from one of the predefined base cases into the five slots for user-defined base cases in the Excel files and then modify them.

The NAVIGATION worksheet of the main input file (base case settings ver3.xls) now has two macros at the bottom of the page. The "copy scenario" button allows the user to copy any of the base cases (either pre-defined or user defined) into one of the five user defined cases. The "begin or resume interview" button starts an interview with the user to guide through setting up a case.

Previously, VISION could also be run via a user interface. The increased flexibility (and complexity) of the model now precludes this mode of operation.

We discourage users making changes directly in the model; if your needs suggest model changes, please contact us.

The typical user does not need to know the inner structure of the VISION model as long as they are familiar with the basics of the nuclear cycle and follow this user guide. ${ }^{\mathrm{d}}$ Nonetheless, it is instructive to

d. There is also a methodology document, which is in need of being updated. 
VISION User Guide, Rev 3.4

consider the full scope of the model as shown in Figure 1-3. The color coding of the modules is the same as Figure 1-1 and designates the following:

- White - fundamental source material (uranium ore, high enriched uranium, $\mathrm{Pu}$ )

- Yellow - front end of the fuel cycle (uranium mining, enrichment, etc.)

- Blue - fuel recycling (separation and fabrication)

- Pink - reactors

- Green - in-process storage, packaging, etc.

- Bright blue - long-term storage and ultimate disposal 
VISION User Guide, Rev 3.4

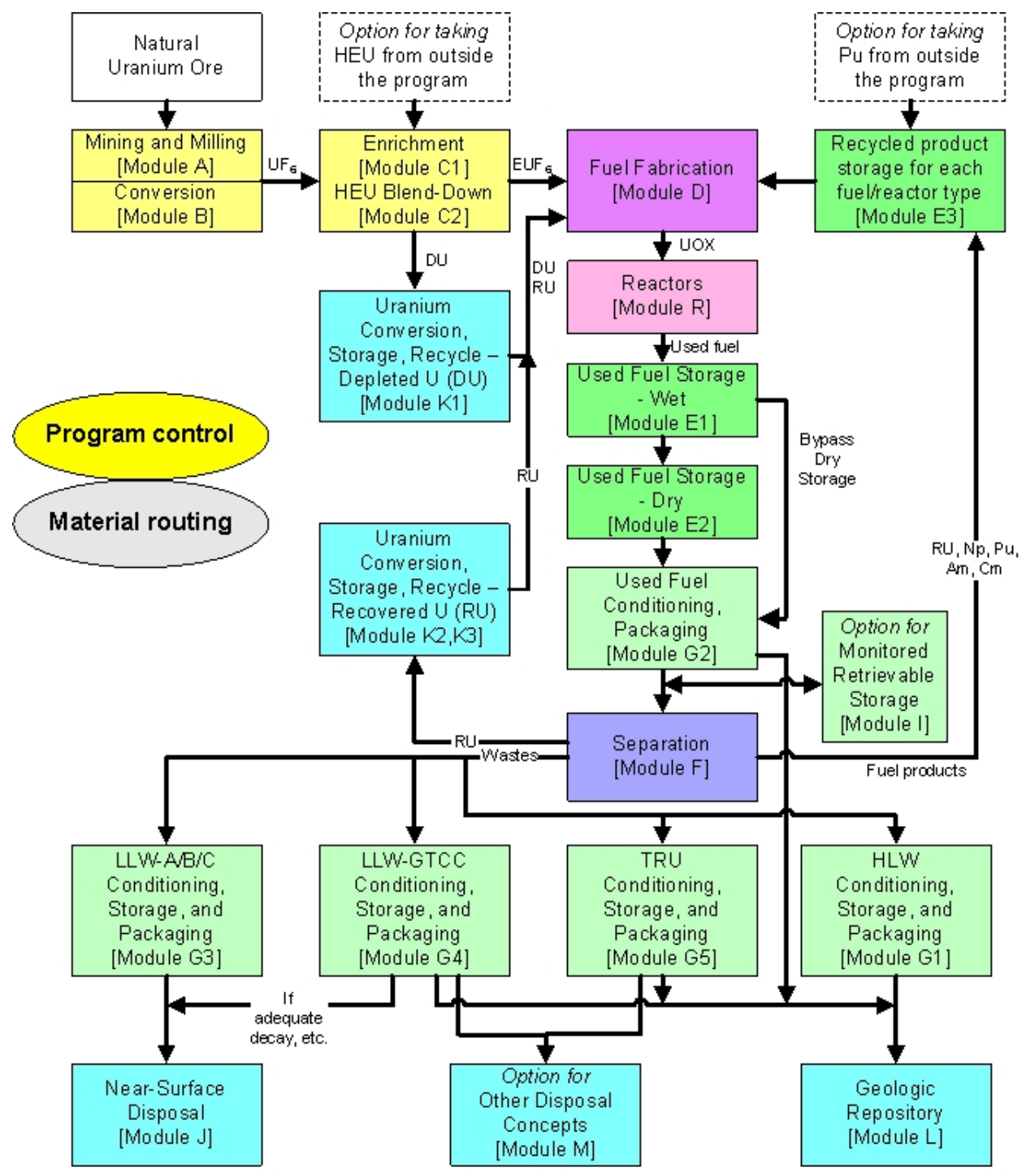

Transportation for High-Level Radioactive Materials (Used fuel, HLW, TRU, LLW-GTCC, recycled fuel) [Module 01]

Transportation for Low-Level Radioactive Materials (LLW-AB/C, uranium fuel, RU, DU, EU) [Module O2]

Figure 1-3. VISION Modules. 
This color scheme is used where practical in this document and in the input and output Excel files.

As can be seen, the model addresses the entire fuel cycle from fundamental source material to ultimate disposal and the various steps and options in-between. After separations, all outputs are tracked. Based on the options selected by the user the model controls how much of each chemical element goes where.

\subsection{Changes from Previous Versions}

Table 1-1 summarizes the increase in flexibility (and complexity) between VISION 2.2 and 3.4. These have been motivated by the following:

- Requested benchmarks against other codes with scenarios lasting more than 100 years. The new model can run for 200 years.

- Interest in studying more reactor types than before, i.e., more than LWR-UOX, LWR-MF, and fast reactors. The new model can handle any uranium-plutonium fuel. It cannot calculate the range of thorium fuel cycles.

- Interest in studying more reactor types concurrently.

- Interest in allowing yearly evolution of reactor type and separation type.

Table 1-1. Major Changes from Version 2.2

\begin{tabular}{|c|c|c|}
\hline Number of . & VISION 2.2 & VISION 3.4 \\
\hline$\ldots$ years of simulation & 100 & 200 \\
\hline ... reactor types & 3 (hardwired) & 10 (user-defined) \\
\hline ... isotopes tracked & 60 & 81 \\
\hline ... times reactor capacity can be changed & $\begin{array}{l}\text { Yearly by } 2 \\
\text { methods }\end{array}$ & $\begin{array}{l}\text { Yearly by } 3 \\
\text { methods }\end{array}$ \\
\hline ... user-defined fuel recipes that can be entered & $\begin{array}{l}2 \text { thermal/run } \\
2 \text { fast/run }\end{array}$ & Hundreds \\
\hline ... times a reactor type's fuel recipe can be changed & 2 & Yearly \\
\hline ... times the routing from reactor to separation plant can be changed & $\begin{array}{l}\text { Yearly (only } \\
\text { by changing } \\
\text { number of } \\
\text { recycles) }\end{array}$ & $\begin{array}{l}\text { Yearly (any } \\
\text { reactor to any } \\
\text { separation) }\end{array}$ \\
\hline ... separation types & 3 (hardwired) & 10 (user-defined) \\
\hline ... times a separation type's capacity can be changed & Yearly & Yearly \\
\hline ... user-defined separation fuel partition matrix that can be entered & 15 & 40 \\
\hline ... times a separation type's fuel partition matrix can be changed & Never & Yearly \\
\hline ... times the routing from separation to fabrication can be changed & $\begin{array}{c}\text { Yearly (only } \\
\text { by changing } \\
\text { number of } \\
\text { recycles) }\end{array}$ & $\begin{array}{l}\text { Yearly (any } \\
\text { separation to any } \\
\text { fuel fab) }\end{array}$ \\
\hline ... times the routing from fabrication to reactor can be changed & Never & Never \\
\hline $\begin{array}{l}\text {... times the routing from separation to waste streams can be } \\
\text { changed }\end{array}$ & Never & Yearly \\
\hline waste management metrics & 7 & 10 \\
\hline Size of base case setting file & 4.5 MB & $30 \mathrm{MB}$ \\
\hline
\end{tabular}




\subsection{How to deal with the complexity of VISION}

Read this guide!

We recognize that VISION is a complex model, but then, nuclear fuel cycles are complex, especially when one considers the wide range of options that creative people have and are devising. Indeed, the first thing that happens when we distribute a new version is that people ask us to add something more.

VISION 3.4 can model almost any fuel cycle, with the following exceptions:

- Thorium/U233 fuel cycles are not included. Fuel cycles constrained by thorium resources or U233 content in fuels. VISION includes U233 and thorium isotopes, but assumes fuel availability is constrained by the supply of enriched uranium or one or more TRU isotopes. So, a $\mathrm{Th} / \mathrm{U} 233$ fuel cycle cannot be modeled until U233 fuel constraint is added.

- Fuel cycles in which the supply of fuel depends on some other technology that you wish to include in the model, e.g., externally-driven accelerators or fission-fusion hybrids as a source of neutrons and/or nuclear fuel.

- Fuel cycles that require the number of two types of reactors to be in some fixed proportion or some constraint that only applies to those two reactor types. VISION can constrain the sum of all reactor types to meet some total electricity level or constrain each reactor type separately. It cannot do a case in-between in which a subset of reactor types has one constraint while the remaining reactor types have another.

- Arrangements in which the used fuel from a given reactor type is sent to more than one separation plant, e.g., $30 \%$ to plant 1 and $70 \%$ to plant 2 . VISION is separation-centric in the sense that fuel is "pulled" into separation plants from reactors in the priority that a user specifies rather than "pushed" from reactors to multiple candidate separation plants. See section 1.2.

- Arrangements in which one fuel supplier of a given type of fuel is used preferentially versus another. VISION is separation-centric in that fuel material is "pushed" from separation plants to one or more "buffer boxes" from which fuels are made. Fuel fabrication buffers do not "pull" fuel from separation plants. See section 1.2.

- Arrangements in which specific uranium mines or enrichment plants are to be modeled. Uranium and separative work units are considered commodities and are not modeled at the level of individual facilities nor considered constraints,

Before you attempt to create a new case, we highly recommend running some of the existing cases, which are described in Appendix A. Learn how to run the model and examine output. Learn the terminology in the user guide and the input and output files.

If the cases you care about are structurally similar to an existing case, use the "copy macro" (described later) to copy the settings from one of the existing base cases to one of the five user-defined slots. Then, you can modify it, either with the macro-driven user interview or manually. By "structurally similar," we mean the logical arrangement of reactors, fuel, and separation types - in particular flows from one reactor type to another with the same basic arrangement of what constrains what.

If the cases you care about are not structurally similar to an existing case, you need to study the user guide in more detail, especially chapters 1 and 2 to understand the theory, assumptions, and priorities. We have found that most problems relate to "routing", e.g., how one designates how reactors feed separation plants or repositories or what fuel sources a particular reactor depends on. The simple fact is that any fuel cycle 
other than once through requires one or more parts of a fuel cycle to depend on a constrained resource such as TRU supply to make MOX or fast reactor fuel, and the relationship of constrained resources to the rest of the fuel cycle can be difficult to model in the way you envision it to work. (Once through fuel cycles are typically conceived as key items such as ore and uranium enrichment to be "commodities" that cost money but are always available.) Contact us; there may be ways to cleverly use the flexibility that already exists in the model. Of course, the more highly constrained parts of the fuel cycle involved, not only is it more tricky to model, but it is more tricky for such an arrangement to work in the real world! 


\section{KEY ASSUMPTIONS AND INITIAL PARAMETERS}

\subsection{Assumptions}

\subsubsection{Facility Behavior and Sizes}

Each reactor, separation, and fuel fabrication type can represent one or more discrete facilities. All facilities of a given type have the same functional behavior and the same unit size, e.g., reactor capacity (GWe/reactor). They generally start and end at different times. If it is important to differentiate among behaviors of reactors or separation plants, the groups should be modeled as different types. For example, we typically model two "types" of LWRs - those that can only use UOX fuel and those with multiple fuel (MF) capability and thus can use either UOX or MOX (or IMF) fuel. Similarly, one might have a separation type for $\mathrm{UREX}+3$, in which the products would be $\mathrm{NpPu}$ and $\mathrm{AmCm}$, and another separation type for UREX+1, in which the product is all-TRU. All separation facilities of a given "type" do the same separation at each time step, so much to fuel products, so much to waste, etc. One can change the behavior over time, but that change applies to all facilities of the same type.

\subsubsection{Combinations}

Users of the model must ensure that the appropriate combinations of reactor, fuel, and operating conditions are selected when setting up a user defined base case or manual scenario. For example, fast reactors will not recycle fuel if no fuel is sent to fast reactors by either (a) routing LWR used fuel to one or more separation types that then route fuel products to a separation-to-reactor buffer so that it can be used to make the fast reactor fuel or (b) setting the "contingent" fuel to enriched uranium so that FR could be started without TRU.

\subsubsection{Priority among Reactors, Separations, and Fuel Fabrication Types}

Generally, the priority among reactor types, among separation types, and among fuel fabrication types is controlled by the user through various input matrices. For example, by "pushing" fuel products from separation to fuel fabrication (by percent) and the 1:1 correspondence between fuel fabrication and reactor fuel type, there is no additional prioritization required at fuel fabrication. Recycled material has already been allocated by the separation efficiency matrices that push fuel products into each fuel fabrication.

There are four exceptions in the current version of VISION; these must be considered in deciding how to set up a scenario.

- First, recycling routing matrices define for each separation type the order in which that separation type pulls used fuel, e.g., pull from Fuel type 1, then Fuel type 3, then Fuel type 2. That separation type will pull fuel each time step until its separation capacity is used. If the user allows more than one separation type to pull the same fuel type, then the separation type with the lower number goes first - a hard-wired prioritization not under user control except by the order in which the user defined separation types.

- Example: Separation 2 and 3 are allowed to pull from Fuel type 2, whether or not they pull from other fuel types. So, Separation 2 is allowed to pull from any available Fuel type 2 to use its current separation capacity. After Separation 2 is completed, Separation 3 could use any remaining available fuel type 2. Separation 2 goes before Separation 3. 
- Second, there is only one schedule for retiring legacy reactors, so if more than one type of reactor exists, legacy reactors retire in the order reactor-1 first, then reactor-2, and so forth.

- Third, if the model cannot order as many of reactor-N as you request via the "\%" market allocation settings, it will build reactor type $\mathrm{N}-1$.

- Fourth used fuel going to a repository will be taken (if the repository is open) from reactor-1 first, reactor-2, and so forth. Although there is only one repository, VISION does keep track of how much of the fuel in the repository came from each reactor type.

In addition, within a given fuel type, the oldest fuel is moved to the repository first.

\subsubsection{Units}

Unless otherwise stated, the model uses the following units:

- Reactor capacity in GWe, i.e., unit of power

- Energy and electricity generation in GWe-FPY (full power years), i.e., unit of energy

- Mass in kilotonnes (kt or ktonnes) - these are converted to t (tonnes) in graphic level output files

- Time in years, calendar years (CY), or full power years (FPY).

- Separation and fuel fabrication capacities are generally in units of kt/CY.

\subsubsection{Reactor and Fuel Types}

The assignments are made by the selection of fuel input and output recipes in the input Excel files. VISION does not perform reactor physics calculations. Instead, it uses input and output recipes that designate, by isotope, the composition of fuel entering and leaving a reactor.

A recipe represents core-averaged compositions.

VISION keeps track of the flow of material by recycle pass through as many as 5 recycle passes. The composition changes are tracked and, for recycle simulations, the library has input/output recipes for 5 recycle passes.

- Recycle pass 0 is virgin material that has not been recycled. Since U235 is the only fissile isotope in nature, all pass 0 fuel is based on uranium.

- Pass 1 is the first recycle pass. Also, material that is transferred from one reactor type to another is re-set to recycle pass 1 .

- Pass 2 through 5 are subsequent recycle passes. For thermal reactors and fast reactors with TRU conversion ratio $<1$, the required TRU and fissile content in input/output recipes generally increases the more times material is recycled and VISION accounts for this. For fast reactors with TRU conversion ratio $>1$, excess fissile and TRU material is made available for other reactors.

- Material that is recycled after the fifth recycle is re-allocated to recycle pass 5. Keeping track of recycle passes is critical to making VISION work as intended.

Material's recycle pass is remembered (conserved) in going from reactor to separation plant, in separation plants, and in fuel fabrication. 
Material recycle pass is updated between separation and fuel fabrication.

- Material going from separation $\mathrm{X}$ to fuel fabrication $\mathrm{X}$, is increased by 1 , except that pass 5 goes to pass 5 .

- Material going from separation X to some other fuel fabrication is reset to 1. So, material recovered from first-pass used MOX (pass 1) that goes to fuel fabrication for a fast reactor is reset to pass 1 and enters fast reactors as such. Material recovered from first-pass used MOX that stays as MOX gets updated to MOX pass 2.

Any type of uranium-plutonium fuel recipe can be used. We have not tested the model with thorium recipes, partly because we are still assembling appropriate recipes. Of course there are as many thorium fuel cycle options as uranium-based options. The model already tracks relevant Th isotopes. The current model will not track use of thorium resources. Once-through thorium options (Th $+U 235$ or Th $+T R U)$ might work; the model would simply create Th to make the fresh fuel. Thorium options with recycled $U 233+T R U$ (or Pu) might work, provided uranium with appropriate U233 content was separated and sent to the appropriate fuel fabrication type. The "flow control" would be sent to the TRU (orPu). Thorium options in which the recycled U233 content should be the control on flow will not work.

The sum of mass fractions in a fuel recipe must equal 1.0. Otherwise, mass will be created or destroyed each time fuel enters or leaves a reactor type.

All recipes for used fuel assume 0 years of cooling (time after exiting the reactor) have occurred. In the model, the used fuel can be decayed while in an interim or longer term storage facility.

The fuel in the system at the beginning of the simulation is assumed to be pass0. That is, if you specify fuel in reactors, in wet storage, in dry storage that is not pass 0 , the model will ignore it. So, you can start simulations with uranium fuel in any type of reactor, but cannot start simulations with TRU-based fuel already in the system. Exception: the specification of separation facilities enables you to seed the simulation with Pu239 that can be fed into fuel later.

Unless otherwise stated, $\mathrm{Cm}$ is meant to include $\mathrm{Cm}, \mathrm{Bk}$, and $\mathrm{Cf}$ isotopes. TRU means all elements above U, specifically $\mathrm{Np}, \mathrm{Pu}, \mathrm{Am}, \mathrm{Cm}, \mathrm{Bk}, \mathrm{Cf}$.

Figure 2-1 shows the Periodic Table from our perspective. The color coding (unavoidably different than the VISION module color coding) denotes groups of elements with similar behavior in chemical separations. Although the user is free to define chemical separation performance by isotope, the examples that come with VISION assume elements of the same color coding behave the same during chemical separation. For example, all of the lanthanides (plus yttrium) are assumed to be separated as a group. The only Group 1/2 elements of significance as fission products are $\mathrm{Rb}, \mathrm{Sr}, \mathrm{Cs}$, and $\mathrm{Ba}$. The only halogens of significance are $\mathrm{Br}$ and I. The only inert gases of significance are $\mathrm{Kr}$ and $\mathrm{Xe}$. H3 and C14 are considered separately because of their ubiquitous role in biological systems. More details can be found in Piet2009. 


\begin{tabular}{|c|c|c|c|c|c|c|c|c|c|c|c|c|c|c|c|c|c|}
\hline $\mathrm{H}$ & & & & & & & & & & & & & & & & & $\mathrm{He}$ \\
\hline $\mathrm{Li}$ & $\mathrm{Be}$ & & & & & & & & & & & B & c & $\mathrm{N}$ & 0 & $\mathbf{F}$ & $\mathrm{Ne}$ \\
\hline $\mathrm{Na}$ & $\mathrm{Mg}$ & & & & & & & & & & & Al & $\mathrm{Si}$ & $P$ & $s$ & $\mathrm{Cl}$ & $\mathrm{Ar}$ \\
\hline K & $\mathrm{Ca}$ & Sc & $\pi$ & $V$ & $\mathrm{Cr}$ & $M n$ & $\mathrm{Fe}$ & Co & $\mathrm{Ni}$ & $\mathrm{Cu}$ & $\mathrm{Zn}$ & $\mathrm{Ga}$ & $\mathrm{Ge}$ & As & $\mathrm{Se}$ & $\mathrm{Br}$ & $\mathrm{Kr}$ \\
\hline $\mathrm{Rb}$ & $\mathrm{Sr}$ & $Y$ & $\mathrm{Zr}$ & $\mathrm{Nb}$ & Mo & $\mathrm{Tc}$ & $\underline{R u}$ & $\underline{R h}$ & $\underline{P d}$ & $\mathrm{Ag}$ & $\mathrm{Cd}$ & In & Sn & $\mathrm{Sb}$ & $\mathrm{Te}$ & 1 & $\mathrm{Xe}$ \\
\hline Cs & $\mathrm{Ba}$ & $\mathrm{La}$ & $\mathrm{Hf}$ & $\mathrm{Ta}$ & $W$ & $\operatorname{Re}$ & Os & Ir & $\mathrm{Pt}$ & $\mathrm{Au}$ & $\mathrm{Hg}$ & TI & $\mathrm{Pb}$ & $\mathrm{Bi}$ & Po & At & $\mathrm{Rn}$ \\
\hline $\mathrm{Fr}$ & $\mathrm{Ra}$ & $A C$ & & & & & & & & & & & & & & & \\
\hline & & & La & $\mathrm{Ce}$ & $\mathrm{Pr}$ & $\mathrm{Nd}$ & $\mathrm{Pm}$ & $\mathrm{Sm}$ & $\mathrm{Eu}$ & $\mathrm{Gd}$ & $\mathrm{Tb}$ & Dy & Ho & $\mathrm{Er}$ & $\mathrm{Tm}$ & $\mathrm{Yb}$ & Lu \\
\hline & & & $A C$ & Th & $\mathrm{Pa}$ & $U$ & $\mathrm{~Np}$ & $\mathrm{Pu}$ & $\mathrm{Am}$ & $\mathrm{Cm}$ & Bk & $\mathrm{Cf}$ & & & & & \\
\hline
\end{tabular}

\begin{tabular}{|l|}
\hline$\frac{M o}{R u}, \mathrm{Rh}, \underline{\mathrm{Pd}}$ constrain waste loading \\
in glass \\
\hline $\begin{array}{l}\text { The other transition metals of significance } \\
\text { are } \mathrm{Se}, \mathrm{Cd}, \mathrm{Sn}, \mathrm{Sb}\end{array}$ \\
\hline Lanthanides + Y tracked separately \\
\hline $\begin{array}{l}\mathrm{AC}, \mathrm{Th}, \mathrm{Pa} \text { are important actinide decay } \\
\text { chain elements }\end{array}$ \\
\hline In UREX+, U is removed separately \\
\hline TRU elements \\
\hline
\end{tabular}

\begin{tabular}{l}
\hline $\mathrm{H} 3$ and $\mathrm{C} 14$ are tracked separately \\
\hline $\begin{array}{l}\text { The only Group 1A/2A elements of } \\
\text { significance are } \mathrm{Rb}, \mathrm{Sr}, \mathrm{Cs}, \mathrm{Ba}\end{array}$ \\
\hline $\begin{array}{l}\text { The only Halogens of significance are } \mathrm{Br} \\
\text { and I }\end{array}$ \\
\hline $\begin{array}{l}\text { The only inert gases of significance are } \\
\mathrm{Kr} \text { and Xe }\end{array}$ \\
\hline In UREX+, Tc is removed separately. \\
\hline $\begin{array}{l}\text { Zr is tracked separately because its mass } \\
\text { is dominated by cladding, not fuel per se }\end{array}$ \\
\hline
\end{tabular}

Figure 2-1. Periodic Table as seen from fuel cycle system analysis perspective.[Piet2009]

Table 2-1 lists the isotopes tracked in VISION. Only isotopes with halflives greater than 0.5 years are tracked. (Exception: $\mathrm{Cm} 242$ at 0.45 year.) The most important isotopes in each chemical group are included, as well as the residual mass (considered stable) in that group. 
VISION User Guide, Rev 3.4

June 2011

Table 2-1. Tracked Isotopes and Chemical Elements [Piet2009]

\begin{tabular}{|c|c|c|c|}
\hline \multicolumn{2}{|c|}{ Actinides and Decay Chain } & \multicolumn{2}{|c|}{ Fission Products } \\
\hline He4 (stable) & & $\mathrm{H} 3$ & \multirow{3}{*}{ Other gases } \\
\hline $\mathrm{Pb} 206$ & \multirow{5}{*}{ Transition metals } & $\mathrm{C} 14$ & \\
\hline $\mathrm{Pb} 207$ & & C-other & \\
\hline $\mathrm{Pb} 208$ & & Kr81 & \multirow{3}{*}{$\begin{array}{l}\text { Inert gases } \\
(\text { Group } 0)\end{array}$} \\
\hline $\mathrm{Pb} 210$ & & Kr85 & \\
\hline Bi209 & & Inert gas other $(\mathrm{Kr}, \mathrm{Xe})$ & \\
\hline Ra226 & \multirow{2}{*}{ Group 2A } & $\mathrm{Rb}$ & \multirow{3}{*}{ Group $1 \mathrm{~A} / 2 \mathrm{~A}$} \\
\hline Ra228 & & Sr90 w/Y90 decay & \\
\hline Ac227 & \multirow{6}{*}{ Actinides } & Sr-other & \\
\hline Th228 & & Zr93 w/Nb93m decay & \multirow{3}{*}{ Zirconium } \\
\hline Th229 & & $\mathrm{Zr95} \mathrm{w} / \mathrm{Nb} 95 \mathrm{~m}$ decay & \\
\hline Th230 & & Zr-other & \\
\hline Th232 & & Tc99 & \multirow{2}{*}{ Technetium } \\
\hline $\mathrm{Pa} 231$ & & Tc-other & \\
\hline U232 & \multirow{6}{*}{ Uranium } & Ru106 w/Rh106 decay & \multirow{3}{*}{$\begin{array}{l}\text { Transition metals that } \\
\text { constrain glass waste } \\
\text { forms }\end{array}$} \\
\hline U233 & & Pd107 & \\
\hline $\mathrm{U} 234$ & & Mo-Ru-Rh-Pd-other & \\
\hline U235 & & $\mathrm{Se} 79$ & \multirow{5}{*}{ Other transition metals } \\
\hline U236 & & Cd113m & \\
\hline U238 & & $\mathrm{Sn} 126 \mathrm{w} / \mathrm{Sb} 126 \mathrm{~m} / \mathrm{Sb} 126$ & \\
\hline $\mathrm{Np} 237$ & Neptunium & Sb125 w/Te125m decay & \\
\hline $\mathrm{Pu} 238$ & \multirow{6}{*}{ Plutonium } & TM-other (Co-Se, Nb, Ag-Te) & \\
\hline $\mathrm{Pu} 239$ & & I129 & \multirow{2}{*}{$\begin{array}{l}\text { Halogens } \\
\text { (Group 7) }\end{array}$} \\
\hline Pu240 & & Halogen-other $(\mathrm{Br}, \mathrm{I})$ & \\
\hline Pu241 & & Cs 134 & \multirow{5}{*}{ Group $1 \mathrm{~A} / 2 \mathrm{~A}$} \\
\hline Pu242 & & Cs135 & \\
\hline $\mathrm{Pu} 244$ & & Cs137 w/Ba137m decay & \\
\hline Am241 & \multirow{3}{*}{ Americium } & Cs-other & \\
\hline Am242m & & $\mathrm{Ba}$ & \\
\hline Am243 & & Ce144 w/Pr144m/Pr144 decay & \multirow{9}{*}{ Lanthanides (plus Y) } \\
\hline $\mathrm{Cm} 242$ & \multirow{8}{*}{ Curium } & Pm147 & \\
\hline $\mathrm{Cm} 243$ & & Sm146 & \\
\hline $\mathrm{Cm} 244$ & & Sm147 & \\
\hline $\mathrm{Cm} 245$ & & Sm151 & \\
\hline $\mathrm{Cm} 246$ & & Eu154 & \\
\hline $\mathrm{Cm} 247$ & & Eu155 & \\
\hline $\mathrm{Cm} 248$ & & Ho166m & \\
\hline $\mathrm{Cm} 250$ & & LA-other plus Yttrium & \\
\hline Bk249 & Berkelium & & \\
\hline Cf249 & \multirow{4}{*}{ Californium } & & \\
\hline $\mathrm{Cf} 250$ & & & \\
\hline $\mathrm{Cf} 251$ & & & \\
\hline $\mathrm{Cf} 252$ & & & \\
\hline
\end{tabular}




\subsubsection{Fuel Flow Control}

For each reactor type, the user can select among these approximations for how the model estimates how much fuel can be made from separated material available in the separated product storage.

0. Minimum of Pu239, Pu240, and Pu241, i.e., whichever isotope is most restrictive.

1. $\mathrm{Pu} 239$

2. $\mathrm{Pu} 240$

3. $\mathrm{Pu} 241$

4. TRU (sum of all TRU isotopes required in the fuel)

5. $\mathrm{Pu}$ (sum of all $\mathrm{Pu}$ isotopes required in the fuel)

For example, with "Pu" flow control (option 5), the model determines from the fresh fuel recipe the fraction of $\mathrm{Pu}$ in the fuel, say $10 \%$. Then, based on the amount of Pu in separated product storage (downstream of the separation plant) the model determines the amount of fuel that can be made, regardless of the mix of individual $\mathrm{Pu}$ isotopes in separated material. The model then fabricates that fuel for use in the reactors. This has the effect of alchemy - the "wrong" mix of Pu isotopes is replaced with the "right" mix of Pu isotopes.

The amount of isotope mismatch is tracked and can be examined to determine if the user believes the current approximations are too crude. An improved approach using 1-group cross sections whereby the recipe is adjusted to match the available mix of isotopes and has been found to work in the timeindependent variable-chemistry model, Fuel-cycle Integration and Tradeoffs (FIT). We have not determined whether this the alchemy effect is strong enough in VISION simulations to warrant putting this submodel into VISION.

Meanwhile, the situation can be bracketed. Flow control " 0 " is the most restrictive and will see the least amount of recycled fuel produced. Flow control " 4 " (TRU is appropriate for fast reactors) or " 5 " (Pu is appropriate for thermal reactors) are the least restrictive and will see the most amount of recycle fuel produced.

The flow control options will have to be expanded in order for some thorium fuel options to work.

\subsubsection{Isotope Decay}

The model tracks and radioactively decays mass at an isotopic level. Isotope decay is currently applied to all locations in the model where mass remains in a facility for 1 or more years. This can be adjusted to no decay or decay only in wet storage when running user defined base cases or manual cases.

There is one exception. Once material has entered a repository, further isotopic decay is not performed as our primary waste management concern is estimating the amount and character of waste forms at the time of emplacement. Repository-relevant decay times are typically much longer than the 200 years of a VISION simulation. By indicating the isotopic content at the time of disposal, the output data can be used with other tools to estimate the composition at any time in the future, e.g., thousands of years.

\subsection{Initial Parameters}

This section describes appropriate initial parameters when simulating the U.S. nuclear power plant fleet. All can be changed by the user to simulate the world or any other set of nuclear fuel cycle facilities. 
These settings are for starting the simulation in the year 2000 without distinguishing between PWR and BWR. We have also developed an alternative set of parameters that start the simulation in 1960 and does distinguish between PWR and BWR.

\subsubsection{Growth Rates}

The amount of nuclear power capacity throughout the simulation depends on three types of user input, as follows:

- Total electrical growth rate (by year)

- Nuclear market share (by year)

- Nuclear generation in 2000, which was 86.002 GWe-FPY/CY but is nonetheless a user-controlled input.

The user is encouraged to set input parameters to replicate the following 2000 values:

- Total electrical generation of 433.7 GWe-FPY.

- Nuclear electrical generation of 86.002 GWe-FPY.

- Nuclear market share of $19.83 \%$.

Table 2-2 provides a set of input parameters that closely replicates actual data from 2000 to 2006 even though VISION is constrained to a fixed reactor capacity factor and fixed average reactor capacity. Furthermore, VISION cannot decrease nuclear generation year by year except by retiring reactors. The actual ups and downs in nuclear generation from 2000 to 2006 arose from slight fluctuations in reactor capacity and increases in capacity (uprates), plus the addition of the $104^{\text {th }}$ operational reactor. VISION was never designed to calculate precise yearly values; nonetheless, by starting the simulation with 2 reactors needing fuel and 3 more reactors starting construction, VISION will calculate nuclear generation similar to the actual data, as shown in Table 2-2.

Table 2-2. Nuclear Generation Data

\begin{tabular}{|c|c|c|c|c|}
\hline & \multicolumn{2}{|c|}{ User Input } & Actual Data [a,b,c] & Calculated by VISION \\
\hline Year & $\begin{array}{l}\text { Total Electricity } \\
\text { Growth Rate }\end{array}$ & $\begin{array}{c}\text { Nuclear Market } \\
\text { Share }\end{array}$ & $\begin{array}{c}\text { Nuclear Generation } \\
\text { (GWe-FPY) }\end{array}$ & $\begin{array}{c}\text { Nuclear Generation } \\
\text { (GWe-FPY) }\end{array}$ \\
\hline 2000 & 1.2 & 19.83 & 86.00 & 86.00 \\
\hline 2001 & 1.2 & 20.58 & 87.71 & 86.00 \\
\hline 2002 & 1.2 & 20.22 & 88.99 & 86.83 \\
\hline 2003 & 1.2 & 19.67 & 87.12 & 88.50 \\
\hline 2004 & 1.2 & 19.86 & 89.95 & 89.34 \\
\hline 2005 & 1.2 & 19.28 & 89.21 & 90.17 \\
\hline 2006 & 1.2 & 19.42 & 89.80 & 90.17 \\
\hline 2007 & 1.2 & 19.19 & 91.42 & 90.17 \\
\hline $\begin{array}{l}2000 \text { nucle } \\
\text { Average L } \\
\text { Average LI } \\
\text { Reactors in } \\
\text { Reactors un } \\
\text { Reactors un }\end{array}$ & $\begin{array}{l}\text { Ner generation }=86 . \\
\text { WRmf capacity }=0 \text {. } \\
\text { WRmf capacity fact } \\
=103 \\
\text { onstruction need fue } \\
\text { onstruction in } 2000\end{array}$ & $\begin{array}{l}\text { GWe-FPY } \\
\text { GWe } \\
0.90 \text { FPY/CY } \\
2000=2 \text { (these bec } \\
\text { these become opera }\end{array}$ & $\begin{array}{l}\text { erational in } 2002-2003 \text {, } \\
\text { n 2003-2005, representi }\end{array}$ & $\begin{array}{l}\text { ng the effect of uprates) } \\
\text { ect of uprates and reactor 104) }\end{array}$ \\
\hline \multicolumn{5}{|c|}{$\begin{array}{l}\text { a. Conversion from thousand } \mathrm{kW} \text {-hr generated each year (i.e., MWe-full power } \mathrm{hr} / \mathrm{CY} \text { ) to } \mathrm{GWe}-\mathrm{FPY} / \mathrm{CY} \text { by } 0.001 \mathrm{GWe} / \mathrm{MWe} \mathrm{x} 1 \\
\text { day/24 hour } \mathrm{x} 1 \mathrm{yr} / 365.25 \text { days }=1.14 \mathrm{e}-7 \mathrm{GWe}-\mathrm{FPY} / \mathrm{CY} \text {. } \\
\text { b. DOE EIA2006a } \\
\text { c. DOE EIA2006b }\end{array}$} \\
\hline
\end{tabular}




\subsubsection{Legacy Reactors}

Nuclear reactors currently operating in the U.S. are designated as legacy reactors. The following four user-input parameters should be self-consistent:

- Nuclear capacity in 2000 (86.0 GWe-FPY/CY).

- Number of legacy reactors, i.e., in 2000 (103 reactors)

- Average capacity factor (0.90 FPY/CY)

- Average capacity per reactor $(0.928 \mathrm{GWe} /$ reactor $)$

The above four values are self-consistent. Indeed, the fourth parameter $(0.928 \mathrm{GWe} /$ reactor $)$ was set to be consistent with the other three parameters.

103 reactors x $0.928 \mathrm{GWe} /$ reactor x 0.90 FPY/CY $=86.0 \mathrm{GWe}-\mathrm{FPY} / \mathrm{CY}$

If the number of legacy reactors, average capacity factor, and average capacity is less than the user-input for 2000 nuclear generation, the model will start the simulation by ordering new reactors to catch-up with the desired nuclear generation.

If the number of legacy reactors, average capacity factor, and average capacity is greater than the userinput for 2000 nuclear generation, those reactors will continue to operate. No new reactors will be ordered until the nuclear demand (escalated from 2000 on the basis of nuclear market share and total electrical growth rate) exceeds the capacity from the legacy reactors.

As there are 103 reactors in 2000, if the case being studied involves MOX, then the allocation of legacy reactors should be 17 LWR-MF (16\%) and 86 LWR (84\%), see Table 2-3. If the case being studied is IMF, then the allocation should be 7 LWR-MFR (6\%) and 96 LWR (94\%), although this may be too conservative for the heterogeneous, blended IMF cases.

Table 2-3. Thermal Reactor Safety Constraints on MOX/IMF [adapted from M. Todosow]

\begin{tabular}{|l|c|c|c|c|c|c|}
\hline & \multicolumn{2}{|c|}{ Single-Pass MOX } & \multicolumn{3}{c|}{ Single-Pass IMF } \\
\hline $\begin{array}{c}\text { Reactors } \\
\text { That Can Use }\end{array}$ & $\begin{array}{c}\% \text { of } \\
\text { Core }\end{array}$ & $\begin{array}{c}\text { Fll Fuel in } \\
\text { F Core) } \\
\text { x Coctors }\end{array}$ & $\begin{array}{c}\% \text { of } \\
\text { Reactors } \\
\text { That Can Use }\end{array}$ & $\begin{array}{c}\% \text { of } \\
\text { Core }\end{array}$ & $\begin{array}{c}\text { Fleet (reactors x } \\
\text { core) }\end{array}$ \\
\hline $\begin{array}{l}\text { Current PWRs } \\
\text { and BWRs }\end{array}$ & $50 \%$ & $33 \%$ & $16 \%$ & $25 \%$ & $25 \%$ & $6 \%$ \\
\hline $\begin{array}{l}\text { Future PWRs and } \\
\text { BWRs }\end{array}$ & $100 \%$ & $\begin{array}{c}100 \\
\%\end{array}$ & $100 \%$ & $50 \%$ & $\begin{array}{c}100 \\
\%\end{array}$ & $50 \%$ \\
\hline
\end{tabular}

\subsubsection{Legacy Fuel}

All used fuel (also known as spent fuel) generated by these reactors, prior to 2000, is called legacy used fuel. Coupled with the LWR/LWR-MF split implied in Table 2-3, U.S. DOE EIA data [DOE EIA2002] have been used to generate Table 2-4. We model the legacy fuel such that all fuel at least 10 years old in 2000 is (or could have been) in dry storage; all fuel less than 10 years is assumed to be in wet storage. ${ }^{\mathrm{e}}$ To

e. After initialization, used fuel generated during the simulation stays in wet or dry storage according to user inputs discussed later. 
use these data, the user inputs the values of mass into the Wet and Dry Storage worksheet with fuel recipe numbers that correspond to the composition reflecting the average burnup. ${ }^{f}$

Table 2-4. U.S. Used Fuel, Prior to 2000

\begin{tabular}{|l|c|c|c|l|}
\hline $\begin{array}{l}\text { Suggested allocation in reactor/storage type in } \\
2000\end{array}$ & $\begin{array}{c}\text { Mass } \\
\text { (kilotonnes) }\end{array}$ & $\begin{array}{c}\text { Average } \\
\text { burnup (GWth- } \\
\text { day/tonne) }\end{array}$ & $\begin{array}{c}\text { Average } \\
\text { age } \\
\text { (years) }\end{array}$ & $\begin{array}{c}\text { Years } \\
\text { discharged }\end{array}$ \\
\cline { 1 - 2 } LWR-UOX (86 of 103 reactors) - wet storage & 17.704 & 38.19 & 4.4 & $\begin{array}{l}1991 \text { to } \\
2000\end{array}$ \\
\cline { 1 - 2 } LWR-MOX (17 of 103 reactors) - wet storage & 3.459 & 26.89 & 16.6 & 1968 to \\
\cline { 1 - 3 } & 17.946 & 3.507 & 32.50 & 1090 \\
\hline LWR-MOX (17 of 103 reactors) - dry storage & 42.616 & & \\
\hline Total & &
\end{tabular}

The fuel in the system at the beginning of the simulation is assumed to be pass 0 . That is, if you specify fuel in reactors, in wet storage, in dry storage that is not pass 0 , the model will ignore it. So, you can start simulations with uranium fuel in any type of reactor, but cannot start simulations with TRU-based fuel already in the system. Exception: the specification of separation facilities enables you to seed the simulation with Pu239 that can be fed into fuel later.

f. The current recipe file has recipes 106 for 38.19 burnup and 107 for 26.89 burnup; these recipes do not include the impact of aging, but they could be adjusted accordingly. 


\section{MECHANICS OF RUNNING VISION}

The Powersim software functions on a presentation level or a modification level.

- In presentation level, the user sees only an unchangeable model interface and defined output graphs and charts.

- In modification level, the user can see the actual model (graph representation of the relationship among variables and all sorts of details) or the interface.

Powersim no longer has a free player version, so a license is required to run VISION at this time. Powersim Studio 8 Expert version is sufficient to run VISION with up to 3 reactor types, for greater than 3 reactor types the Executive version is required. If you have a licensed version of Powersim, then you can access both the presentation and development levels with the proper permissions. [Note: Opening the model directly from the file name rather than opening the Powersim software and then opening the model file ${ }^{g}$ will access only the presentation level.] This section of the user guide supports both levels of operation.

\subsection{Installing VISION}

VISION is comprised of several Microsoft Excel input files, a Powersim Studio core, and several Microsoft Excel output files.

- All must be co-located in the same folder on a PC to function.

- You must use Powersim Studio 8 or better, preferably with service release 7 and feature pack 3.

- The output files are macro-enabled Excel 2007 format (xlsm).

- The input files are Excel2003 format (xls). All four are designated as ver3. Other versions will not work.

- Depending on what you are doing, one or more Excel files must be open. For example, to use a graph-building Excel file, you must have the main input file (base case settings ver3.xls) and an output file (typically output data-1.xlsm) open. For reasons known only to Microsoft, the Excel files must be "open" in the same execution of Excel or one file may not be able to see the others. If you have problems, check to see if the open Excel file list on your PC has one or more with "Microsoft Excel" in front of the file name while others do not. If so, the other files may not be able to see it; it may not be able to see other files. Similarly, if you have the main output file (output data-1.xIsm) open before you launch Powersim to run VISION, which would normally open output data-1.xlsm itself, you could find two versions of the file open (one as read-only) and are likely to have problems. When in doubt, close Excel files and open them at the same time. Do not open output data-1.xlsm when running VISION; let Powersim do it.

- Some of the input and output Excel files are large. So, if you attempt to do much with other nonVISION Excel files when Powersim tries to dump data into the main output file (output data-

g. The Powersim VISION model file has an extension of sip. If opened by clicking on the filename, you can only access the presentation level. If you open the file by first launching Powersim and then having it open the file, you can access the modification level.

h. Another behavior you may notice is that if you try to copy and paste from one spreadsheet to another, instead of behaving normally and allowing you to directly paste data, formula, etc., the destination file may need for you to tell is you are pasting text. This Excel behavior has nothing to do with VISION per se, but the linkage of spreadsheets in the VISION package may force you to confront it. 
1.xlsm), which occurs at the end of each simulation run, ${ }^{\mathrm{i}}$ Excel can effectively "time out" and Powersim then reports it is unable to transfer data to the Excel output file.

There are a set of files required to run the model.

We use Powersim Studio 8 Service Release 7 Feature Pack 3. It appears to also work with Studio 8 Service Release 5 and 6, as long as Feature Pack 3 is installed. Studio 8 Expert version works for up to 3 reactor types. Above 3 reactor types, then Executive version is required because the number of variables in the model exceed 700,000. You must use Powersim Studio 2008 or better. The output files are macroenabled Excel 2007 format (xlsm). The input files are Excel 2003 format (xls). The required files are as follows:

- VISION Release 3.4.sip - this is the main model

- vision base case settings ver3.xls - inputs most of the specifications for pre-defined or userdefined simulations.

- vision recipes ver3.xls - contains the fuel recipes

- vision half life ver3.xls - contains the decay information for different isotopes

- vision heatdosetox ver3.xls - contains the isotope-specific dose conversion factors and other parameters used in calculations for dose, radiotoxicity, and heat

- output data-1.xlsm - collects the data produced by Powersim.

Note that the input files are Excel2003 format (xls) and the output files are macro-enabled Excel2007 format (xlsm). The system will store data for up to 5 runs in the input and output files.

The user will rarely, if ever, need to access or change the heatdosetox and half life files, which contain isotope-specific data used by VISION.

The file vision base case settings ver3.xls reads the list of available recipes from vision recipes ver3.xls. Powersim will work fine if the link between these two files isn't updated, but the list of available recipes in vision base case settings ver3.xls will not be up to date.

\section{Cautions:}

1. The only one of these files that can be renamed is VISION Release 3.4.sip. All others are called by the main model, which will fail if files with those names do not exist.

2. The Excel files must be in the same folder as the sip file.

3. Do not change the format of any of the above files, e.g., add or delete columns or rows. Do not re-order the sequence of rows or columns. Do not rename the worksheets within a file. One can re-order the sequence of worksheets within a given file, except for output data-1.xIsm and output data-2.xIsm in which even the sequence of worksheets is fixed.

4. Several of these Excel files contain macros, when you open the file, Excel may ask you whether you want to enable the macros, click "Enable Macros."

i. You'll note "dumping" of data by flickering of open Excel files, the more you attempt to do in any Excel file during this data transfer, the more risk of more connection problems of Powersim to Excel, which can force you to rerun cases. 
The following files are not required to run the model, but they are valuable and are described in section 6:

output data-2.xlsm - reformats the data in output data-1

output_checks.xIsm - assists the user in checking the validity of the simulations just run

output_fuel_masses_by_class.xlsm - graphs fuel masses by class, e.g., mass of TRU

output_fuel_masses.xlsm - graphs fuel masses (summed over all classes)

output_reactors.xlsm - graphs reactor information

output_separations.xlsm - graphs separation information

output_uranium xlsm - graphs information on uranium resources and use

output_used_fuel_masses.xlsm - graphs information on used fuel

output waste.xls - graphs waste management information (future work)

Any of these optional files may be renamed.

\section{Cautions:}

5. output data-1.xIsm will have a varying number of columns of data because the number of reactors, separations, or fuels can vary from 1 to 10 . Before using any of the graphing files, use output data-2.xIms, which copies data from output data-1 and puts into a standard 10-reactor, 10-fuel, 10separation format. All the graphing files read from output data-2.x/sm via links. Therefore, the graphing files will not show the results of new Powersim runs until both output data-2.xIsm's data-loading macro is run and the link between output data-2 and the graphing file is updated.

6. After completing a run, the following files should be saved-base case settings ver3.xIs, output data-2.xIsm, and any relevant graphing files. Change their names to prevent VISION from using them or modifying them.

Users experienced in using Excel may find it convenient to develop their own output files that extract only data relevant from their studies from output data-2.xlsm. For example, it is possible to copy the existing graphical output files and then modify them.

Figure 3-1 shows the relationship among the files. There are three types of data transfer. First, the Powersim model reads from four Excel files and writes to one Excel file (black arrows); these data transfers are required. Second, there are links ${ }^{j}$ among Excel files. VISION will run if these are not up to date, but the data will not be updated, e.g., vision base case settings ver3.xls would not necessarily have the most recent list of recipes in vision recipes ver3.xls and the graphing files would not have updated information. Third, a macro in output data-2.xlsm copies from output data-1.xlsm and vision base case settings ver3.xls and pastes into output data-2.xlsm.

j. Links among Excel spreadsheets are powerful but sometimes cause trouble. Excel files are supposed to update data transferred via links automatically when you open a file, if that file can find the other file - which is why they need to be in the same

folder. You may have to give Excel permission to update the links. If for some reason the link did not update, e.g., it could

not find the file, go to "Data" on the top Excel menu in the destination Excel file. You will then see a block called

"Connections". If the spreadsheet has incoming links, click on "Edit Links" and look at the "Status" of links:

"Unknown" $\rightarrow$ click on "Update Values"

"Error: Source not found" $\rightarrow$ use "change source" to show Excel where to find the right file.

"OK" $\rightarrow$ Excel has found the file and the links are fine.

"Source is open" $\rightarrow$ Excel has found the file, the links are fine, and the file is currently open. 


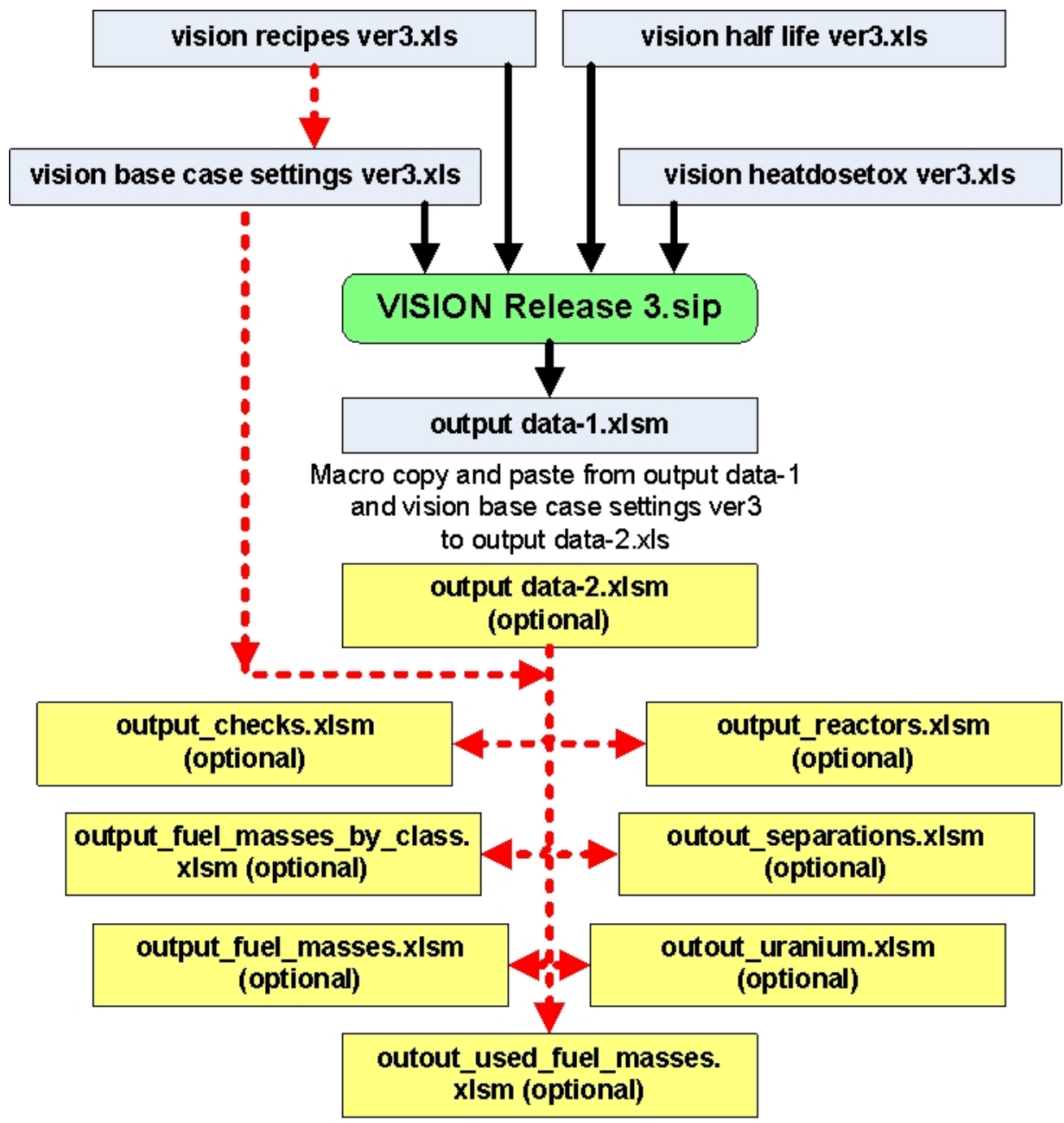

Read or write by Powersim model, required

$\rightarrow-\rightarrow$ Link from one Excel file to another, optional

Figure 3-1. Relationship among VISION files.

\subsection{Getting to the Main Page}

Whether you open VISION by clicking on the model icon or by starting Powersim and then opening the main model file, VISION will open output data-1.xlsm. 


\section{Cautions:}

7. Do not close this file or make any changes to it until you are finished running VISION.

8. Do not open output data-1.xIsm yourself, let VISION do it.

VISION then opens in the presentation level with a title page that indicates the version and date of the model you have opened.

If you will be using the presentation level, follow these steps:

1. Pressing "enter" brings you to the disclaimer page

2. Once you read this, press "I agree" to continue

If you would like to use the modification level, press the icon, shaped like a projection screen (恩), in the toolbar at the top (remember to +first open Powersim and then open the model if you want to access the modification level). It will open in one of the pages of the model, depending on what was open when the model was last saved. To get to the Main Page, go to the "interface" page, which is third from the left. The left-most page is "Program Directory," which has links to the interface page as well as the others. You may wish to resize the image so that the entire main page fits on your screen.

Either way, you should see the Main Page (figure 3-2).

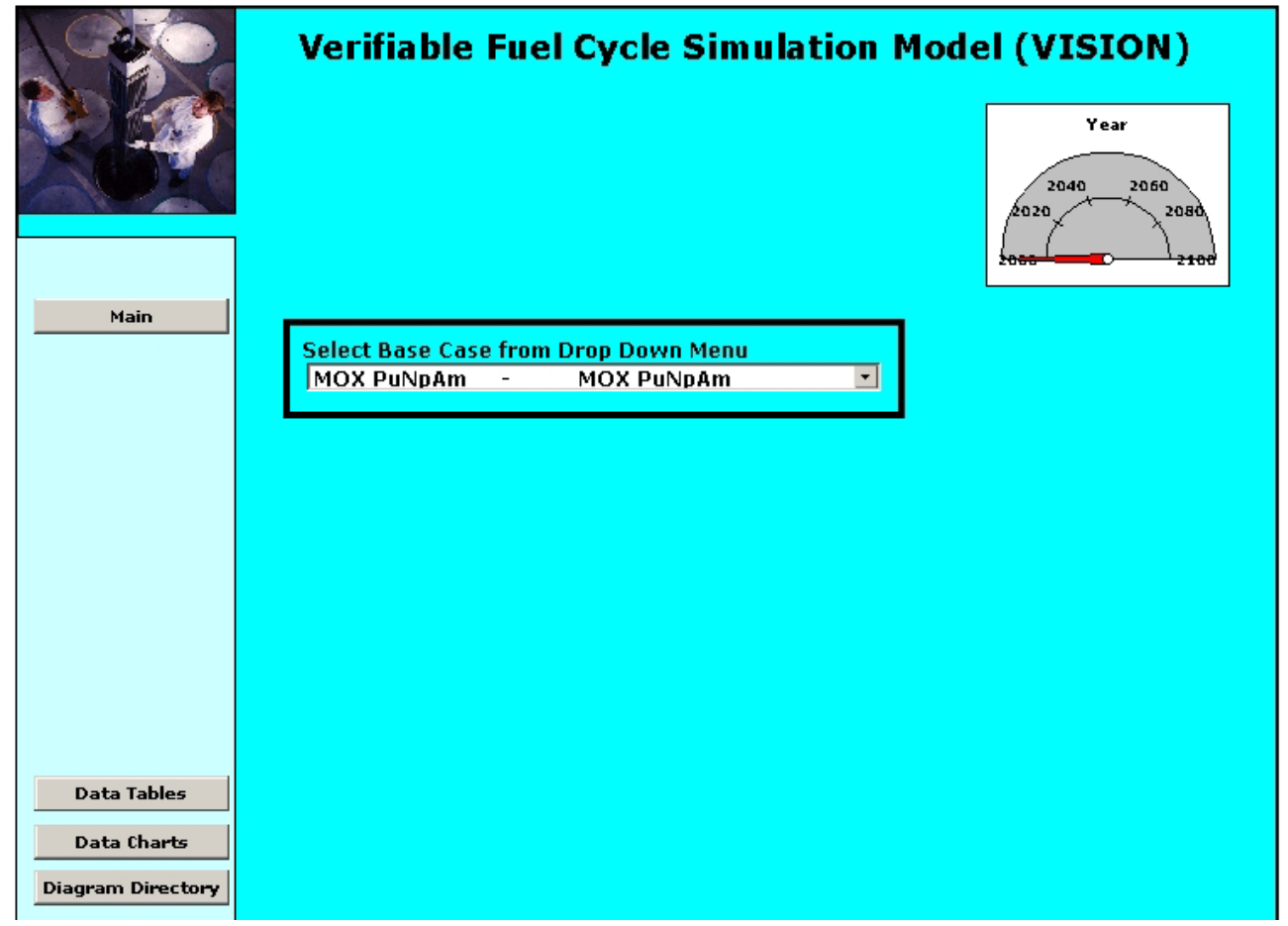

Figure 3-2. VISION main screen in Powersim Studio. 


\subsection{Running VISION}

There is one pull-down menu and three key Powersim buttons needed to run the model:

The pull-down menu selects the case to run, each case corresponds to a set of parameters in a column in base case settings ver3.xls, either a pre-defined case or the last five options, which are allocated for user defined cases.

Select Base Case from Drop Down Menu

MOX PuNp FR Burner

Within the box, the user sees the list of the entire selection of base cases from which the user may choose. At the end of the list are "User Defined" base cases that can be set by the user. To run one of the base cases, click the base case you want to run and then hit the play button on the tool bar. All of the predefined cases are constructed with two phases that often have a technology change between the two phases. The example above shows MOX transitioning to a burner fast reactor.

The Powersim model internal settings and the output file, output data-1.xlsm, are structured so that the user can run from 1 to 5 simulation runs into a single output file. To run more than 5 simulations, finish the first five, copy the output data-1.xlsm file and rename it something else, and start another set of simulation runs.

14

Reset (control-R) resets all the settings to their defaults and erases any data generated during the execution. The model will return to "run 1." Data already saved in output data-1.xlsm will not be immediately erased, but will be written over as soon as additional runs are executed.

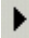

Play/Stop (control space) toggles between playing (running) the model and stop.

DII

Advance simulation one step (control shift space) advances a stopped simulation one time step (a quarter year). After completing a run, use this button to advance to the next run, to a maximum of "run 5.'

\section{Cautions:}

9. Do not attempt to go to the next "run" without clicking on the "advance simulation"

10. When you advance to a new run, the settings in the interface return to their defaults. You must again select the appropriate base case.

11. After the $5^{\text {th }}$ run, clicking on the "advanced simulation" button will return the model to the $1^{\text {st }}$ run. If you proceed to additional runs without copying and saving output files, VISION will write over your previously performed run 1 data in output data-1.xlsm. 

this. ${ }^{k}$ All "times" in input and output are in calendar years.

Depending on whether you opened presentation level or modification level, you will also see various Powersim software buttons above this VISION page and a Powersim list of models and variables to the left of this VISION page.

The left-hand buttons in the left-hand column allow you to navigate among the various pages of the control panel, while the rest of this page provides access to data output and different sections of the model. In later sections of this document we will discuss how to load input values using Excel files and we will also present how to set-up VISION to run several scenarios.

The "Year" gauge in the top right corner indicates the progress of the model while running a scenario.

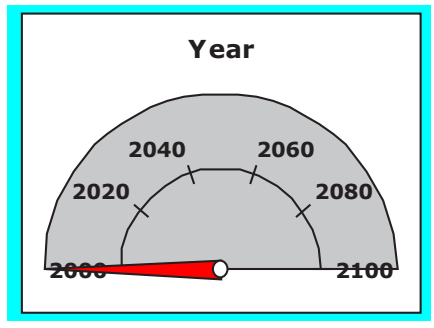

\subsubsection{Data Tables}

The tables within Powersim provide limited output values from latest run of the VISION model. A more extensive set of output values is available via the Excel output tables. The data tables only show one run of the VISION model. Use the Excel outputs to save data from the run; these tables are intended only to help observe what is happening during a simulation.

\subsubsection{Data Charts}

The user can scroll down and see a number of charts that provide output values from the VISION model, although this is limited. A more extensive set of output values is available via the Excel output tables. The data charts will show only the latest run of the VISION model. Use the Excel outputs to save data from the run; these charts are intended only to help observe what is happening during a simulation.

\subsubsection{Diagram Directory}

Clicking on any of the buttons in the diagram directory will take the user to that portion of the model specified. The model will show all the dynamic logic within the VISION model. In order to get back to the main interface from this screen, use the arrows in the bottom left corner to scroll to the farthest right and then click on the "Interface" tab from the bottom set of tabs.

k. The time step can be adjusted by going to "'Simulation" on the tool bar and then going to "simulation settings" at the bottom of the pull down menu. However, we have not tested the model at alternative time steps. At higher time steps, it is likely that use of input parameter smaller than the time step, e.g., 0.25 years for enrichment time, would not work. 


\subsection{Settings You Have to Change in Powersim}

All user settings for running simulations are made within one or more of the four Excel input files, with the following exceptions. These parameters must be changed within Powersim Studio itself. This is done to minimize the core memory required and maximize simulation speeds.

Once you are finished, return to the interface page by going to Project Explorer - VISION Flow Model Simulation Controls - Shared Diagrams. After clicking on Shared Diagrams, click on the "Interface" tab at the bottom of the page.

Start time of simulation - We discourage changing the start time of the simulation, but it should work. The issue is that many of the input file data tables are written to start at 2000. Powersim will still read the right data correctly if the user instead interprets them (or rewrites them) to start at some other date, but it can be confusing to the user in filling out the data.

- Simulation - Simulation Settings - Start time (nominally 1/1/2000), change according to your needs.

Number of years of simulation - The model comes set to run 100 years, from 2000 to 2100 . The time period can be changed up to 200 years as follows:

- Simulation - Simulation Settings - Stop time (nominally 1/1/2100), change according to your needs. Attempting to run the model over 200 years will not work because base case settings ver3.xls and output data-1.xlsm are set up for $\leq 200$ years.

- Project explorer - Global Ranges (next to the bottom) - change "Future Look Ahead" from 181 to 81 plus the number of years of simulation, e.g., 281 for a 200 -year simulation.

Number of reactor types - The model comes set to run 3 reactor types, to increase that ...

- Project explorer - Global Ranges (next to the bottom)

- Fueltype - click on the "+" sign to the left of "fueltype". Right click on " 3 " to insert additional items up to as many as 10 . Then rename the items so that they list from 1 to the maximum number.

- Reactors - double click on "reactors" to open it, change "last" from 3 to as many as 10.

Number of separation types - The model comes set to run 3 separation types, to increase that ...

- Project explorer - Global Ranges (next to the bottom)

- Fueltype - click on the "+" sign to the left of "fueltype". Right click on " 3 " to insert additional items up to as many as 10 . Then rename the items so that they list from 1 to the maximum number.

- Separations - double click on "Separations" to open it, change "last" from 3 to as many as 10 .

Maximum length of fuel residence in reactors - The model comes set with a maximum of 50 time steps (12.5 years at $1 / 4$-year time steps) fuel residence time. If you need to change it .....

- Project explorer - Global Ranges (next to the bottom) 
- Age in Reactor - double click on "Age in Reactor" to open it, change "last" from 50 time steps to a higher value, but no greater than the number of years of the simulation (times the number of time steps per year).

Maximum length of dry storage - The model comes set to have as many as 5 years of dry storage. This can be increased as follows:

- $\quad$ Project explorer - Global Ranges (next to the bottom)

- Age in dry storage - double click on "Age Dry Storage" to open it, change "last" from 5 to a higher value, but no greater than the number of years of the simulation.

Maximum length of wet storage - The model comes set to have as many as 10 years of wet storage. This can be increased as follows:

- Project explorer - Global Ranges (next to the bottom)

- Age in wet storage - double click on "Age Wet Storage" to open it, change "last" from 10 to a higher value, but no greater than the number of years of the simulation.

Reactor Life - The model comes set to run up to 60 years for reactor lifetime.

- $\quad$ Project explorer - Global Ranges (next to the bottom)

- Reactor Life - double click on "Reactor Life" to open it, change "last" from 60 to a higher value, but no greater than the number of years of the simulation. By definition, for a lifetime-core, the reactor life and the fuel residence time must be set to the same value.

Number of recipes in a given portion of the recipe file. The recipe file has 7 pages of recipes. The parameters in the Powersim model have to be consistent with the recipe file. If you wish to user more recipes on a given page than how the current recipe file and Powersim Model are arranged, you have to do four things.

1. Add the recipe columns on the appropriate page of the recipe file. For once through (100s, 200s), that is a single column per recipe. For recycle recipes $(300 \mathrm{~s}, 400 \mathrm{~s}, 500 \mathrm{~s}, 600 \mathrm{~s}, 700 \mathrm{~s})$, that is 6 columns per recipe, a blank and then 5 recycle pages.

2. Add titles for all new columns in the "Fuels" global range. This is an enumerated range, and therefore what you add must be in the exact sequence in which you've added the recipes in the recipe file. For example, imagine you have added 5 new MOX recipes on the 300s worksheet. Then, you would add 30 new names after $315-5$, possibly $316-0,316-1, \ldots 320-5$, corresponding to new recipes 316 to 320 . Note that the enumerated list must have a blank for each blank column in the recipe file, typically designated as recipe 0 .

3. Change the range for the associated named range to include the fuels you just added to the "Fuels" enumerated list. For example, in the above example, you would change the last item in the LWR MOX recipe range from 315-5 to 320-5.

4. Change the instructions on (Rr) Fuel Recipes page in the model so that the model knows the expanded range to read from Excel for fresh fuel recipes, (used) fuel recipes, other fuel parameters. There should not be any "question marks" on this page once you are done. 
VISION User Guide, Rev 3.4

\begin{tabular}{|l|l|l|ll|l|}
\hline & Name & $\begin{array}{l}\text { Number } \\
\text { of } \\
\text { recipes }\end{array}$ & First recipe & & $\begin{array}{l}\text { Last } \\
\text { recipe }\end{array}$ \\
\hline $100 \mathrm{~s}$ & UOX Recipes & 10 & UOX User BU & (Recipe 101) & 110 \\
\hline $200 \mathrm{~s}$ & Other Once Thru Recipes & 10 & NGNP & (Recipe 201) & 210 \\
\hline $300 \mathrm{~s}$ & LWR MOX Recipes & 15 & MOX-RU-Pu-1 & (Recipe 301-1) & $315-5$ \\
\hline $400 \mathrm{~s}$ & LWR IMF Recipes & 15 & IMF-NpPu-1 & (Recipe 401-1) & $415-5$ \\
\hline $500 \mathrm{~s}$ & Other Thermal Recipes & 10 & 501-1 & & $510-5$ \\
\hline $600 \mathrm{~s}$ & FR Metal Cooled Recipes & 30 & UOX to FR mtl-User-1 (Recipe 601-1) & $630-5$ \\
\hline $700 \mathrm{~s}$ & FR Other Cooled Recipes & 10 & \multicolumn{2}{|l|}{ 701-1 } & $710-5$ \\
\hline
\end{tabular}

\subsection{Suggestions for Inputting Data}

If you have used VISION in the past, be aware that much of the information previously input on the Reals 1 worksheet page are now in reactor, separation, or fuel fabrication worksheets. This actually makes input easier as data are grouped more logically.

It helps if you go methodologically through the worksheets in sequence (same sequence whether you use the navigation buttons or the tabs at the bottom). Previous versions of the model did not have worksheets in the same sequence as mass actually flows.

While doing so, it is very helpful to color code the cells in the Excel input files appropriate to your cases and to how you conceptualize the problem. The vision base case settings ver3.xls file has many examples.

It helps to print out the three base case settings worksheets that list the available recipes, separation efficiency matrices, and recycle routing strategy matrices.

We suggest you keep consistency by "numbers" among reactors, separation, and fuel fabrication such that (1) $=\mathrm{LWR} / \mathrm{UOX} / \mathrm{UOX}$ separation, (2) = LWR MF/MOX/MOX separation, (3) $=$ FR/FR/FR separation, etc even if one doesn't have MOX in a particular simulation so that there is no separation type for fuel 2, hence separation 2 is set to zero capacity. 


\section{VISION INPUT VIA BASE CASE SETTINGS FILE}

This is the master input file. The Excel file vision base case settings ver3.xls contains multiple worksheets. If the file does not open at the NAVIGATION worksheet, click on that tab, it is the most left of the tabs and is colored red.

\section{NAVIGATION List_of_reactor_types_\&_recipes $/$ List_of_separation_types $>$ List_of_routing_strategies $\lambda$ Run Informatior}

From the NAVIGATION worksheet, one goes to the other worksheets to input the required data. One can, of course, manually go to different worksheets by clicking on the tabs at the bottom of the page. Other than the basic information worksheets, which have red-colored tabs and just provide information, each worksheet follows the same general arrangement.

Explanations of the variables in that worksheet appear on the left most and right most columns. These denote the variable names (as they are called in Powersim), units, and ranges of appropriate variables. In between are the various base cases, pre-defined on the left and user-defined on the right, typically columns CU to CY. There are five columns set aside for user-defined cases. The buttons on the NAVIGATION worksheet page will take you to the user-defined columns.

The first three rows of most worksheets contain column labels, data must be entered starting in row 4 .

Cautions:

13. If VISION is not open when you change an input file, save the file before opening VISION to ensure VISION reads your updated information. If VISION is open when you change an input file, VISION will not see the change until you save the file and advance to the next run in VISION.

14. It takes considerable effort to set up a base case setting file, therefore we avoid changing the format of files. This does mean that previous parts of files are sometimes no longer used, indicated by shading the cells red. The only change in the last 1-2 years is in the Separation 1 through Separation 10 pages. Rows 13-213 are shifted 1 row to 14-214.

The rest of this section explains what information appears in each worksheet, listed in order they appear in the base case settings ver3.xls file.

\subsection{Basic Information (RED) Worksheets}

These worksheets do not accept information from the user; they provide navigation and lists of options currently entered into appropriate locations. The four worksheet tabs are colored red, they are as follows:

- NAVIGATION

- List_of_reactor_types_\&_recipes

- List_of_separation_types

- List_of_routing_strategies 
VISION User Guide, Rev 3.4

\subsubsection{Basic (RED) - NAVIGATION}

The NAVIGATION page (figure 4-1) has a link for each one of the pages within the vision base case settings ver3.xls file. There are links on each of the pages within the file that return to the

NAVIGATION page for convenience. Some pages have cross-linked buttons, e.g., the worksheet List of separation types has a button to the separation matrices on Separation Stream Splits, which is where new separation matrices are entered. It has a button back to List of separation types for the user to verify that the new matrix name was registered.

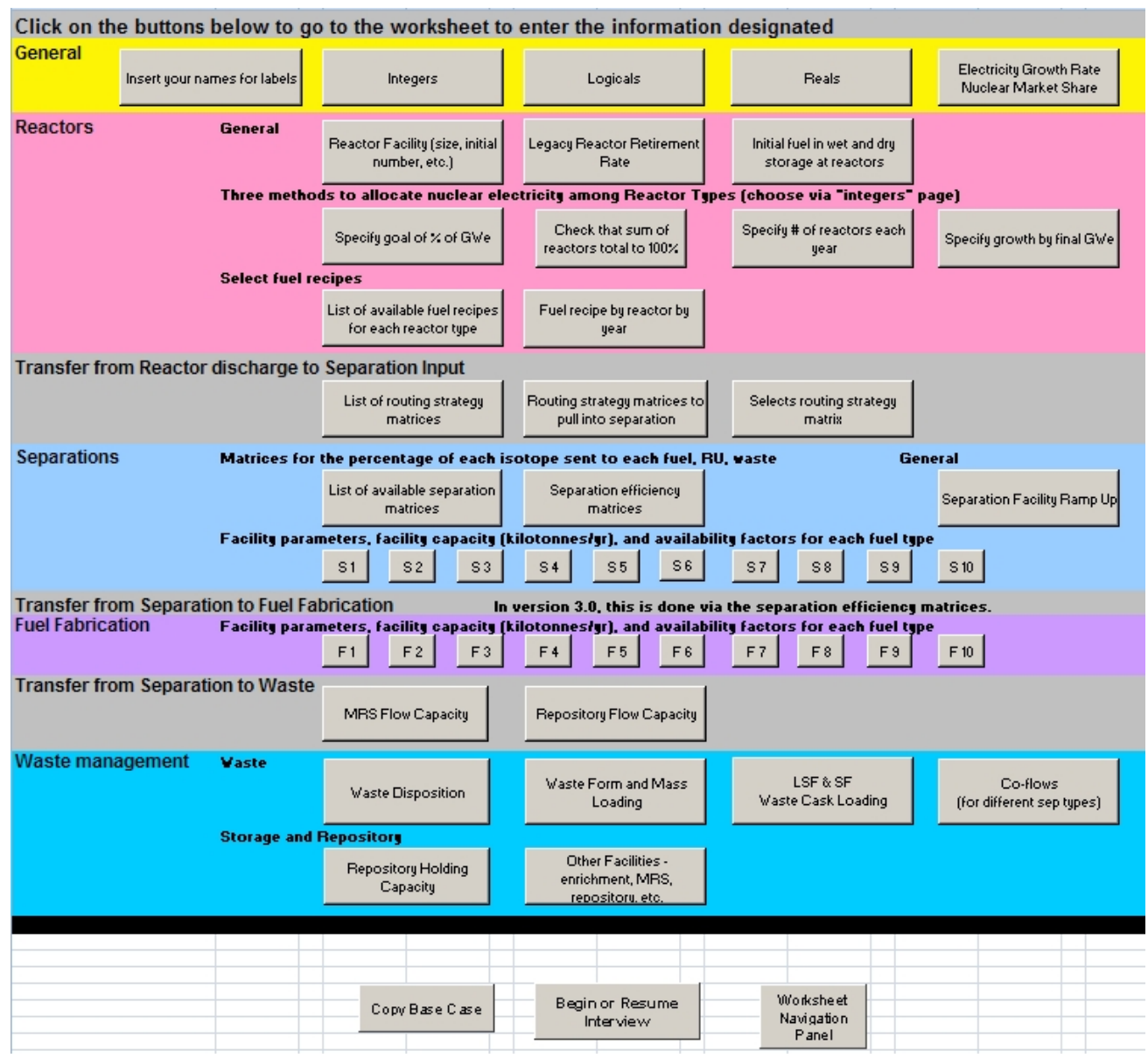

Figure 4-1. NAVIGATION worksheet page. 


\subsubsection{Basic (RED) - List of reactor types and recipes}

This worksheet lists the available recipes by reading what information has been entered into vision recipes ver3.xls. If you wish to use a recipe that is not listed on this worksheet, go to vision recipes ver3.xls (see section 5) and enter it. It should then appear on this worksheet.

There are also three special options that are available to the user.

- A correlation for LWR UOX fuel as function of burnup between 33 and $100 \mathrm{GWth}$-day/tonneiHM.

- A correlation for fast reactor metal fuel as a function of TRU CR between 0.00 and 1.00 - not yet implemented.(NEW)

- A correlation for fast reactor oxide fuel as a function of TRU CR between 0.00 and 1.00 - not yet implemented.(NEW)

Table 4-1 explains how to select fuel recipes. The user can add recipes to the blank columns in the 100, $200,300,400,500,600$, or 700 pages, sequentially from the left. Changing any of the pre-defined recipes would invalidate base cases that use them.

Table 4-1. Fuel Recipe Numbering Scheme

Transformation Performance
Transmutation - change from input composition to output composition is determined by which reactor
Fuel recipes are found in the fuel recipe file, numbered from -2 to as high as 799 . At present, only a
limited number of columns are used and linked back to the List of reactor types \& recipes, but in
principle the user could add columns up to x 99 for each recipe type.
-2 to 0 - Correlation for fast reactor metal fuels (NEW)
0 to 2 - Correlation for fast reactor oxide fuels (NEW)
33 to 100 - Correlation for LWR burnup
101 to 199 - LWR uranium fuels
201 to 299 - Uranium fuels for other reactors
301 to 399 - LWR MOX
401 to 499 - LWR IMF
501 to 599 - Fuels to recycle in other reactors
601 to 699 - Fuels for metal-fueled fast reactors
701 to 799 - Fuels for other fast reactors
Fuel recipes are later user selected for each reactor type for each year.

The recipe file has 7 pages of recipes. The parameters in the Powersim model have to be consistent with the recipe file. If you wish to user more recipes on a given page than how the current recipe file and Powersim Model are arranged, you have to do four things.

1. Add the recipe columns on the appropriate page of the recipe file. For once through (100s, 200s), that is a single column per recipe. For recycle recipes $(300 \mathrm{~s}, 400 \mathrm{~s}, 500 \mathrm{~s}, 600 \mathrm{~s}, 700 \mathrm{~s})$, that is 6 columns per recipe, a blank column and then 5 column for 5 recycle passes.

2. Add titles for all new columns in the "Fuels" global range. This is an enumerated range, and therefore what you add must be in the exact sequence in which you've added the recipes in the recipe file. For example, imagine you have added 5 new MOX recipes on the 300 s worksheet. Then, you would add 30 new names after $315-5$, possibly $316-0,316-1, \ldots 320-5$, corresponding 
to new recipes 316 to 320 . Note that the enumerated list must have a blank for each blank column in the recipe file, typically designated as recipe 0 .

3. Change the range for the associated named range to include the fuels you just added to the "Fuels" enumerated list. For example, in the above example, you would change the last item in the LWR MOX recipe range from 315-5 to 320-5.

4. Change the instructions on (Rr) Fuel Recipes page in the model so that the model knows the expanded range to read from Excel for fresh fuel recipes, (used) fuel recipes, other fuel parameters. There should not be any "question marks" on this page once you are done.

\begin{tabular}{|l|l|l|ll|l|}
\hline & Name & $\begin{array}{l}\text { Number } \\
\text { of } \\
\text { recipes }\end{array}$ & First recipe & Last \\
recipe
\end{tabular}

\subsubsection{Basic (RED) - List of separation types}

This worksheet lists the separation types from 01 to 40 by reading what information has been entered into the Separation Stream Splits worksheet. If you wish to user a matrix that is not listed on this worksheet, go to Separation Stream Splits and enter it. Table 4-2 shows the numbering scheme. The user is encouraged to add separation matrix values to any of the blank matrices. Changing any of the pre-defined matrices would invalidate pre-defined base cases that use them.

Table 4-2. List of Separation Efficiency Matrices

Transformation Performance

Partition - how the contents of used fuel are allocated among fuel product streams, 3 grades of recovered uranium (RU), and several waste form options.

Separation efficiency matrices are numbered from 1 to 40 .

1 to 20 - aqueous

21 to 30 - electrochemical

31 to 39 - other

40 - once through

About half are blank and available for user definition. 


\subsubsection{Basic (RED) - List of routing strategies}

Recall that the recycle routing matrices send fuels from used fuel storage to separation types. This worksheet lists the recycling routing options from 01 to 15 by reading what information has been entered into the Recycle Strategy Matrix worksheet. If you wish to user a matrix that is not listed on this worksheet, go to Recycle Strategy Matrix and enter it. The current matrices are listed in Table 4-3. Changing any of the pre-defined matrices would invalidate pre-defined base cases that use them.

Table 4-3. List of Recycling Routing Matrices

\begin{tabular}{|c|c|}
\hline 1 & Reserved for development testing \\
\hline 2 & Reserved for development testing - 3 region base case (see Appendix A) \\
\hline 3 & Reserved for development testing - 10 reactor case (see Appendix A) \\
\hline 4 & Blank \\
\hline 5 & Blank \\
\hline 6 & $\begin{array}{l}\text { 1-tier recycling } \\
\text { UOX (assumed to be pass } 0 \text { of fuel-1 and fuel-2) is routed to separation-1 } \\
\text { FR fuel (assumed to be pass } 1 \text { thru pass } 5 \text { of fuel-3) is routed to separation-3 }\end{array}$ \\
\hline 7 & $\begin{array}{l}\text { 2-tier recycling } \\
\text { UOX (assumed to be pass } 0 \text { of fuel- } 1 \text { and fuel-2) is routed to separation-1 } \\
\text { MOX (assumed to be pass } 1 \text { up to pass5 of fuel-2) is routed to separation-2 } \\
\text { FR fuel (assumed to be pass } 1 \text { up to pass } 5 \text { of fuel-2) is routed to separation-3 }\end{array}$ \\
\hline 8 & $\begin{array}{l}\text { One thermal recycle, then dispose } \\
\text { UOX (assumed to be pass0 of fuel-1 and fuel-2) is routed to separation-1 } \\
\text { MOX ((or IMF) assumed to be pass1 of fuel-2) is routed to disposal }\end{array}$ \\
\hline 9 & $\begin{array}{l}\text { Multiple thermal recycle } \\
\text { UOX (assumed to be pass } 0 \text { of fuel- } 1 \text { and fuel-2) is routed to separation- } 1 \\
\text { MOX ((or IMF) assumed to be pass } 1 \text { thru pass } 5 \text { of fuel- } 2 \text { ) is routed to separation- } 2\end{array}$ \\
\hline 10 & Blank \\
\hline 11 & Blank \\
\hline 12 & $\begin{array}{l}\text { Stop fast recycling, send everything to thermal reactors. This is actually the same routing as 2-tier } \\
\text { assuming that FR fuel is separated and then the products are sent to thermal reactors. So, the routing used } \\
\text { fuel-to-separation is the same as 2-tier, but the routing from separation-to-fuel is different. The latter is set } \\
\text { by separation efficiency matrices. } \\
\text { UOX (assumed to be pass } 0 \text { of fuel-1 and fuel-2) is routed to separation-1 } \\
\text { MOX (assumed to be pass } 1 \text { up to pass } 5 \text { of fuel-2) is routed to separation-2 } \\
\text { FR fuel (assumed to be pass1 up to pass5 of fuel-2) is routed to separation-3 }\end{array}$ \\
\hline 13 & $\begin{array}{l}\text { Stop thermal recycling, send everything to fast reactors. This is actually the same routing as 2-tier } \\
\text { assuming that MOX fuel is separated and then the products are sent to fast reactors. So, the routing used } \\
\text { fuel-to-separation is the same as 2-tier, but the routing from separation-to-fuel is different. The latter is set } \\
\text { by separation efficiency matrices. } \\
\text { UOX (assumed to be pass0 of fuel-1 and fuel-2) is routed to separation-1 } \\
\text { MOX (assumed to be pass1 up to pass } 5 \text { of fuel-2) is routed to separation-2 } \\
\text { FR fuel (assumed to be pass1 up to pass5 of fuel-2) is routed to separation-3 }\end{array}$ \\
\hline 14 & $\begin{array}{l}\text { Stop recycling, send everything to disposal } \\
\text { Passes } 0 \text { through } 5 \text { of fuels } 1,2 \text {, and } 3 \text { are routed to disposal. }\end{array}$ \\
\hline 15 & $\begin{array}{l}\text { Once through } \\
\text { Pass } 0 \text { of fuels } 1,2 \text {, and } 3 \text { are routed to disposal. In once through, no fuel every gets past pass } 0 \text {, therefore } \\
\text { no routing is required for passes } 1 \text { to } 5 \text {. }\end{array}$ \\
\hline
\end{tabular}

\subsection{General (YELLOW) Worksheets}

The general worksheets require the user to provide general information about cases. Compared to previous versions of VISION, relatively little information remains in these worksheets. Virtually all data 
on reactors, separation, and fuel fabrication are now on worksheets dedicated to each of those functions. The six general worksheet tabs are colored yellow, they are as follows:

- Run Information

- Integer 1

- Logical 1

- Reals 1

- Growth Rate

- User help on growth rates

\subsubsection{General (YELLOW) - Run Information}

This worksheet requests the user to provide labels for

- Your name for each simulation run

- Names for fuel types

- Names for reactor types

- Names for separation types

The user does not need to enter anything into rows 5-7, but should ensure that the numbers calculated there are correct. The spreadsheet looks at the number of names entered for each case and thus determines (via the number of blanks) how many fuel, reactor, and separation types there are. Then, cells I5, I6, and I7 denote the maximum number of those types among the five runs.

\section{Cautions:}

15. These data are for five runs, which may or may not be user-defined cases 1-5.

16. The cells I7, I8, and I9 tell output data-2.xIsm how many fuel types, reactor types, and separation types have data in output data-1.xIsm. If these parameters are incorrect, then the translation from output data-1 to output data-2.xIsm will be incorrect. The macros that copy each type of page from output data-1 to output data-2 read one of these three cells. If the macros do not appear to be working correctly, change the settings in the cells. The value for cell I7 (fuel types) must generally be as high as or higher than the others. 


\subsubsection{General (YELLOW) - Integer 1}

This worksheet page allows the user to set basic parameters that control all reactors, all fuel types, all separations for the entire simulation. Table 4-4 lists the parameters and recommended values for this worksheet.

Table 4-4. Integer Worksheet Parameters

\begin{tabular}{|c|c|c|c|}
\hline Parameter & Units or Allowed Variables & Impact & $\begin{array}{l}\text { Recommended } \\
\text { Values }\end{array}$ \\
\hline $\begin{array}{l}\text { Base case } 1 \& 2 \\
\text { Selection }\end{array}$ & $\begin{array}{l}\text { Positive Integer between } 1 \text { and } \\
102\end{array}$ & $\begin{array}{l}\text { This is a sequential number } \\
\text { starting from the left. }\end{array}$ & $\begin{array}{l}\text { Do not change, } \\
\text { for information } \\
\text { only }\end{array}$ \\
\hline $\begin{array}{l}\text { Base case uranium } \\
\text { resource to use switch }\end{array}$ & $\begin{array}{l}1=\text { Known } \\
2=\text { Known and Unknown } \\
3=\text { Known }+ \text { Unknown }+ \\
\text { Imagined }\end{array}$ & $\begin{array}{l}\text { The corresponding values are } \\
\text { input on the Reals } 1 \text { Worksheet. } \\
\text { The model keeps track of how } \\
\text { uranium resource is depleted. }\end{array}$ & Select "3" \\
\hline $\begin{array}{l}\text { Base case used fuel } \\
\text { decay switch }\end{array}$ & $\begin{array}{l}0=\text { Decay All } \\
1=\text { Decay Wet Storage Only } \\
2=\text { Decay None }\end{array}$ & $\begin{array}{l}\text { Which inventories calculate } \\
\text { isotope decay? }\end{array}$ & Select "0" \\
\hline $\begin{array}{l}\text { Base case repository } \\
\text { open date }\end{array}$ & Date between 2000 and 2100 & $\begin{array}{l}\text { Overridden by Repository } \\
\text { Capacity Worksheet. Zero flow } \\
\text { means repository is closed. }\end{array}$ & $\begin{array}{l}2017 \text { or } \\
\text { thereafter }\end{array}$ \\
\hline $\begin{array}{l}\text { Base case TR Pu } \\
\text { control switch }\end{array}$ & \multicolumn{3}{|c|}{ Moved to Reactor Facility worksheet, to be deleted here } \\
\hline $\begin{array}{l}\text { Base Case FR Pu } \\
\text { control switch }\end{array}$ & \multicolumn{3}{|c|}{ Moved to Reactor Facility worksheet, to be deleted here } \\
\hline $\begin{array}{l}\text { Base case start legacy } \\
\text { reactor retirement date }\end{array}$ & Date between 2000 and 2100 & $\begin{array}{l}\text { This determines when legacy } \\
\text { reactors start the retirement } \\
\text { process and move into the } \\
\text { condition of readying to retire, } \\
\text { which means the model can order } \\
\text { replacement reactors and then } \\
\text { stops ordering fuel for them. } \\
\text { Reactors actually go off line } \\
\text { about six years (legacy reactors } \\
\text { retirement delay + legacy } \\
\text { reactors shut down delay) years } \\
\text { later. }\end{array}$ & 2020 \\
\hline $\begin{array}{l}\text { Base case date to } \\
\text { switch to ramp } 2\end{array}$ & \multicolumn{3}{|l|}{ No longer used } \\
\hline $\begin{array}{l}\text { Base case separation } \\
\text { capacity basis }\end{array}$ & \multicolumn{3}{|l|}{ No longer used } \\
\hline $\begin{array}{l}\text { Separations } \\
\text { combination switch }\end{array}$ & \multicolumn{3}{|c|}{$\begin{array}{l}\text { To be deleted, function replaced with reactor-to-separation recycle routing strategy } \\
\text { matrices }\end{array}$} \\
\hline $\begin{array}{l}\text { Manually set FBR } \\
\text { switch }\end{array}$ & \multicolumn{3}{|l|}{ No longer used } \\
\hline $\begin{array}{l}\text { Base case reactor order } \\
\text { case }\end{array}$ & \multicolumn{2}{|c|}{$\begin{array}{l}\text { O- let system optimize reactor mix using the percent goals set on } \\
\text { Reactor \%s worksheet times the nuclear power growth specified on } \\
\text { Growth Rate. } \\
1 \text { - force VISION to use the number of reactors input by the user on } \\
\text { the Reactor \#'s worksheet. } \\
2 \text { - force VISION to build reactors to match the user specified growth } \\
\text { for each reactor type via the end-simulation value on Reactor } \\
\text { Facility worksheet times the year by year fraction of that value on } \\
\text { Reactor Growth \% of Final worksheet. }\end{array}$} & $\begin{array}{l}\text { Select "0" for } \\
\text { cases without } \\
\text { FR }\end{array}$ \\
\hline
\end{tabular}


VISION User Guide, Rev 3.4

\begin{tabular}{|c|c|c|c|}
\hline Parameter & Units or Allowed Variables & Impact & $\begin{array}{c}\text { Recommended } \\
\text { Values }\end{array}$ \\
\hline $\begin{array}{l}\text { Base case fuel fab order } \\
\text { case }\end{array}$ & \multicolumn{2}{|c|}{$\begin{array}{l}0 \text { - let system optimize fuel fabrication capacity growth } \\
1 \text { - force VISION to build fuel fabrication capacity set on Fuel Fab } 1 \\
\text { through } \mathbf{1 0} \text { worksheets }\end{array}$} & Select "0" \\
\hline $\begin{array}{l}\text { Base case separations } \\
\text { order case }\end{array}$ & \multicolumn{2}{|c|}{$\begin{array}{l}0 \text { - let system optimize separation capacity growth } \\
1 \text { - force VISION to build separation capacity on Separation } 1 \\
\text { through } \mathbf{1 0} \text { worksheets }\end{array}$} & Select "0" \\
\hline
\end{tabular}

\subsubsection{General (YELLOW) - Logical 1}

It is particularly important that the user correctly set all these switches appropriate for their scenario. Do not depend on one switch overriding another. Table 4-5 lists the parameters for this worksheet.

Table 4-5. Logical 1 Worksheet Parameters

\begin{tabular}{|c|c|c|c|}
\hline Parameter & Units or Allowed Variables & Impact & $\begin{array}{l}\text { Recommended } \\
\text { Values }\end{array}$ \\
\hline $\begin{array}{l}\text { Base case send SF to } \\
\text { repository }\end{array}$ & \multicolumn{2}{|c|}{$\begin{array}{l}\text { TRUE means used fuel is allowed to go to repository, other } \\
\text { settings determine which parts of the repository are used } \\
\text { (permanent or retrievable or both), the size of the repository, } \\
\text { and the receipt rate at the repository. } \\
\text { FALSE means used fuel can never go to a repository even if } \\
\text { other switch settings imply the existence of a repository. } \\
\text { HLW and other wastes are sent to the repository either way. }\end{array}$} & Generally TRUE \\
\hline $\begin{array}{l}\text { Base case retrieve SF } \\
\text { from repository switch }\end{array}$ & $\begin{array}{l}\text { TRUE creates a retrievable repo } \\
\text { FALSE means that used fuel in } \\
\text { retrieved. If material is sen } \\
\text { allowed to be retrieved fron } \\
\text { act as though a permanent } r \\
\text { equal to the repository hold } \\
\text { HLW and other wastes are not } r \\
\text { either way. }\end{array}$ & $\begin{array}{l}\text { fuel. } \\
\text { cannot be } \\
\text { ory and is not } \\
\text { y, the system will } \\
\text { a capacity limit } \\
\text { kists } \\
\text { the repository }\end{array}$ & $\begin{array}{l}\text { Depends on your } \\
\text { scenario }\end{array}$ \\
\hline $\begin{array}{l}\text { Base case unlimited } \\
\text { repository flow capacity } \\
\text { switch }\end{array}$ & $\begin{array}{l}\text { If TRUE, set repository flow rec } \\
\text { a generic high upper limit. } \\
\text { If FALSE, set repository flow re } \\
\quad \text { Capacity worksheet } \\
\text { Either value applies to used fuel } \\
\text { retrievable repository. Receipt } \\
\text { never limited. }\end{array}$ & $\begin{array}{l}\text { eals worksheet as } \\
\text { sitory Flow } \\
\text { ermanent and/or } \\
\text { ther wastes are }\end{array}$ & $\begin{array}{l}\text { Usually set to } \\
\text { FALSE }\end{array}$ \\
\hline $\begin{array}{l}\text { Base case unlimited } \\
\text { repository holding } \\
\text { capacity switch }\end{array}$ & $\begin{array}{l}\text { If TRUE, then the retrievable re } \\
\text { i.e., the year-by-year setting } \\
\text { Capacity worksheet are ove } \\
\text { repository limit set on Real } \\
\text { If FALSE, set repository holdins } \\
\text { Holding Capacity Worksh } \\
\text { repository capacity limit is } \\
\text { repository capacity limit is } \\
\text { repository holding capacity } \\
\text { Worksheet) and the permar } \\
\text { (Reals 1). } \\
\text { Capacity for HLW and other wa }\end{array}$ & $\begin{array}{l}\text { ity is unlimited, } \\
\text { ry Holding } \\
\text { permanent } \\
\text { remains in effect. } \\
\text { he Repository } \\
\text { permanent } \\
\text { the retrievable } \\
\text { between the } \\
\text { Holding Capacity } \\
\text { capacity limit } \\
\text { ited. }\end{array}$ & $\begin{array}{l}\text { Usually set to } \\
\text { FALSE }\end{array}$ \\
\hline
\end{tabular}




\begin{tabular}{|c|c|c|c|}
\hline Parameter & Units or Allowed Variables & Impact & $\begin{array}{l}\text { Recommended } \\
\text { Values }\end{array}$ \\
\hline $\begin{array}{l}\text { Base case SF } \\
\text { permanent repository } \\
\text { switch }\end{array}$ & \multicolumn{2}{|c|}{$\begin{array}{l}\text { TRUE creates a permanent repository for used fuel, the size of } \\
\text { the permanent repository is set on the Reals } 1 \text { page. The size } \\
\text { of the permanent repository should always be less than or } \\
\text { equal to the size of the repository holding capacity set on the } \\
\text { Repository Holding Capacity worksheet. } \\
\text { FALSE means that there is no permanent repository. (This is } \\
\text { overridden if "retrieve from repository" is FALSE, i.e., the } \\
\text { repository acts as if it is permanent.) } \\
\text { HLW and other wastes can go to a repository and are not } \\
\text { retrieved from the repository either way. }\end{array}$} & $\begin{array}{l}\text { Depends on your } \\
\text { scenario }\end{array}$ \\
\hline Base case BU is waste & \multicolumn{2}{|c|}{ To be deleted, function now handled by fuel recipes } & \\
\hline $\begin{array}{l}\text { Base case use burned } U \\
\text { phase } 1\end{array}$ & \multicolumn{2}{|c|}{ To be deleted, function now handled by fuel recipes } & \\
\hline $\begin{array}{l}\text { Base case unlimited } \\
\text { MRS capacity switch }\end{array}$ & \multicolumn{2}{|c|}{$\begin{array}{l}\text { TRUE means the MRS capacity is unlimited. } \\
\text { FALSE means the MRS capacity is limited. }\end{array}$} & $\begin{array}{l}\text { Not yet working, } \\
\text { MRS holding } \\
\text { capacity always } \\
\text { unlimited. }\end{array}$ \\
\hline $\begin{array}{l}\text { Base case unlimited } \\
\text { product storage } \\
\text { capacity switch }\end{array}$ & \multicolumn{2}{|c|}{$\begin{array}{l}\text { TRUE means Storage Facilities have unlimited product storage. } \\
\text { FALSE means Storage Facilities have limited capacity. }\end{array}$} & $\begin{array}{l}\text { Not yet working, } \\
\text { always unlimited. }\end{array}$ \\
\hline $\begin{array}{l}\text { Base case use youngest } \\
\text { least cycled fuel first }\end{array}$ & \multicolumn{2}{|c|}{$\begin{array}{l}\text { To be deleted, function handled by separation-to-reactor recycle } \\
\text { routing strategy matrices }\end{array}$} & \\
\hline $\begin{array}{l}\text { Base case use MRS } \\
\text { switch }\end{array}$ & TRUE / FALSE & $\begin{array}{l}\text { TRUE creates an MRS } \\
\text { (managed retrievable } \\
\text { storage) or centralized } \\
\text { storage facility. } \\
\text { FALSE turns off the option } \\
\text { of an MRS/ centralized flow } \\
\text { facility }\end{array}$ & Depends on scenario \\
\hline
\end{tabular}

\subsubsection{General (YELLOW) - Reals 1}

These are often the most important parameters of the entire simulation, see Table 4-6.

Table 4-6. Reals Worksheet Parameters

\begin{tabular}{|c|c|c|c|}
\hline Parameter & $\begin{array}{l}\text { Units or Allowed } \\
\text { Variables }\end{array}$ & Impact & $\begin{array}{c}\text { Recommended } \\
\text { Values }\end{array}$ \\
\hline $\begin{array}{l}\text { Base case known uranium } \\
\text { resources }\end{array}$ & \multirow[t]{3}{*}{ Kilotonnes of U } & \multirow[t]{3}{*}{$\begin{array}{l}\text { Gives the model the values for these } \\
\text { three benchmarks }\end{array}$} & $3,100 \mathrm{kt}-\mathrm{U}$ \\
\hline $\begin{array}{l}\text { Base case estimated } \\
\text { conventional uranium } \\
\text { resources (includes known } \\
\text { uranium resources) }\end{array}$ & & & $16,000 \mathrm{kt}-\mathrm{U}$ \\
\hline $\begin{array}{l}\text { Base case estimated } \\
\text { unconventional uranium } \\
\text { resources }\end{array}$ & & & $4,200,000 \mathrm{kt}-\mathrm{U}$ \\
\hline Base case natural enrichment & \multirow{2}{*}{$\begin{array}{l}\text { Units or allowed } \\
\text { variables }\end{array}$} & \multirow[t]{2}{*}{ Impact } & 0.711 \\
\hline Base case tail enrichment & & & 0.25 \\
\hline
\end{tabular}


VISION User Guide, Rev 3.4

\begin{tabular}{|c|c|c|c|}
\hline Parameter & $\begin{array}{l}\text { Units or Allowed } \\
\text { Variables }\end{array}$ & Impact & $\begin{array}{l}\text { Recommended } \\
\text { Values }\end{array}$ \\
\hline $\begin{array}{l}\text { Base case USA year- } 2000 \\
\text { demand level }\end{array}$ & $\begin{array}{l}>0 \text { GWe-FPY/year } \\
\text { (not zero) }\end{array}$ & $\begin{array}{l}\text { Initial nuclear power generation } \\
\text { rate }^{1}\end{array}$ & $\begin{array}{l}86.00193 \text { GWe- } \\
\text { FPY to match } \\
\text { 2000 U.S. data }\end{array}$ \\
\hline $\begin{array}{l}\text { Base case Initial Nuclear } \\
\text { Power Percent }\end{array}$ & $\begin{array}{l}>0 \text { to } 100 \\
\text { (do not use \% symbol) }\end{array}$ & $\begin{array}{l}\text { VISION calculates the initial total } \\
\text { electricity demand in } 2000 \text { from the } \\
\text { nuclear electricity / nuclear market } \\
\text { share, }=433.7 \text { GWe-FPY for U.S. }\end{array}$ & $\begin{array}{l}19.83 \text { to match } \\
2000 \text { U.S. data }\end{array}$ \\
\hline $\begin{array}{l}\text { Base case unlimited } \\
\text { repository flow capacity }\end{array}$ & $\geq 0$ kilotonne/yr & $\begin{array}{l}\text { This specifies the flow rate of } \\
\text { material to the repository when the } \\
\text { unlimited repository flow capacity } \\
\text { switch in Logical } 1 \text { worksheet is set } \\
\text { to TRUE. } \\
\text { The repository flow capability only } \\
\text { applies to unprocessed used fuel; } \\
\text { the receipt rate for HLW and TRU } \\
\text { waste is unlimited. }\end{array}$ & $50 \mathrm{kt} /$ year \\
\hline $\begin{array}{l}\text { Base case unlimited } \\
\text { repository holding capacity }\end{array}$ & $\geq 0$ kilotonne & $\begin{array}{l}\text { This specifies the overall repository } \\
\text { holding capacity (permanent } \\
\text { repository capacity + retrievable } \\
\text { repository capacity), when the } \\
\text { unlimited repository holding } \\
\text { capacity is set to TRUE on Logical } \\
\mathbf{1} \text { worksheet . } \\
\text { The capacity limit only applies to } \\
\text { unprocessed used fuel, the } \\
\text { repository has unlimited capacity } \\
\text { for HLW and TRU waste. }\end{array}$ & 7000 kilotonne \\
\hline $\begin{array}{l}\text { Base case permanent } \\
\text { repository limit }\end{array}$ & $\geq 0$ kilotonne & $\begin{array}{l}\text { This specifies the permanent } \\
\text { repository capacity; it should be } \\
\text { less than the repository holding } \\
\text { capacity, which is set with the } \\
\text { Repository Holding Capacity } \\
\text { worksheet or the above value. } \\
\text { The capacity only applies to } \\
\text { unprocessed used fuel, the } \\
\text { repository has unlimited capacity } \\
\text { for HLW and TRU waste. }\end{array}$ & 63 kilotonne \\
\hline Delete last row & & & \\
\hline
\end{tabular}

\subsubsection{General (YELLOW) - Growth Rate Worksheet and User Help on Growth Rates Worksheet}

The growth rate of nuclear power demand is set by a combination of the total electricity growth rate and the market share of nuclear power. In the upper table on Growth Rate, the annual percent growth rate of electricity is specified, year by year. In the lower table on Growth Rate, the annual market share of nuclear reactors as a percent of electricity is specified.

This worksheet is used if "Base case reactor order case" on the Integer $\mathbf{1}$ worksheet is set to 0 , in which case nuclear power demand is set on Growth Rate for the entire reactor fleet. If "Base case reactor order

\footnotetext{
${ }^{1}$ Average LWR/LWRmf capacity $\mathrm{x}$ average LWR/LWRmf capacity factor $\mathrm{x}$ number of legacy reactors should equal to the nuclear power generation in 2000
} 
case" is set to 1, then growth is not determined by Growth Rate, but instead is determined by the precise number of reactors specified on Reactor \#'s. If "Base case reactor order case" is set to 2, then growth is not determined by Growth Rate, but instead is determined by each reactor type separately using a combination of the end-simulation capacity set on Reactor Facility and the year by year values set on Reactor Growth \% of Final.

A second worksheet, User Help on Growth Rates, is provided to help the user calculate the appropriate nuclear market share when a electricity grow rate and nuclear growth rate are known, or when specific nuclear market penetrations at specific times are known.

\subsection{Reactor (PINK) Worksheets}

The set of reactor worksheets provide input for the reactor fleet. The worksheets Reactor Facility, Legacy Reactor Retirement Rate, Wet and Dry Storage, and Reactor Fuel Types are used in all simulations. In a given simulation, only one of the worksheets Reactor \%s, Reactor \#'s, or Reactor Growth \% of Final are used, depending on which reactor order case on Integer 1 was selected. When Reactor \%s is used, then Reactor \%s Total provides the user with the total of the percentages he specified on Reactor \%s; that total should be 100. Table 4-7 summarizes how these worksheets work together.

Table 4-7. Reactor Capacities and Transformation Performance in VISION

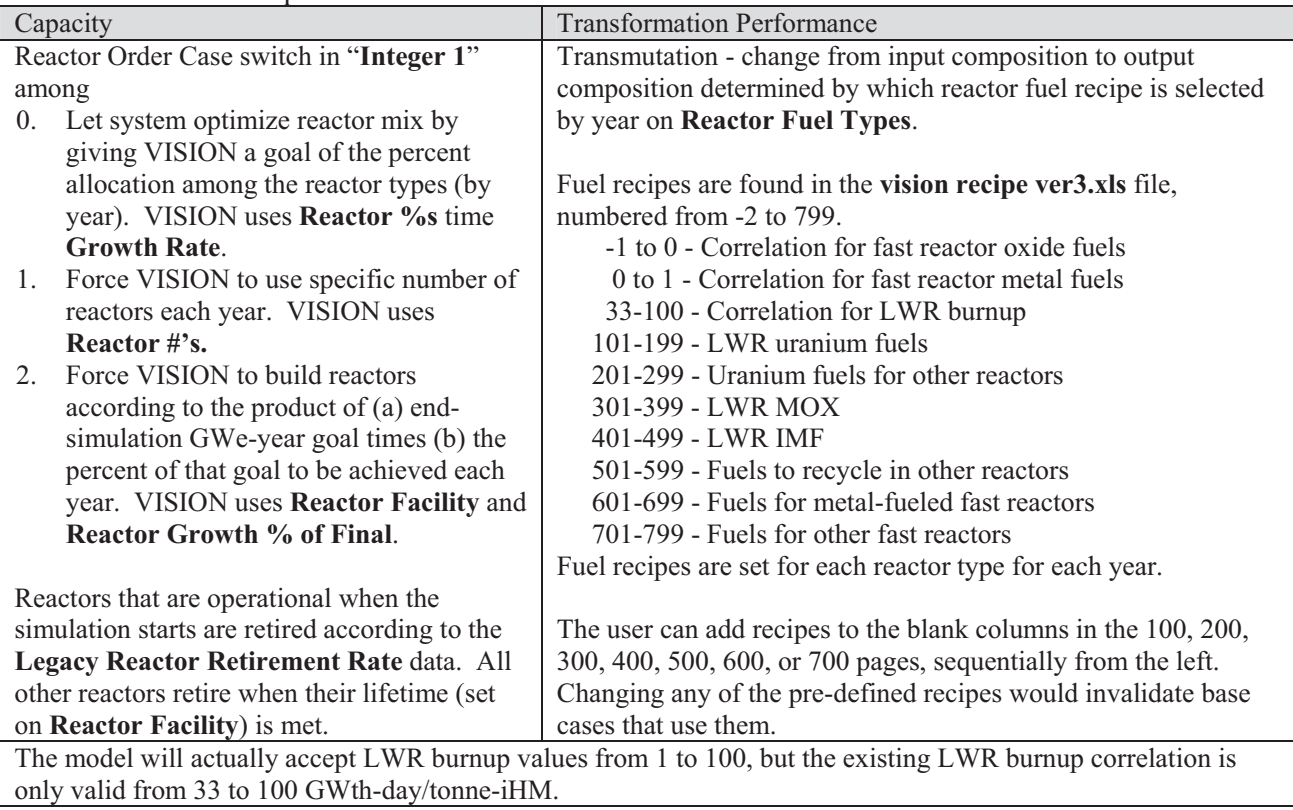

All user settings for running simulations are made within one or more of the four Excel input files, with the following exceptions. These parameters must be changed within Powersim Studio itself. Once you are finished, return to the interface page by going to Project Explorer - VISION Flow Model Simulation Controls - Shared Diagrams. After clicking on Shared Diagrams, click on the "Interface" tab at the bottom of the page. 
Number of reactor types - The model comes set to run 3 reactor types, to increase that ...

- Project explorer - Global Ranges (next to the bottom)

- Fueltype - click on the "+" sign to the left of "fueltype". Right click on " 3 " to insert additional items up to as many as 10 . Then rename the items so that they list from 1 to the maximum number.

- Reactors - double click on "reactors" to open it, change "last" from 3 to as many as 10.

Maximum length of fuel residence in reactors - The model comes set with a maximum of 50 years fuel residence time. If you need to change it .....

- Project explorer - Global Ranges (next to the bottom)

- Age in Reactor - double click on "Age in Reactor" to open it, change "last" from 50 to a higher value, but no greater than the number of years of the simulation.

Reactor Life - The model comes set to run up to 60 years for reactor lifetime.

- $\quad$ Project explorer - Global Ranges (next to the bottom)

- Reactor Life - double click on "Reactor Life" to open it, change "last" from 60 to a higher value, but no greater than the number of years of the simulation.

Number of recipes in a given portion of the recipe file. The recipe file has 7 pages of recipes. The parameters in the Powersim model have to be consistent with the recipe file. If you wish to user more recipes on a given page than how the current recipe file and Powersim Model are arranged, you have to do four things.

1. Add the recipe columns on the appropriate page of the recipe file. For once through $(100 \mathrm{~s}, 200 \mathrm{~s})$, that is a single column per recipe. For recycle recipes $(300 \mathrm{~s}, 400 \mathrm{~s}, 500 \mathrm{~s}, 600 \mathrm{~s}, 700 \mathrm{~s})$, that is 6 columns per recipe, a blank and then 5 recycle pages.

2. Add titles for all new columns in the "Fuels" global range. This is an enumerated range, and therefore what you add must be in the exact sequence in which you've added the recipes in the recipe file. For example, imagine you have added 5 new MOX recipes on the 300s worksheet. Then, you would add 30 new names after $315-5$, possibly $316-0,316-1, \ldots 320-5$, corresponding to new recipes 316 to 320 . Note that the enumerated list must have a blank for each blank column in the recipe file, typically designated as recipe 0 .

3. Change the range for the associated named range to include the fuels you just added to the "Fuels" enumerated list. For example, in the above example, you would change the last item in the LWR MOX recipe range from 315-5 to 320-5.

4. Change the instructions on (Rr) Fuel Recipes page in the model so that the model knows the expanded range to read from Excel for fresh fuel recipes, (used) fuel recipes, other fuel parameters. There should not be any "question marks" on this page once you are done. 


\begin{tabular}{|l|l|l|ll|l|}
\hline & Name & Number & First & & Last \\
\hline $100 \mathrm{~s}$ & UOX Recipes & 10 & UOX User BU & (Recipe 101) & 110 \\
\hline $200 \mathrm{~s}$ & Other Once Thru Recipes & 10 & NGNP & (Recipe 201) & 210 \\
\hline $300 \mathrm{~s}$ & LWR MOX Recipes & 15 & MOX-RU-Pu-1 & (Recipe 301-1) & $315-5$ \\
\hline $400 \mathrm{~s}$ & LWR IMF Recipes & 15 & IMF-NpPu-1 & (Recipe 401-1) & $415-5$ \\
\hline $500 \mathrm{~s}$ & Other Thermal Recipes & 10 & $501-1$ & & $510-5$ \\
\hline $600 \mathrm{~s}$ & FR Metal Cooled Recipes & 30 & \multicolumn{2}{|l|}{ UOX to FR mtl-User-1 (Recipe 601-1) } & $630-5$ \\
\hline $700 \mathrm{~s}$ & FR Other Cooled Recipes & 10 & $701-1$ & & $710-5$ \\
\hline
\end{tabular}

\subsubsection{Reactor (PINK) - Reactor Facility}

Table 4-8 lists the parameters entered on this worksheet. Note that fuel residence time, fuel burnup, and capacity factor are not entered here, but instead are entered with fuel composition data in vision recipe ver3.xls.

Table 4-8. Reactor Capacities and Transformation Performance in VISION

\begin{tabular}{|c|c|c|c|c|}
\hline Parameter & $\begin{array}{l}\text { Units or } \\
\text { Allowable } \\
\text { Values }\end{array}$ & Impact & $\begin{array}{l}\text { Recommended } \\
\text { Value for } \\
\text { LWRs }\end{array}$ & $\begin{array}{c}\text { Recommended } \\
\text { Value for Fast } \\
\text { Reactors }\end{array}$ \\
\hline Licensing Time & $\begin{array}{l}\geq 0.25 \text { years } \\
(\geq \text { time step })\end{array}$ & $\begin{array}{l}\text { Sets duration of licensing, between } \\
\text { when reactors are ordered and when } \\
\text { they start construction. }\end{array}$ & 2 & 2 \\
\hline Construction Time & $\begin{array}{l}\geq 0.25 \text { years } \\
(\geq \text { time step })\end{array}$ & $\begin{array}{l}\text { Sets duration of construction } \\
\text { between when they are licensed and } \\
\text { when they are ready for fuel. } \\
\text { Reactors don't actually start } \\
\text { operation unless fuel is available. }\end{array}$ & 4 & 4 \\
\hline Lifetime & $\begin{array}{l}\geq 0.25 \text { years } \\
(\geq \text { time step })\end{array}$ & $\begin{array}{l}\text { How long reactors operate. If you } \\
\text { want a value greater } 60 \text { years, you } \\
\text { need to change the "global range" } \\
\text { for lifetime in Powersim. }\end{array}$ & 60 & 60 \\
\hline Reactor power & GWe/reactor & $\begin{array}{l}\text { Converts \#s of reactors into power. } \\
\text { If reactor order case }=0 \text { or } 2 \text {, it only } \\
\text { determines the number of reactors } \\
\text { but the mass flows are really } \\
\text { controlled by energy demand and } \\
\text { fuel burnup. If reactor order case = } \\
1 \text {, this parameter times Reactor \#'s } \\
\text { divided by fuel burnup determines } \\
\text { mass flows. }\end{array}$ & $\begin{array}{l}0.928 \mathrm{GWe} \text { per } \\
\text { reactorm }\end{array}$ & $\begin{array}{c}\text { Depends on } \\
\text { your scenario }\end{array}$ \\
\hline $\begin{array}{l}\text { Fuel Flow Control } \\
\text { switch }\end{array}$ & $0,1,2,3,4,5$ & $\begin{array}{l}\text { Controls the limiting isotope(s) } \\
\text { which will determine the amount of } \\
\text { new fuel that can be produced given } \\
\text { the minimum amount of that } \\
\text { specific isotope in a given fuel } \\
\text { recipe. } \\
0=\min (\mathrm{Pu} 239, \mathrm{Pu} 240, \mathrm{Pu} 241) \\
1=\mathrm{Pu} 239 \\
2=\mathrm{Pu} 240\end{array}$ & $5($ total $\mathrm{Pu})$ & 4 (total TRU) \\
\hline
\end{tabular}

m. 103 reactors $\mathrm{x} 0.928 \mathrm{GWe} /$ reactor reactor size $\mathrm{x} 0.90 \mathrm{FPY} / \mathrm{CY}$ capacity factor $=86.0 \mathrm{GWe}-\mathrm{FPY} / \mathrm{CY}$ in 2000 . 
VISION User Guide, Rev 3.4

\begin{tabular}{|c|c|c|c|c|}
\hline & & $\begin{array}{l}3=\mathrm{Pu} 241 \\
4=\mathrm{TRU} \\
5=\mathrm{Pu}\end{array}$ & & \\
\hline Thermal Efficiency & 0.01 to 1.00 & & 0.34 & 0.38 \\
\hline Legacy Reactors & Integer & $\begin{array}{l}\text { Number of reactors operational } \\
\text { when simulation starts }\end{array}$ & $\begin{array}{l}86 \text { LWR-UOX } \\
17 \text { LWR-MOX }\end{array}$ & 0 \\
\hline Fresh Reactors & Integer & $\begin{array}{l}\text { Number of reactors just beginning } \\
\text { service when simulation starts }\end{array}$ & 0 & 0 \\
\hline $\begin{array}{l}\text { Reactors near } \\
\text { retirement }\end{array}$ & Integer & $\begin{array}{l}\text { Number of reactors starting the } \\
\text { retirement process when simulation } \\
\text { starts }\end{array}$ & 0 & 0 \\
\hline $\begin{array}{l}\text { Reactors under } \\
\text { construction }\end{array}$ & Integer & $\begin{array}{l}\text { Number of reactors starting } \\
\text { construction when simulation starts }\end{array}$ & $\begin{array}{c}3 \\
\text { (See Table 2-2) }\end{array}$ & 0 \\
\hline $\begin{array}{l}\text { Reactors under } \\
\text { construction need } \\
\text { fuel }\end{array}$ & Integer & & 0 & 0 \\
\hline $\begin{array}{l}\text { Reactors being } \\
\text { licensed }\end{array}$ & Integer & $\begin{array}{l}\text { Number of reactors starting } \\
\text { licensing when simulation starts }\end{array}$ & $\begin{array}{c}2 \\
\text { (See Table 2-2) }\end{array}$ & 0 \\
\hline $\begin{array}{l}\text { Final GWe for } \% \\
\text { Growth }\end{array}$ & GWe-year & $\begin{array}{l}\text { Used when reactor order case on } \\
\text { Integer } \mathbf{1}=2 .\end{array}$ & 0 & 0 \\
\hline
\end{tabular}

\subsubsection{Reactor (PINK) - Legacy Reactor Retirement Rate}

As of 2000, there were 103 operating reactors in the U.S. In this model, these reactors are called legacy reactors, reactors present before the simulation starts. Many, if not most, of these reactors have or will obtain license extensions to operate beyond their original lifespan. To specify the retirement of these legacy reactors, the user must specify the number of reactors remaining during a 30 -year period in the Legacy Reactor Retirement Rate worksheet and specify the Base Case Start Legacy Reactor Retirement Date on the Integer 1 worksheet. A retirement rate that considers both the start date and the expected lifetime of these reactors has been calculated and is used for all of the base case options.

Remember that reactors are retired in the order they are defined: reactor type 1 , then type 2 , then type 3 , etc.

\subsubsection{Reactor (PINK) - Wet and Dry Storage}

When fuel is discharged from a reactor, it goes into "wet" storage, where "wet" is meant to imply that cooling of the fuel is required. For UOX or MOX or IMF, this is the traditional water pool. Regardless of its destination, fuel must stay in wet storage for a minimum time set by the user for each reactor type. That is, the model never allows fuel to move from wet storage until the minimum time set by the user is achieved.

When fuel is moved from "wet" storage, it goes to "dry" storage. It can move into repository or separation capacity to the extent that either has sufficient capacity to process that fuel; in such cases the model ignores the time period for "dry" storage. Otherwise, used fuel accumulates in dry storage until moved to a centralized monitored retrievable storage at the end of the time period specified by the user, provided that the MRS is turned on. If the MRS is not turned on, the used fuel stays in dry storage until there is capacity to move it to separations or repository.

All used fuel (also known as spent fuel) generated by these reactors, prior to 2000, is called legacy used fuel. Coupled with the LWR/LWR-MF split implied in Table 2-3, U.S. DOE EIA data [DOE EIA2002] have been used to generate Table 2-4, repeated below. To use these data, the user inputs the values of 
mass into the Wet and Dry Storage worksheet with fuel recipe numbers that correspond to the composition reflecting the average burnup. ${ }^{\mathrm{n}}$ We make the simplifying assumption that legacy fuel prior to 2000 is modeled as being in wet storage if younger than 10 years and being in dry storage if older than 10 years. The 10 -year threshold is set to be consistent with the 10 -year minimum time in wet storage we use in LWR simulations.

Table 2-4. U.S. Used Fuel, Prior to 2000 (replicated here)

\begin{tabular}{|l|c|c|c|l|}
\hline $\begin{array}{l}\text { Suggested allocation in reactor/storage type in } \\
2000\end{array}$ & $\begin{array}{c}\text { Mass } \\
\text { (kilotonnes) }\end{array}$ & $\begin{array}{c}\text { Average } \\
\text { burnup (GWth- } \\
\text { day/tonne) }\end{array}$ & $\begin{array}{c}\text { Average } \\
\text { age } \\
\text { (years) }\end{array}$ & $\begin{array}{c}\text { Years } \\
\text { discharged }\end{array}$ \\
\cline { 1 - 2 } LWR-UOX (86 of 103 reactors) - wet storage & 17.704 & 38.19 & 4.4 & $\begin{array}{l}1991 \text { to } \\
2000\end{array}$ \\
\cline { 1 - 2 } LWR-MOX (17 of 103 reactors) - wet storage & 3.459 & 26.89 & 16.6 & 1968 to \\
\cline { 1 - 2 } LWR-UOX (86 of 103 reactors) - dry storage & 17.946 & 3.507 & 1990 \\
\hline LWR-MOX (17 of 103 reactors) - dry storage & 3.5016 & 32.60 & 10.6 & \\
\hline Total & 42.616 & &
\end{tabular}

\subsubsection{Reactor (PINK) - Reactor \%s and Reactor \%s Total}

This worksheet is used when reactor order case on Integer $\mathbf{1}$ is set to 0 . It allows the user to set the percent of each type of reactor to be requested for new reactors being ordered. The user sets the percent for each type of reactor as a function of time. The sum must equal 100 and can be quickly checked by looking on the Reactor\% Total worksheet.

\subsubsection{Reactor (PINK) - Reactor \#'s}

This worksheet is used when reactor order case on Integer $\mathbf{1}$ is set to 1. This option should be used with caution by the user, since specifying the number of reactors will override the specifications for reactor power generation and possibly order fast reactors for which there is no fuel. When using this option, the number of reactors must be specified for the full 100 years or 200 years of the simulation and for each type of reactor.

\subsubsection{Reactor (PINK) - Reactor Growth \% of Final}

This worksheet is used when reactor order case on Integer $\mathbf{1}$ is set to 2. This option should be used with caution by the user, since specifying the end-simulation growth value input on Reactor Facility times these values will override the specifications for reactor power generation and possibly order fast reactors for which there is no fuel.

\subsubsection{Reactor (PINK) - Reactor Fuel Types}

The worksheet specifies the reactor fuel recipe for each reactor type for each year, see Table 4-9. It is recommended that the user not attempt to use a "reactor type" beyond the range of fuel types that an actual reactor technology could reasonably be expected to accommodate, e.g., burn fast reactor fuels in a LWR or use fast breeder reactor fuel compositions in a reactor initially using fast burner reactor fuel compositions. ${ }^{\circ}$

n. The current recipe file has recipes 106 for 38.19 burnup and 107 for 26.89 burnup; these recipes do not include the impact of aging, which would transform some Pu241 into Am241, but they could be adjusted accordingly.

o. Breeders typically require blankets surrounding the core; burners do not. So, a reactor initially built only for burner fuels would not be capable of later using breeder fuel compositions without substantial modification. 
Recall that selecting a fuel recipe number invokes several parameters from vision recipes ver3.xls, as described further in section 5. These factors are interconnected and therefore they reside together in the recipe file. They are follows:

- Fuel burnup (GWth-day/tonne-iHM)

- Capacity factor

- Fuel residence time (calendar years) - remember that a Powersim model change is required if this is to be set over 50 years. See section 3.4

- The input and output compositions for this primary fuel.

- The number of a contingent fuel (if any) that VISION will use in this reactor if the primary fuel cannot be made. The contingent fuel should be a uranium-based fuel.

- Uranium priority 1 to 6 - what type of uranium supply (EU, NU, DU, RU) should be used to make up the correct amount of uranium in the fuel once the uranium in the incoming separationto-fuel buffer is accounted for.

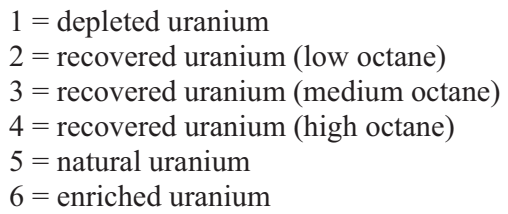

VISION deals with four types of uranium, DU, RU, NU, and EU.

- NU and EU are ordered as needed for a particular fuel for a particular reactor.

- There is a single stock of DU, used as needed.

- RU is controlled strictly by what the user does in the separation stream splits. RU sent to waste, remains in waste. RU sent to a buffer box, stays in that buffer box until and unless fuel is made from it. So, if RU is sent to buffer 2, then fuel fab three cannot use it.

- The fuel recipe file determines where VISION obtains uranium in what order, for each recipe. See the rows "Uranium Priority". The once through recipes have uranium priority 6/0/0/0/0/0, meaning to use EU with no backup plan. Some MOX recipes are "3" so that RU is used; others use DU.

- With regard to recycle passes, RU is like any other product. If the material is staying with its current stream, it gets reset from pass $\mathrm{N}$ to $\mathrm{N}+1$ coming out of separation, so that $\mathrm{RU}$ from recycling pass 3 material goes into the buffer for pass 4 fabrication. (Pass 5 goes to Pass 5). If material is moving from a different stream, it always goes into the pass 1 buffer box.

- There is no single separated RU inventory box in the current version from which multiple fuel fabrication steps could draw. There was in previous versions, but with the increased flexibility, it was deemed unwise to have a single RU box because there could be radically different U235 enrichments from RU that arise from different types of used fuel. Instead, it is up to the user to put RU from separations where it might be used. 


\begin{tabular}{|c|c|}
\hline Reactor technology & Appropriate reactor fuel numbers in vision recipe ver3.xls \\
\hline LWR & 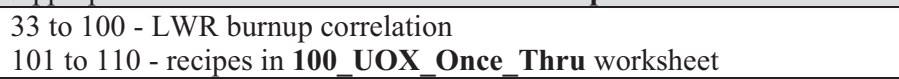 \\
\hline LWR MF (multiple fuel) & 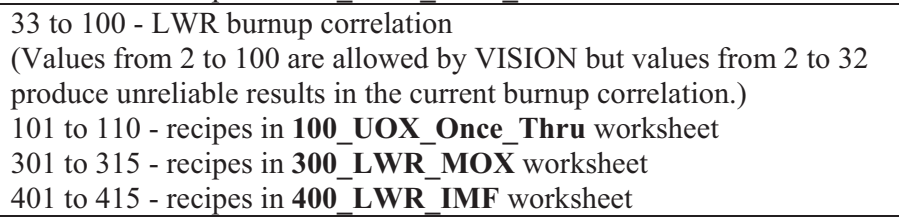 \\
\hline HWR or VHTR & $\begin{array}{l}\text { Appropriate recipes among } \\
201 \text { to } 210 \text { - recipes in } \mathbf{2 0 0} \text { _Other_Once_Thru worksheet }\end{array}$ \\
\hline $\begin{array}{l}\text { HWR or VHTR possibly } \\
\text { using recycled material }\end{array}$ & $\begin{array}{l}\text { Appropriate recipes among } \\
201 \text { to } 210 \text { - recipes in 200_Other_Once_Thru worksheet } \\
501 \text { to } 510 \text { - recipes in 500_Other_Thermal_Recycle worksheet } \\
\text { Currently all the } 500 \text { recipe slots are blank. }\end{array}$ \\
\hline $\begin{array}{l}\text { Fast burner reactor, sodium } \\
\text { cooled }\end{array}$ & $\begin{array}{l}-1.00 \text { to } 0.00 \text { - fast reactor metal TRU CR correlation } \\
0.00 \text { to } 1.00 \text { - fast reactor oxide TRU CR correlation Appropriate recipes } \\
\text { among } \\
601 \text { to } 630 \text { - recipes in } \mathbf{6 0 0} \text { Metal_Cooled_FR worksheet }\end{array}$ \\
\hline $\begin{array}{l}\text { Fast breeder reactor, } \\
\text { sodium cooled }\end{array}$ & $\begin{array}{l}\text { Appropriate recipes among } \\
601 \text { to } 630 \text { - recipes in } \mathbf{6 0 0} \text { Metal_Cooled_FR worksheet }\end{array}$ \\
\hline $\begin{array}{l}\text { Fast reactors with other } \\
\text { coolants }\end{array}$ & 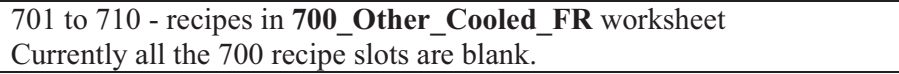 \\
\hline
\end{tabular}

If for example you want to vary the capacity factor of a reactor type, create duplicate recipes that vary only by the capacity factor and select among them. ${ }^{\mathrm{p}}$

The appropriate primary fuel in a LWR capable of using multiple fuels (LWR-MF) is one of the MOX (fuel numbers $2 \mathrm{xx}$ ) or IMF (fuel numbers $3 \mathrm{xx}$ ) recipes. If the contingent fuel is a UOX recipe (typically fuel number 103, for 51 GWth-day/tonne burnup UOX), then that UOX is used when the supply of MOX or IMF is inadequate. That UOX is considered by VISION to be MOX recycle pass 0 and is distinct from UOX that may be used as the primary fuel in UOX-only LWRs.

Recipes 101, 601, and 602 are special cases as they evoke the LWR burnup correlation (recipe 101) or fast reactor TRU CR correlations (recipes 601, 602). In these cases, the user must specify the burnup in the appropriate places in vision recipes ver3.xls, which is used whenever such recipes are selected. If you want to use the LWR burnup correlation, use 33 to 100 .

\subsection{Reactor to Separation Routing (GREY) Worksheets}

These two worksheets control the routing of used fuel from reactor wet/dry storage into separation types.

p. Strictly speaking, one should also modify the recipe slightly to account for differences as the capacity factor during irradiation is varied. 


\subsubsection{Reactor to Separation Routing (GREY) - Recycle Strategy Option}

The user specifies on this page which of the recycle routing strategy matrices defined on the Recycle Strategy Matrix worksheet is used for each year. Since each recycle routing strategy matrix addresses all recycle passes, all reactor/fuel types, and all separation types, only one matrix is selected for each year.

Changing recycle routing strategy matrix from one year to the next means that the fleet's recycling strategy has fundamentally changed.

\subsubsection{Reactor to Separation Routing (GREY) - Recycle Strategy Matrix}

These matrices provide the priority for separations and disposal. Within a fuel type, the prioritization by pass and reactor source must also be specified for each separation facility type. This is accomplished through the matrices in this page. Each separation facility type is assumed to accept one type of fuel. In cases where more than one type of fuel is sent to a single type of separations facility, all of the fuel entering that separations facility will be considered the nominal fuel type for that facility when it exits. At any given point in time, material coming from a given Reactor, Pass can only be specified as a single Fuel Type, Pass. At any given point in time, material coming from a given Reactor, Pass can only be specified as going all to separations or all to disposal. The matrices must be filled out using a 3 numeral code. The first e numerals indicate the reactor type and the fourth numeral indicates the pass.

Fuel types correspond to codes 10 to 19 .

Recycle passes correspond to code 0 to 5 .

Each matrix defines the priority order for fuel to enter a given separation type.

Recall that the same fuel recipe can be used in multiple places. For example, in a MOX capable reactor, the primary fuel is one of the MOX recipes (fuel number 2xx) and the contingent fuel is a UOX recipe (typically fuel number 103). Thus, a strategy of one recycle pass in a MOX-capable reactor means that there are both pass0 and pass 1 fuel in that fuel slot. Consider an example where MOX is fuel-2, hence code " $11 \mathrm{x}$ ". So, the recycling routing matrix must account for both 110 (MOX, pass $0=$ UOX) and 111 (MOX, pass 1). The user can then decide which of two approaches to use, as follows:

- Pull 110 (MOX, pass 0 = UOX) to the same separation plant as 100 (UOX, pass 0) and 111 (MOX, pass $1=\mathrm{MOX}$ ) to a separate separation plant designed for MOX. This implicitly assumes there is a mechanism to physically separate MOX from UOX in the LWR-MOX reactors, as is appropriate if the fuels are different assemblies.

- Pull 110 and 111 to the same separation plant, designed for a UOX-MOX fuel mix. This would be appropriate if the fuels are co-mingled within fuel assemblies.

Said another way, the underlying cause for the complexity and the different ways of modeling a scenario correspond to actual variations in how a scenario would work in reality. The complexity isn't the model, the model is reflecting the complexity of the real world.

The user determines the priority order in which each separation plant capacity is used, e.g., specifying if fast reactor fuel is fuel type-3 (hence code $12 \mathrm{x}$ ), then two strategies can be created:

- Pull 125, 124, 123, 122, 121 into the separation type means that the most recycled fuel goes first.

- Pull 121, 122, 123, 124, 125 into the separation type means the least recycled fuel goes first. 
In this example, if the user has defined a contingent (uranium) fuel for the fast reactor, that fuel (code 120) would need to be added to the list.

\section{Cautions:}

17. The recycle routing strategy matrix must account for all fuels and recycle passes that may exist during a simulation.

18. The user may be tempted to use routing matrix 15 as a catch all or default matrix. Be aware that it does what it says, send used fuel to the repository. So, for example, in a recycle scenario, if one uses routing matrix 15 with non-zero flow to a repository before turning on separations, the model will indeed send used fuel to the repository. If you want the repository turned on for some fuel types, which are not to be recycled, but unavailable for fuel types that are to be recycled, use a routing matrix that does not send those fuel cycles to the repository from the beginning of the simulation.

Table 4-3. List of Recycling Routing Matrices (repeated from earlier subsection)

\begin{tabular}{|l|l|}
\hline 1 & Reserved for development testing \\
\hline 2 & Reserved for development testing \\
\hline 3 & Reserved for development testing \\
\hline 4 & Blank \\
\hline 5 & Blank \\
\hline 6 & $\begin{array}{l}\text { 1-tier recycling } \\
\text { UOX (assumed to be pass0 of fuel-1 and fuel-2) is routed to separation-1 } \\
\text { FR fuel (assumed to be pass1 thru pass5 of fuel-3) is routed to separation-3 }\end{array}$ \\
\hline 7 & $\begin{array}{l}\text { 2-tier recycling } \\
\text { UOX (assumed to be pass0 of fuel-1 and fuel-2) is routed to separation-1 } \\
\text { MOX (assumed to be pass1 up to pass5 of fuel-2) is routed to separation-2 }\end{array}$ \\
\hline 8 & $\begin{array}{l}\text { One thermal recycle, then dispose } \\
\text { UOX (assumed to be pass0 of fuel-1 and fuel-2) is routed to separation-1 } \\
\text { MOX ((or IMF) assumed to be pass1 of fuel-2) is routed to disposal }\end{array}$ \\
\hline 9 & $\begin{array}{l}\text { Multiple thermal recycle } \\
\text { UOX (assumed to be pass0 of fuel-1 and fuel-2) is routed to separation-1 } \\
\text { MOX ((or IMF) assumed to be pass1 thru pass5 of fuel-2) is routed to separation-2 }\end{array}$ \\
\hline 10 & Blank \\
\hline 11 & Blank \\
\hline 12 & $\begin{array}{l}\text { Stop fast recycling, send everything to thermal reactors. This is actually the same routing as 2-tier } \\
\text { assuming that FR fuel is separated and then the products are sent to thermal reactors. So, the routing used } \\
\text { fuel-to-separation is the same as 2-tier, but the routing from separation-to-fuel is different. The latter is set } \\
\text { by separation efficiency matrices. } \\
\text { UOX (assumed to be pass0 of fuel-1 and fuel-2) is routed to separation-1 } \\
\text { MOX (assumed to be pass1 up to pass5 of fuel-2) is routed to separation-2 } \\
\text { FR fuel (assumed to be pass1 up to pass5 of fuel-2) is routed to separation-3 }\end{array}$ \\
\hline 13 & $\begin{array}{l}\text { Stop thermal recycling, send everything to fast reactors. This is actually the same routing as 2-tier } \\
\text { assuming that MOX fuel is separated and then the products are sent to fast reactors. So, the routing used } \\
\text { fuel-to-separation is the same as 2-tier, but the routing from separation-to-fuel is different. The latter is set } \\
\text { by separation efficiency matrices. } \\
\text { UOX (assumed to be pass0 of fuel-1 and fuel-2) is routed to separation-1 } \\
\text { MOX (assumed to be pass1 up to pass5 of fuel-2) is routed to separation-2 } \\
\text { FR fuel (assumed to be pass1 up to pass5 of fuel-2) is routed to separation-3 }\end{array}$ \\
\hline 14 & $\begin{array}{l}\text { Stop recycling, send everything to disposal } \\
\text { Passes 0 through 5 of fuels 1,2, and 3 are routed to disposal. }\end{array}$ \\
\hline & \\
\hline
\end{tabular}


15 Once through

Pass 0 of fuels 1,2 , and 3 are routed to disposal. In once through, no fuel every gets past pass 0 , therefore no routing is required for passes 1 to 5 .

\subsection{Separation (BLUE) Worksheets}

There are three types of separation worksheets, as follows:

- Facility Ramp Up - defines for each separation type what fraction of the facility's rated capacity is operational during the first several years of operation.

- Separation 1 through 10 - defines several parameters for that separation type, including capacity and which separation efficiency matrix is to be used, by year.

- Separation Stream Splits - defines the performance of a separation type.

Table 4-10 summarizes how these worksheets work together.

Table 4-10. Separation Facility Capacities and Transformation Performance in VISION

\begin{tabular}{|c|c|}
\hline Capacity & 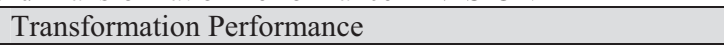 \\
\hline $\begin{array}{l}\text { Separations Order switch in Integer } 1 \\
\text { among } \\
\text { 0. Let VISION optimize separation } \\
\text { capacity. VISION builds separation } \\
\text { capacity subject to the Separations } \\
\text { Data, which is set on the } \\
\text { Separations worksheets. } \\
\text { 1. Force VISION to build specific } \\
\text { separation capacity each year, the } \\
\text { capacity is also set on the } \\
\text { Separations worksheets. Note: The } \\
\text { Separations Date switch in } \\
\text { Separation X worksheets overrides } \\
\text { capacity specifications; capacity is } \\
\text { built but not used. }\end{array}$ & $\begin{array}{l}\text { Partition - how the contents of used fuel are allocated } \\
\text { among fuel product streams, } 3 \text { grades of recovered } \\
\text { uranium (RU), and several waste form options. This is } \\
\text { determined by the separation efficiency matrices defined } \\
\text { on the Separation Stream Splits worksheet. } \\
\text { Separation efficiency matrices are numbered from } 1 \text { to } 40 . \\
1 \text { to } 20 \text { - aqueous } \\
21 \text { to } 30 \text { - electrochemical } \\
31 \text { to } 39 \text { - other } \\
40 \text { - once through } \\
\text { About half are blank and available for the user to define. } \\
\text { The user is encouraged to add separation matrix values to } \\
\text { any of the blank matrices. Changing any of the pre- } \\
\text { defined matrices would invalidate base cases that use } \\
\text { them. } \\
\text { The list of recipes (including any the user has added) is } \\
\text { given on page "List of separation types" }\end{array}$ \\
\hline
\end{tabular}

All user settings for running simulations are made within one or more of the four Excel input files, with the following exceptions. These parameters must be changed within Powersim Studio itself. Once you are finished, return to the interface page by going to Project Explorer - VISION Flow Model -

Simulation Controls - Shared Diagrams. After clicking on Shared Diagrams, click on the "Interface" tab at the bottom of the page.

Number of separation types - The model comes set to run 3 separation types, to increase that ...

- Project explorer - Global Ranges (next to the bottom) 
- Separations - double click on "Separations" to open it, change "last" from 3 to as many as 10 .

\subsubsection{Separation (BLUE) - Facility Ramp Up}

This page allows the user to specify the speed with which a Separation Facility comes on line. The first column specifies the year number (1-20). The second column represents the percentage of the facility completed with one representing $100 \%$ or the facility is complete. This column is cumulative. Years (120) must total $100 \%$. Each reactor has a rate 1 and rate 2 . The second rate is more efficient than the first.

\subsubsection{Separation (BLUE) - Separation 1 through Separation 10}

Table 4-11 lists the parameters set on these worksheets, one for each separation type. Most of the parameters are straightforward, with exception of specification of separation efficiency matrix by recycle pass. Except in rare circumstances, the array of selection of separation efficiency matrices for the six recycle passes ( 0 through 5 ) will be identical. The only known exception is recycling 2 or more times in one type of reactor, e.g., LWR-MOX, and then sending fuel to another type of reactor, e.g., fast reactor. Otherwise, all recycle passes in a given separation facility should have the same separation efficiency matrix.

Table 4-11. Parameters set on the Separation Worksheets

\begin{tabular}{|c|c|c|c|}
\hline Parameter & $\begin{array}{l}\text { Units or Allowed } \\
\text { Variables }\end{array}$ & Impact & $\begin{array}{l}\text { Recommended } \\
\text { Values }\end{array}$ \\
\hline Construction Time & $\begin{array}{l}\geq 0.25 \text { years } \\
(\geq \text { time step })\end{array}$ & $\begin{array}{l}\text { Sets delay for construction of } \\
\text { separation facilities. }\end{array}$ & 5 \\
\hline Lifetime & $\begin{array}{l}\geq 0.25 \text { years } \\
(\geq \text { time step })\end{array}$ & How long separation plants operate. & 60 \\
\hline Separation duration & $\begin{array}{l}\geq 0.25 \text { years } \\
(\geq \text { time step })\end{array}$ & $\begin{array}{l}\text { How long material resides in the } \\
\text { separation plant }\end{array}$ & 1 \\
\hline $\begin{array}{l}\text { Unlimited separation } \\
\text { capacity }\end{array}$ & \multicolumn{2}{|c|}{$\begin{array}{l}\text { TRUE = VISION does not limit separation by capacity } \\
\text { FALSE = VISION does limit separation by capacity } \\
\text { TRUE is unrealistic but a helpful option for debugging a case if } \\
\text { one suspects that mass flow is choked at separations. }\end{array}$} & FALSE \\
\hline Separation facility size & $\begin{array}{l}>0 \text { kilotonnes/ } \\
\text { calendar year } \\
\text { (not zero) }\end{array}$ & $\begin{array}{l}\text { Determines the unit size of these } \\
\text { facilities. Only integer number of } \\
\text { these facilities can be built. If allowed } \\
\text { by user input settings, VISION will } \\
\text { calculate the number of required } \\
\text { facilities and round up. }\end{array}$ & $\begin{array}{l}\text { Depends on } \\
\text { your scenario }\end{array}$ \\
\hline Initial Pu239 stockpile & $\geq 0$ kilotonnes-Pu239 & $\begin{array}{l}\text { This allows the user to specify the } \\
\text { amount of Pu239, available from } \\
\text { sources external to the fuel cycle. Use } \\
\text { of this option allows you to start a test } \\
\text { or prototype FR sooner than would be } \\
\text { possible if one depended on separation } \\
\text { product streams. }\end{array}$ & $\begin{array}{l}\text { Depends on } \\
\text { your scenario }\end{array}$ \\
\hline
\end{tabular}


VISION User Guide, Rev 3.4

\begin{tabular}{|c|c|c|c|}
\hline Parameter & $\begin{array}{l}\text { Units or Allowed } \\
\text { Variables }\end{array}$ & Impact & $\begin{array}{c}\text { Recommended } \\
\text { Values }\end{array}$ \\
\hline Separations date & $\begin{array}{l}\text { Date between } 2000 \text { and } \\
2100 \text {, inclusive }\end{array}$ & $\begin{array}{l}\text { This date overrides the separation } \\
\text { capacity specified elsewhere. This } \\
\text { means that separation capacity can } \\
\text { exist before the specified start date but } \\
\text { that separations will not start before } \\
\text { that date. }\end{array}$ & 2020 \\
\hline $\begin{array}{l}\text { Number of recycle passes } \\
(200 \text { rows) }\end{array}$ & \multicolumn{3}{|c|}{$\begin{array}{l}\text { To be deleted, function handled by recycle routing and separation efficiency } \\
\text { matrices }\end{array}$} \\
\hline $\begin{array}{l}\text { Capacity for that separation } \\
\text { facility type by year }(200 \\
\text { rows })\end{array}$ & $\begin{array}{l}0 \text { to } 1000 \text { Kilotonnes/ } \\
\text { calendar year }\end{array}$ & $\begin{array}{l}\text { Determines the capacity each year if } \\
\text { Separations Order switch in Integer } 1 \\
=1 \text {, otherwise no impact. }\end{array}$ & \\
\hline $\begin{array}{l}\text { Separation efficiency matrix } \\
\text { numbers by year ( } 200 \text { rows) } \\
\text { for recycle pass } 0 \text {, then pass } \\
1,2,3,4 \text {, and } 5 \text {. }\end{array}$ & 1 to 40 & $\begin{array}{l}\text { This decides which of the separation } \\
\text { efficiency matrices is used for each } \\
\text { recycle pass for each year. }\end{array}$ & \\
\hline $\begin{array}{l}\text { Separations capacity } \\
\text { availability factor }\end{array}$ & $\begin{array}{l}0.00 \text { to } 1.00 \\
\text { FPY/calendar year }\end{array}$ & $\begin{array}{l}\text { Determines the fraction of time during } \\
\text { a year that separation facilities } \\
\text { generate } 100 \% \text { of their rated capacity }\end{array}$ & 1.0 \\
\hline
\end{tabular}

Some examples:

Matrix 1 - simulates UREX +1 or electrochemical separation, sends TRU to fuel-2, with waste segregated into several types, appropriate to use for separation-1 (all recycle passes) if these are operating on UOX or MOX and all TRU is to be recovered and sent to fuel-2.

Matrix 2 - same as matrix 1 except sends TRU to fuel-3, appropriate to use for separation-2 (all recycle passes) if these are operating on UOX or MOX and all TRU is to be recovered and sent to fuel-3. So, material separated from used MOX (if a 1-pass MOX strategy) is sent elsewhere. TRU gets into MOX not from separation-2 but from separation-1. TRU sent from UOX pass 0 goes to fresh MOX pass 1.

Matrix 6 - simulates UREX+2 so that $\mathrm{NpPu}$ is recovered and sent to fuel-2, AmCm goes into waste.

Matrix 13 - simulates UREX+4 so that NpPuAm is recovered and set to fuel-2, Cm goes into waste.

Matrix 16 - simulates COEX so that $\mathrm{U}$ and $\mathrm{Pu}$ is recovered and sent to fuel-2, NpAmCm goes into waste.

\subsubsection{Separation (BLUE) - Separation Stream Splits (Separation Efficiency Matrices)}

This worksheet specifies the isotopic composition (on a mass percent basis for each isotope) for each stream exiting a given separations option. There are 40 separations options available, including various versions of UREX+, COEX, Electrochemical (Table 4-12). One separation strategy can be defined for each fuel type for each year.

The separation efficiency matrices perform several functions, as follows:

- Identify which TRU elements are recovered and how they are grouped, see examples in Table 4-12. 
- Identify what fraction of fission product become impurities in fuel material.

- Identify where fuel products go, i.e., new fuel fabrication 1 through 10 . This separation-to-fuelfab routing could instead be done by a different set of routing matrices of fuel products into fuel fabrication. That alternative modeling approach would be appropriate if we wanted to specify fuel fabrication by pulling feedstock from multiple separation facilities, instead of the current approach of pushing fuel products from separation into fuel fabrication buffers.

- NOTE: The RU buffers are not used as we are unsure they are needed. Instead, send RU to the appropriate fuel product buffers. Unused $R U$ will accumulate there and not be counted as waste.

It is anticipated that some scenarios will involve multiple reactor types in which case the stockpile of $R U$ would need to be kept separate, e.g., relatively high enriched used uranium from VHTR would be put into RU-H and moderately enriched uranium from $L W R$ would be $R U-M$, and low enriched uranium from used HWR fuel would be RU-L.

- Define how many and which waste streams are produced.

- Identify which chemical elements go into which waste stream.

- Identify how much uranium and TRU does into each waste stream.

Table 4-12. Definition of Separation Efficiency Matrices

\begin{tabular}{|c|l|l|l|}
\hline & Technology & $\begin{array}{l}\text { Fuel goes to fuel } \\
\text { fabrication } \\
\text { number }\end{array}$ & Waste strategy \\
\hline 1 & UREX+1 (all TRU recovered) & 2 & Segregated waste streams \\
\hline 2 & UREX+1 (all TRU recovered) & 3 & Segregated waste streams \\
\hline 3 & UREX+1 (all TRU recovered) & 2 & All to HLW \\
\hline 4 & UREX+1 (all TRU recovered) & 3 & All to HLW \\
\hline 5 & Blank & & \\
\hline 6 & UREX+2 (NpPu recovered, AmCm to waste) & 2 & Segregated waste streams \\
\hline 7 & UREX+2 (NpPu recovered, AmCm to waste) & 3 & Segregated waste streams \\
\hline 8 & UREX+2 (NpPu recovered, AmCm to waste) & 2 & All to HLW \\
\hline 9 & UREX+2 (NpPu recovered, AmCm to waste) & 3 & All to HLW \\
\hline 10 & Blank & & Segregated waste streams \\
\hline 11 & UREX+3 (NpPu and AmCm recovered) & $\begin{array}{l}\text { NpPu to 2 } \\
\text { AmCm to 3 }\end{array}$ & All to HLW \\
\hline 12 & UREX+3 (NpPu and AmCm recovered) & NpPu to 2 & AmCm to 3 \\
& & NpPuAm to 2 & Segregated waste streams \\
\hline 13 & UREX+4 (NpPu, Am, and Cm recovered) & Cm to waste & \\
\hline 14 & Blank & & \\
\hline 15 & Blank & & \\
\hline 16 & COEX & 2 & All to HLW \\
\hline 17 & COEX & 3 & All to HLW \\
\hline 18 & Blank & & \\
\hline 19 & Blank & & Segregated waste streams \\
\hline 20 & Blank & 3 & \\
\hline 21 & Electrochemical (all TRU recovered) & 3 & \\
\hline 22 & Electrochemical (all TRU recovered) & 4 & Segregated waste streams \\
\hline 23 & Electrochemical (all TRU recovered) & & All to HLW \\
\hline 24 & Electrochemical (all TRU recovered) & & \\
\hline 25 & Blank & & \\
\hline & & & \\
\hline
\end{tabular}


VISION User Guide, Rev 3.4

June 2011

\begin{tabular}{|c|c|c|c|}
\hline 26 & Blank & & \\
\hline 27 & Blank & & \\
\hline 28 & Blank & & \\
\hline 29 & Blank & & \\
\hline 30 & Blank & & \\
\hline 31 & $\begin{array}{l}\text { Dry (only volatile fission products are removed, } \\
\text { everything else becomes quite impure new fuel) }\end{array}$ & 2 & All to HLW \\
\hline 32 & $\begin{array}{l}\text { Dry (only volatile fission products are removed, } \\
\text { everything else becomes quite impure new fuel) }\end{array}$ & 3 & All to HLW \\
\hline 33 & $\begin{array}{l}\text { Dry (only volatile fission products are removed, } \\
\text { everything else becomes quite impure new fuel) }\end{array}$ & 7 & All to HLW \\
\hline 34 & Blank & & \\
\hline 35 & Blank & & \\
\hline 36 & Blank & & \\
\hline 37 & Blank & & \\
\hline 38 & Blank & & \\
\hline 39 & Blank & & \\
\hline 40 & Once through (everything to HLW) & NA & All to HLW \\
\hline
\end{tabular}

The samples in base case settings ver3.xls denote two bounding waste management strategies. Of course, the user can define whatever strategy she wants.

- Segregated waste streams - waste is segregated into several streams with the intention that many would not be classified as HLW. See Table 4-13, 4-14, and 4-15.

- All to HLW - other than volatile species, all waste goes into a single waste form that would be HLW.

Table 4-13. Illustrative UREX+1 Separation Efficiency Matrix

\begin{tabular}{|c|c|c|c|c|c|c|c|c|c|c|}
\hline & $\begin{array}{l}\mathrm{Pu} \mathrm{Np} \\
\text { Am Cm } \\
\text { Recycle } \\
\text { Stream }\end{array}$ & $\begin{array}{c}\text { RU } \\
\text { Stream }\end{array}$ & $\begin{array}{c}\text { I } \\
\text { Stream }\end{array}$ & $\begin{array}{c}\text { Gas } \\
\text { Stream }\end{array}$ & $\begin{array}{c}\text { Tc } \\
\text { Stream }\end{array}$ & $\begin{array}{l}\text { Cs Sr } \\
\text { Stream }\end{array}$ & $\begin{array}{l}\text { LnFP } \\
\text { Stream }\end{array}$ & $\begin{array}{l}\text { Discard } \\
\text { Stream }\end{array}$ & $\begin{array}{c}\text { UDS } \\
\text { Stream }\end{array}$ & $\begin{array}{c}\text { Zr SS } \\
\text { Stream }\end{array}$ \\
\hline $\begin{array}{l}\text { Ra to } \\
\mathrm{Pa}\end{array}$ & & & & & & & 100 & \multirow{13}{*}{$\begin{array}{l}\vec{J} \\
0 \\
0 \\
0 \\
0\end{array}$} & \multirow{13}{*}{ 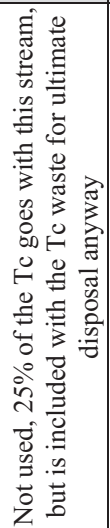 } & \multirow{13}{*}{ 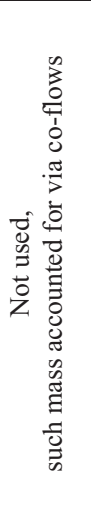 } \\
\hline $\mathrm{U}$ & & 99.9 & & & & & 0.1 & & & \\
\hline $\mathrm{Np}$ & $\begin{array}{l}99.9 \\
\end{array}$ & & & & & & 0.1 & & & \\
\hline $\mathrm{Pu}$ & 99.9 & & & & & & 0.1 & & & \\
\hline $\mathrm{Am}$ & 99.9 & & & & & & 0.1 & & & \\
\hline $\begin{array}{l}\mathrm{Cm}- \\
\mathrm{Cf}\end{array}$ & 99.9 & & & & & & 0.1 & & & \\
\hline H3 & & & & $\begin{array}{l}99.9 \\
\end{array}$ & & & 0.1 & & & \\
\hline C14 & & & & & & & 100 & & & \\
\hline $\mathrm{Kr}$ & & & & 99.9 & & & 0.1 & & & \\
\hline $\mathrm{Sr}, \mathrm{Cs}$ & & & & & & 99.9 & 0.1 & & & \\
\hline $\mathrm{Tc}$ & & & & & 99.9 & & 0.1 & & & \\
\hline I & & & 99.9 & & & & 0.1 & & & \\
\hline $\begin{array}{l}\text { FP } \\
\text { other }\end{array}$ & & & & & & & 100 & & & \\
\hline $\begin{array}{l}\text { RU = } \\
\text { Sum o } \\
\text { The se }\end{array}$ & ered & $\mathrm{F}$ & sior & $\begin{array}{l}\text { Ict, L } \\
00 \text {. }\end{array}$ & anthe & $\mathrm{s}, \mathrm{UD}$ & adisso & I solids. & & \\
\hline
\end{tabular}


Table 4-14. Illustrative Separation Efficiency for U+UPu+NpPuAm+CsSr+I+Tc Separation of UOX

\begin{tabular}{|c|c|c|c|c|c|c|c|c|c|c|c|}
\hline & $\begin{array}{c}\text { RU } \\
\mathrm{Pu} \mathrm{Np} \\
\text { Am Cm } \\
\text { Recycle } \\
\text { Stream } \\
\end{array}$ & $\begin{array}{c}\mathrm{Pu} \mathrm{Np} \\
\text { Am Cm } \\
\text { Recycle } \\
\text { Stream } \\
\end{array}$ & $\begin{array}{c}\text { RU } \\
\text { Stream } \\
\end{array}$ & $\begin{array}{c}\text { I } \\
\text { Stream } \\
\end{array}$ & $\begin{array}{c}\text { gas } \\
\text { Stream } \\
\end{array}$ & $\begin{array}{c}\text { Tc } \\
\text { Stream } \\
\end{array}$ & $\begin{array}{c}\text { Cs Sr } \\
\text { Stream } \\
\end{array}$ & $\begin{array}{c}\text { Lnfp } \\
\text { Stream }\end{array}$ & $\begin{array}{l}\text { Discard } \\
\text { Stream }\end{array}$ & $\begin{array}{c}\text { UDS } \\
\text { Stream } \\
\end{array}$ & $\begin{array}{c}\mathrm{Zr} \mathrm{SS} \\
\text { Stream } \\
\end{array}$ \\
\hline $\begin{array}{l}\text { Ra to } \\
\mathrm{Pa}\end{array}$ & & & & & & & & 100 & \multirow{13}{*}{ 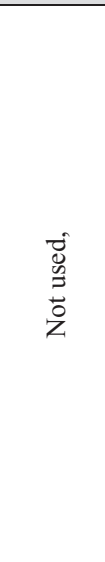 } & \multirow{13}{*}{ 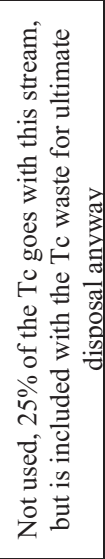 } & \multirow{13}{*}{ 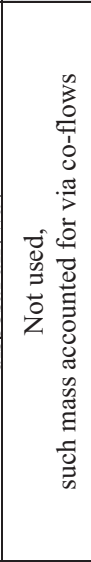 } \\
\hline $\mathrm{U}$ & 1.3 & & 98.6 & & & & & 0.1 & & & \\
\hline $\mathrm{Np}$ & & 99.9 & & & & & & 0.1 & & & \\
\hline $\mathrm{Pu}$ & 99.9 & & & & & & & 0.1 & & & \\
\hline $\mathrm{Am}$ & & 99.9 & & & & & & 0.1 & & & \\
\hline $\begin{array}{l}\mathrm{Cm}- \\
\mathrm{Cf}\end{array}$ & & 99.9 & & & & & & 0.1 & & & \\
\hline $\mathrm{H} 3$ & & & & & 99.9 & & & 0.1 & & & \\
\hline C14 & & & & & & & & 100 & & & \\
\hline $\mathrm{Kr}$ & & & & & 99.9 & & & 0.1 & & & \\
\hline $\begin{array}{l}\mathrm{Sr}, \\
\mathrm{Cs}\end{array}$ & & & & & & & 99.9 & 0.1 & & & \\
\hline $\mathrm{Tc}$ & & & & & & 99.9 & & 0.1 & & & \\
\hline I & & & & 99.9 & & & & 0.1 & & & \\
\hline $\begin{array}{l}\text { FP } \\
\text { otherr }\end{array}$ & & & & & & & & 100 & & & \\
\hline $\begin{array}{l}\text { RU }=1 \\
\text { Sum o } \\
\text { The } 1 . \\
\text { The se }\end{array}$ & $\begin{array}{l}\text { overec } \\
\text { umber } \\
\text { U mi } \\
\text { ation }\end{array}$ & $\begin{array}{l}\text { iium, } \mathrm{F} \\
\text { ach ro } \\
\text { vith } \mathrm{Pu} \\
\text { ency n }\end{array}$ & issic & $\begin{array}{l}\text { oduct } \\
\text { to } 100 \\
0: 50 \mathrm{~L} \\
\mathrm{t} \text { addr }\end{array}$ & $=$ lan & iides, & $\mathrm{s}=\mathrm{un}$ & olved & & & \\
\hline
\end{tabular}

Table 4-15. Illustrative Electrochemical Separation Efficiency of FR Metal Fuel

\begin{tabular}{|c|c|c|c|c|c|c|c|c|c|c|}
\hline & $\begin{array}{c}\mathrm{RU} \\
\mathrm{Pu} \mathrm{Np} \\
\mathrm{Am} \mathrm{Cm} \\
\text { Recycle } \\
\text { Stream }\end{array}$ & $\begin{array}{c}\mathrm{RU} \\
\text { Stream } \\
\end{array}$ & I Stream & $\begin{array}{c}\text { gas } \\
\text { Stream } \\
\end{array}$ & Tc Stream & $\begin{array}{c}\text { Cs Sr } \\
\text { Strea } \\
\mathrm{m}\end{array}$ & $\begin{array}{c}\text { LnFP } \\
\text { Stream } \\
\end{array}$ & $\begin{array}{l}\text { discard } \\
\text { Stream }\end{array}$ & $\begin{array}{c}\text { UDS } \\
\text { Stream } \\
\end{array}$ & $\begin{array}{c}\text { Zr SS } \\
\text { Stream } \\
\text { (Metal } \\
\text { Waste } \\
\text { Stream) } \\
\end{array}$ \\
\hline $\begin{array}{l}\text { Ra to } \\
\mathrm{Pa}\end{array}$ & & & \multirow{13}{*}{ 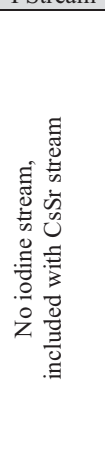 } & & \multirow{13}{*}{ 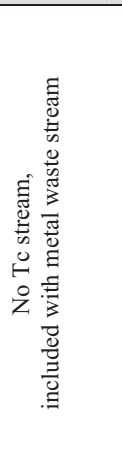 } & & & \multirow{13}{*}{ 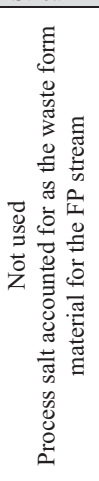 } & \multirow{13}{*}{ 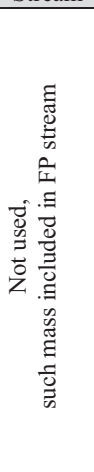 } & 100 \\
\hline $\mathrm{U}$ & 3.4 & 93.3 & & & & & & & & 3.3 \\
\hline $\mathrm{Np}$ & 99.9 & & & & & & & & & 0.1 \\
\hline $\mathrm{Pu}$ & 99.9 & & & & & & & & & 0.1 \\
\hline $\mathrm{Am}$ & 99.9 & & & & & & & & & 0.1 \\
\hline $\begin{array}{l}\mathrm{Cm}- \\
\mathrm{Cf}\end{array}$ & 99.9 & & & & & & & & & 0.1 \\
\hline $\mathrm{H} 3$ & & & & 99.9 & & & & & & 0.1 \\
\hline C14 & & & & & & & & & & 100 \\
\hline $\mathrm{Kr}$ & & & & 99.9 & & & & & & 0.1 \\
\hline $\mathrm{Sr}, \mathrm{Cs}$ & & & & & & 99.9 & & & & 0.1 \\
\hline Tc & & & & & & & & & & 100 \\
\hline I & & & & & & 99.9 & & & & 0.1 \\
\hline $\begin{array}{l}\text { FP } \\
\text { other }\end{array}$ & & & & & & & 50 & & & 50 \\
\hline $\begin{array}{l}\mathrm{RU}=\mathrm{r} \\
\text { Sum of } \\
\text { The sep }\end{array}$ & . & $\overline{\mathrm{FP}}$ & & & & & $\mathrm{d} \mathrm{so}$ & & & \\
\hline
\end{tabular}




\subsection{Fuel Fabrication (PURPLE) Worksheets}

The set of fuel fabrication worksheets is simpler than reactors or separations, primarily because of the 1:1: correspondence between fuel fabrication and fuel type, i.e., there is one fuel fabrication type dedicated to each fuel type. There are other simplifying factors. There is no fuel fab facility rampup specification. The routing coming into fuel fabrication is a "push" time from separations, whereas the routing from reactors into separations is a "pull" type. And, the transformation in fuel fabrication facilities is effectively to blend recycled TRU (if any) with a uranium stream. Because of the 1:1 correspondence, those composition requirements are set via fuel recipes, not on fuel fab worksheets.

Thus, there is a single type of fuel fabrication worksheet, Fuel Fab 1 through 10, which defines several parameters for that separation type, including capacity and which separation efficiency matrix is to be used, by year. Table 4-16 shows how fuel fabrication capacities and transformation performance are set.

Table 4-16. Fabrication Facility Capacities and Transformation Performance in VISION

\begin{tabular}{|l|l|}
\hline Capacity & Transformation Performance \\
$\begin{array}{l}\text { Famong } \\
\text { 0. Let VISION optimize fuel fab } \\
\text { capacity. }\end{array}$ & $\begin{array}{l}\text { Blending - Fuel is made according to the compositions } \\
\text { according to the selection of fuel recipes available in } \\
\text { vision recipes ver3.xls by fuel number in the Reactor } \\
\text { Fuel Types worksheet. }\end{array}$ \\
$\begin{array}{l}\text { Force VISION to build specific fuel } \\
\text { fab capacity each year, the capacity is }\end{array}$ & $\begin{array}{l}\text { Each fuel fab type has two types of source material, } \\
\text { recycled and uranium. The only available recycled } \\
\text { material is what is in the separation-to-fuel-fab buffer, } \\
\text { which is controlled by Separation Stream Splits. } \\
\text { Uranium is used according to uranium priority set with the } \\
\text { fuel recipes, e.g., whether to use enriched uranium (EU) or } \\
\text { recovered uranium (RU). }\end{array}$ \\
\hline
\end{tabular}

All user settings for running simulations are made within one or more of the four Excel input files, with the following exceptions. These parameters must be changed within Powersim Studio itself. Once you are finished, return to the interface page by going to Project Explorer - VISION Flow Model -

Simulation Controls - Shared Diagrams. After clicking on Shared Diagrams, click on the "Interface" tab at the bottom of the page.

Maximum length of dry storage - The model comes set to have as many as 5 years of dry storage. This can be increased as follows:

- $\quad$ Project explorer - Global Ranges (next to the bottom)

- Reactor Life - double click on "Age Dry Storage" to open it, change "last" from 5 to a higher value, but no greater than the number of years of the simulation.

Maximum length of wet storage - The model comes set to have as many as 10 years of wet storage. This can be increased as follows:

- Project explorer - Global Ranges (next to the bottom)

- Reactor Life - double click on "Age Wet Storage" to open it, change "last" from 10 to a higher value, but no greater than the number of years of the simulation. 
Reactor Life - The model comes set to run up to 60 years for reactor lifetime.

- $\quad$ Project explorer - Global Ranges (next to the bottom)

- Reactor Life - double click on "Reactor Life" to open it, change "last" from 60 to a higher value, but no greater than the number of years of the simulation.

Number of recipes in a given portion of the recipe file. The recipe file has 7 pages of recipes. The parameters in the Powersim model have to be consistent with the recipe file. If you wish to user more recipes on a given page than how the current recipe file and Powersim Model are arranged, you have to do four things.

1. Add the recipe columns on the appropriate page of the recipe file. For once through $(100 \mathrm{~s}, 200 \mathrm{~s})$, that is a single column per recipe. For recycle recipes $(300 \mathrm{~s}, 400 \mathrm{~s}, 500 \mathrm{~s}, 600 \mathrm{~s}, 700 \mathrm{~s})$, that is 6 columns per recipe, a blank and then 5 recycle pages.

2. Add titles for all new columns in the "Fuels" global range. This is an enumerated range, and therefore what you add must be in the exact sequence in which you've added the recipes in the recipe file. For example, imagine you have added 5 new MOX recipes on the 300s worksheet. Then, you would add 30 new names after $315-5$, possibly $316-0,316-1, \ldots 320-5$, corresponding to new recipes 316 to 320 . Note that the enumerated list must have a blank for each blank column in the recipe file, typically designated as recipe 0 .

3. Change the range for the associated named range to include the fuels you just added to the "Fuels" enumerated list. For example, in the above example, you would change the last item in the LWR MOX recipe range from 315-5 to 320-5.

4. Change the instructions on (Rr) Fuel Recipes page in the model so that the model knows the expanded range to read from Excel for fresh fuel recipes, (used) fuel recipes, other fuel parameters. There should not be any "question marks" on this page once you are done.

\begin{tabular}{|l|l|l|lc|l|}
\hline & Name & Number & First & & Last \\
\hline $100 \mathrm{~s}$ & UOX Recipes & 10 & UOX User BU & (Recipe 101) & 110 \\
\hline $200 \mathrm{~s}$ & Other Once Thru Recipes & 10 & NGNP & (Recipe 201) & 210 \\
\hline $300 \mathrm{~s}$ & LWR MOX Recipes & 15 & MOX-RU-Pu-1 & (Recipe 301-1) & $315-5$ \\
\hline $400 \mathrm{~s}$ & LWR IMF Recipes & 15 & IMF-NpPu-1 & (Recipe 401-1) & $415-5$ \\
\hline $500 \mathrm{~s}$ & Other Thermal Recipes & 10 & $501-1$ & & $510-5$ \\
\hline $600 \mathrm{~s}$ & FR Metal Cooled Recipes & 30 & UOX to FR mtl-User-1 (Recipe 601-1) & $630-5$ \\
\hline $700 \mathrm{~s}$ & FR Other Cooled Recipes & 10 & 701-1 & & $710-5$ \\
\hline
\end{tabular}

\subsubsection{Fuel Fabrication (PURPLE) - Fuel Fab 1 through Fuel Fab 10}

Table 4-17 lists the parameters set on the Fuel Fab worksheets, one for each separation type. Most of the parameters are straightforward and generally similar to analogous settings in the Separations worksheets. 
VISION User Guide, Rev 3.4

Table 4-17. Parameters Set on Fuel Fab Worksheets

\begin{tabular}{|c|c|c|c|}
\hline Parameter & $\begin{array}{l}\text { Units or Allowed } \\
\text { Variables }\end{array}$ & Impact & $\begin{array}{l}\text { Recommended } \\
\text { Values }\end{array}$ \\
\hline Fuel Fab construction time & $\begin{array}{l}\geq 0.25 \text { years } \\
(\geq \text { time step })\end{array}$ & $\begin{array}{l}\text { Sets delay for construction of } \\
\text { fabrication facilities, does not } \\
\text { impact fuel flows. }\end{array}$ & 2 years \\
\hline Fuel Fab lifetime & $\begin{array}{l}\geq 0.25 \text { years } \\
(\geq \text { time step })\end{array}$ & $\begin{array}{l}\text { Determines lifetime of fuel fab } \\
\text { facilities, does not impact fuel } \\
\text { flows. }\end{array}$ & 60 years \\
\hline Fuel Fab license time & $\begin{array}{l}\geq 0.25 \text { years } \\
\text { ( } \geq \text { time step) }\end{array}$ & Sets delay for facility licensing & 1 year \\
\hline Enrichment time & $\begin{array}{l}\geq 0.25 \text { years } \\
(\geq \text { time step })\end{array}$ & $\begin{array}{l}\text { Determines the delay for the } \\
\text { enrichment process. Individual } \\
\text { enrichment plant types are not } \\
\text { tracked. }\end{array}$ & 1 year \\
\hline Used fuel wet storage time & $\begin{array}{l}1 \text { to } 10 \text { years } \\
\text { (integer values only) } \\
\text { ( } \geq \text { time step) }\end{array}$ & $\begin{array}{l}\text { Determines the minimum time } \\
\text { used fuel must stay at the reactor } \\
\text { before going anywhere else. If } \\
\text { you wish to increase beyond } 10 \\
\text { years, you have to change } \\
\text { Powersim, see section 3.4. }\end{array}$ & $\begin{array}{l}\text { Before on-site } \\
\text { separation - } 1 \text { year } \\
\text { Before off-site } \\
\text { separation - } 10 \\
\text { year }\end{array}$ \\
\hline Used fuel dry storage time & $\begin{array}{l}1 \text { to } 5 \text { years } \\
\text { (integer values only) } \\
\text { ( } \geq \text { time step) }\end{array}$ & $\begin{array}{l}\text { Has no effect on when fuel can } \\
\text { move to repository or separation } \\
\text { facilities, which are controlled by } \\
\text { their processing rates. Determines } \\
\text { how long fuel must wait in dry } \\
\text { storage before going to an MRS (if } \\
\text { there is one). If you wish to } \\
\text { increase beyond } 5 \text { years, you have } \\
\text { to change Powersim, see section } \\
3.4 \text {. }\end{array}$ & 1 year \\
\hline $\begin{array}{l}\text { Unlimited fuel fabrication } \\
\text { capacity for LWR }\end{array}$ & $\begin{array}{l}>0 \text { kilotonne } / \mathrm{yr} \\
\text { (not zero) }\end{array}$ & $\begin{array}{l}\text { This allows the user to set a } \\
\text { number such that the Fuel Fab } \\
\text { Facilities will be able to produce } \\
\text { as much fuel as is necessary. The } \\
\text { associated "logical" switch must } \\
\text { be set to use unlimited fuel } \\
\text { fabrication. }\end{array}$ & $1000 \mathrm{kt} / \mathrm{year}$ \\
\hline $\begin{array}{l}\text { Base case fuel fabrication } \\
\text { facility size }\end{array}$ & $\begin{array}{l}>0 \text { kilotonnes/year } \\
\text { (not zero) }\end{array}$ & $\begin{array}{l}\text { Determines the unit size of these } \\
\text { facilities. Only integer number of } \\
\text { these facilities can be built. If } \\
\text { allowed by user input settings, } \\
\text { VISION will calculate the number } \\
\text { of required facilities and round up. }\end{array}$ & $\begin{array}{l}\text { Depends on your } \\
\text { scenario }\end{array}$ \\
\hline $\begin{array}{l}\text { Capacity for that fuel } \\
\text { fabrication facility type by } \\
\text { year ( } 200 \text { rows) }\end{array}$ & $\begin{array}{l}0 \text { to } 1000 \text { Kilotonnes/ } \\
\text { calendar year }\end{array}$ & $\begin{array}{l}\text { Determines the capacity each year } \\
\text { if Fuel Fab Order switches in } \\
\text { Integer } \mathbf{1}=1 \text {, otherwise no } \\
\text { impact. }\end{array}$ & \\
\hline $\begin{array}{l}\text { Base case fuel fabrication } \\
\text { capacity factor ( } 200 \text { rows) }\end{array}$ & $\begin{array}{l}0.00 \text { to } 1.00 \\
\text { FPY/calendar year }\end{array}$ & $\begin{array}{l}\text { Determines the fraction of time } \\
\text { during a year that fuel fabrication } \\
\text { facilities generate } 100 \% \text { of their } \\
\text { rated capacity }\end{array}$ & $1.0 \mathrm{FPY} / \mathrm{CY}$ \\
\hline
\end{tabular}




\subsection{Waste Management (BRIGHT BLUE) Worksheets}

The final set of worksheets primarily addresses waste management. This includes Other Facilities. The mass of waste is defined by the flow through separations and the separation efficiency matrices selected on the Separation worksheets and defined on the Separation Stream Splits worksheets. Waste (kilotonnes) times the waste loading provides the mass of waste forms (kilotonnes). The waste form mass times the waste form density provides the waste form volume. The waste loadings (kilotonnewaste/kilotonne-wasteform) and waste form density (kilotonne-wasteform $/ \mathrm{m} 3$-wasteform) are input on the Waste Form and Mass Loading worksheet. Unprocessed used fuel mass is converted to wasteform volume by the parameters on the LSF \& SF Waste worksheet. The Waste Disposition worksheet provides the parameters that determine the type of disposition facility that each waste stream goes to - (1) decay storage, (2) LLW ABC Class waste, (3) LLW GTCC waste, (4) HLW, (5) HLW, and (6) not waste. The Repository Holding Capacity and Repository Flow Capacity worksheets provide the allowable inventory and receipt rate of repositories.

\subsubsection{Waste Management (BRIGHT BLUE) - Other Facilities}

This worksheet accepts input for facilities not defined elsewhere, see Table 4-18.

Table 4-18. Parameters Set on Other Facilities Worksheet

\begin{tabular}{|l|l|l|l|}
\hline \multicolumn{1}{|c|}{ Parameter } & \multicolumn{1}{|c|}{$\begin{array}{c}\text { Units or Allowed } \\
\text { Variables }\end{array}$} & \multicolumn{1}{c|}{$\begin{array}{c}\text { Recommended } \\
\text { Values }\end{array}$} \\
\hline Enrichment duration & To be deleted, parameter on Fuel Fabrication worksheets \\
\hline Wet storage duration & To be deleted, parameter on Fuel Fabrication worksheets \\
\hline Dry storage duration & To be deleted, parameter on Fuel Fabrication worksheets \\
\hline MRS duration & Integer values only & & $\begin{array}{l}\text { Depends on your } \\
\text { scenario }\end{array}$ \\
\hline MRS construction time & $\begin{array}{l}\geq 0.25 \text { years } \\
(\geq \text { time step })\end{array}$ & Has no effect on mass flows & $\begin{array}{l}\text { Depends on your } \\
\text { scenario }\end{array}$ \\
\hline MRS lifetime & $\begin{array}{l}\geq 0.25 \text { years } \\
(\geq \text { time step })\end{array}$ & $\begin{array}{l}\text { Depends on your } \\
\text { scenario }\end{array}$ \\
\hline $\begin{array}{l}\geq 0.25 \text { years } \\
\text { Repository Construction }\end{array}$ & $\begin{array}{l}\text { Depends on your } \\
\text { scenario }\end{array}$ \\
\hline Repository Lifetime & Integer values only & & $\begin{array}{l}\text { Depends on your } \\
\text { scenario }\end{array}$ \\
\hline
\end{tabular}

\subsubsection{Waste Management (BRIGHT BLUE) - Coflows (Inactive for VISION 3.4)}

This page allows the definition of 6 co-flow streams for each of the 15 separation strategies. The first five materials, ZR, SS, process discard, salts and metals 3, require the user to specify the number of kilograms of material per kilogram of fuel. The sixth material, Rags and Bags, requires the user to specify the volume (in cubic meters) per kilogram of fuel. These materials are part of the fuel cycle, but are not active parts of the fuel. They are important however for waste, storage, and economic purposes. The numbers are currently approximations and need further refining.

\subsubsection{Waste Management (BRIGHT BLUE) - Waste Disposition}

The "Waste Disposition" page is split up into three parts, one for each fuel type. This page specifies the waste classification for each stream from separations. The type of separations process (aqueous or electrochemical) is set elsewhere in the base case settings file, but the user needs to have decided what 
separation strategy will be used for each fuel type in order to properly specify the waste classification for each stream from separations. The rows beneath each fuel type list the possible separation streams; different separation strategies and fuels will use different subsets of the streams. There are six categories listed at the bottom of the page which are as follows: 1-Decay Storage, 2-LLW ABC, 3-GTCC, 4-HLW, 5-TRUW, 6-Not Waste. Next to each option listed beneath the "Separation Stream" the user can enter numbers (1-6) corresponding to the numbers listed above. Numbers (1-5) deal with different levels of storage and disposal. Number (6) allows the user to specify what elements go through recycling.

If you do not define where a waste stream goes, it disappears.

\subsubsection{Waste Management (BRIGHT BLUE) - Waste Form and Mass Loading}

This page allows the user to specify mass and volume of the wasteform for each separation stream in a given fuel type. The values for wasteform loading are in the form of a mass fraction defined as mass of contaminant stream/mass of wasteform. The user is encouraged to specify a low, mid, and high waste loading (and accompanying waste density). The values for wasteform density are in the form of tonne of wasteform per cubic meter of wasteform. The color coding allows the user to see where the information was obtained from. To the far right of the users screen is a list showing the same colors and the sources associated with those colors. From the different documents, there may be ranges given with respect to the different amounts of mass contributed and so forth. The low end of the range corresponds to the "low" in the Excel file. The same goes for the "Med" and "High".

\subsubsection{Waste Management (BRIGHT BLUE) - Worksheet for LSF \& SF Waste}

This page allows the user to set the cask mass loading (kilotonnes of casked fuel per kilotonne of fuel) and cask (with fuel) density (kilotonnes of casked fuel per cubic meter) for legacy spent fuel and spent fuel. The numbers currently in the worksheet are preliminary and should be used with caution.

\subsubsection{Waste Management (BRIGHT BLUE) - MRS Flow Capacity}

The user can include a monitored retrievable storage (MRS) facility in the analysis. The parameters that can be specified are

- Whether MRS is present or not.

- Dry storage time before material can be moved to the monitored retrievable storage.

- MRS capacity.

\subsubsection{Waste Management (BRIGHT BLUE) - Repository Holding Capacity}

The user can include a retrievable repository facility in the analysis. The retrievable repository capacity is not limited in total mass, but the rate that material can be sent to the repository is limited. The oldest (longest time out of the reactor) and then most cycled fuel has priority for entering the repository.

The user can include a permanent repository facility. The user can specify a limit on the permanent repository in terms of either legacy used fuel (pre-2000), used fuel, or both. The user specified repository receipt rate for the retrievable repository also applies to the permanent repository.

This page allows the user to specify the total repository holding capacity (permanent and retrievable) as a function of time. This page is used when Base Case Unlimited Repository Holding Capacity Switch (on the Logical 1 worksheet) is set to FALSE. 


\subsubsection{Waste Management (BRIGHT BLUE) - Repository Flow Capacity}

This page allows the user to specify the total repository flow capacity as a function of time. This page is used when Base Case Unlimited Repository Flow Capacity Switch (on the Logical 1 worksheet) is set to FALSE. 


\section{VISION INPUT VIA RECIPES VER3.XLS file}

This file contains the following types of input information:

- Fuel recipes described below

- Fuel interpolation correlations described below

- Worksheets for a future 1-group perturbation approach (not currently used)

Each recipe data column contains the following information:

- Fuel burnup (GWth-day/tonne-iHM)

- Capacity factor (FPY/calendar years)

- Fuel residence time (calendar years)

- The input and output compositions for this primary fuel.

- Uranium priority 1 to 6 - what type of uranium supply (EU, NU, DU, RU) should be used to make up the correct amount of uranium in the fuel once the uranium in the incoming separationto-fuel buffer is accounted for.

- The number of a contingent fuel (if any) that VISION will use in this reactor if the primary fuel cannot be made. The contingent fuel should be a uranium-based fuel.

- The mass fractions for the input fuel composition. These must sum to 1.0

- The mass fractions for the output fuel composition. These must sum to 1.0.

- 1-Group cross sections for (n,fission) - not yet used

- 1-Group cross sections for (n,gamma) - not yet used

- 1-Group cross sections for $(n, 2 n)$ - not yet used

Table 4-10 (replicated here) lists the available fuel recipes, which are found on seven worksheets in this file.

The data in the recipe file, and heatdosetox file, come from the Transmutation Library.[Piet2010] 
Table 4-10. Fuel Types (replicated here)

\begin{tabular}{|c|c|}
\hline Reactor technology & Appropriate reactor fuel numbers in vision recipe ver3.xls \\
\hline LWR & $\begin{array}{l}33 \text { to } 100 \text { - LWR burnup correlation } \\
101 \text { to } 110 \text { - recipes in 100_UOX_Once_Thru worksheet }\end{array}$ \\
\hline LWR MF (multiple fuel) & 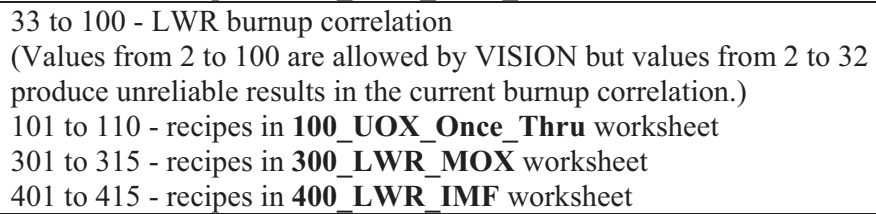 \\
\hline HWR or VHTR & $\begin{array}{l}\text { Appropriate recipes among } \\
201 \text { to } 210 \text { - recipes in } \mathbf{2 0 0} \text { _other_Once_Thru worksheet }\end{array}$ \\
\hline $\begin{array}{l}\text { HWR or VHTR possibly } \\
\text { using recycled material }\end{array}$ & $\begin{array}{l}\text { Appropriate recipes among } \\
201 \text { to } 210 \text { - recipes in 200_Other_Once_Thru worksheet } \\
501 \text { to } 510 \text { - recipes in 500_Other_Thermal_Recycle worksheet } \\
\text { Currently all the } 500 \text { recipe slots are blank. }\end{array}$ \\
\hline $\begin{array}{l}\text { Fast burner reactor, sodium } \\
\text { cooled }\end{array}$ & $\begin{array}{l}-1.00 \text { to } 0.00 \text { - fast reactor metal TRU CR correlation } \\
0.00 \text { to } 1.00 \text { - fast reactor oxide TRU CR correlation } \\
\text { Appropriate recipes among } \\
601 \text { to } 630 \text { - recipes in } \mathbf{6 0 0} \text { _Metal_Cooled_FR worksheet }\end{array}$ \\
\hline $\begin{array}{l}\text { Fast breeder reactor, } \\
\text { sodium cooled }\end{array}$ & 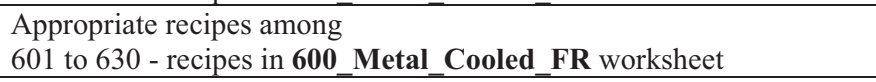 \\
\hline $\begin{array}{l}\text { Fast reactors with other } \\
\text { coolants }\end{array}$ & $\begin{array}{l}701 \text { to } 710 \text { - recipes in 700_Other_Cooled_FR worksheet } \\
\text { Currently all the } 700 \text { recipe slots are blank. }\end{array}$ \\
\hline
\end{tabular}

\section{Cautions:}

19. Do not reorder or change the list of isotopes on each worksheet; all must be the same.

20. Changing any of the pre-defined recipes will invalidate case cases that use them.

\subsection{List of Recipes Worksheet}

This worksheet page simply lists the recipes that have been entered on the seven pages of recipes. Base case settings ver3.xls reads this page.

\subsection{User Help Worksheet}

This worksheet page is not used by any other file or worksheet. It is simply an aid to the user. Recall that the recipe pages require the following data:

- Fuel burnup (GWth-day/tonne-iHM)

- Capacity factor (FPY/calendar years)

- Fuel residence time (calendar years)

And, the base case settings ver3.xls file will have a thermal efficiency (GWe/GWth). The user may not have these parameters and may instead have fueling rate or electricity generation rate or \# of refueling 
batches. This page guides the user to calculate the required values from other combinations of parameters.

\subsection{0 - LWR Once Through Recipes}

This page contains the UOX fuel recipes. Recall that as an alternative to selecting one of these recipes, the user can input a value from 33 to 100, which VISION will interpret as a value for LWR UOX burnup and use the LWR burnup correlation (Interpolation LWR BU worksheet) instead of one of these recipes.

Recipe 101 is a special case as it uses the LWR burnup correlation (recipe 101) in a different way. In these cases, the user must specify the burnup in cell N5. If you want to use the LWR burnup or TRU CR correlations by year, use 33 to 100 (LWR burnup correlation). Recipe 101 can be used, for example, to create a series of user defined recipes for particular purposes. For example, recipes 106 and 107 were created from recipe 101 by inputting the appropriate pre-2000 burnup value for legacy fuel, then copying and pasting into those columns. Thus, recipes 106 and 107 approximate the average composition of fuel 0-10 and 11-40 years old in 2000. Having these recipes allows the user to then define in the Wet and Dry Storage worksheet the appropriate composition.

Similarly, one would want to create a new 100-series recipe if you wanted a contingent fuel to be 45 GWth-day/tonne burnup instead of 51, which is recipe 103.

Recipes for 33 and 51 GWth-day/tonne-iHM UOX come from [Stillman2004]. The LWR burnup correlation comes from [Yacout2008], so that the recipes for wet and dry storage are derived from that correlation.

The "Depleted U Composition" column is used to calculate the depleted U and should not be changed.

\subsection{0 - Other Once Thru Recipes}

This worksheet contains recipes for other thermal reactors using once-through or all-uranium fuel.

\section{$5.5300-$ MOX Recipes}

This worksheet page contains the MOX recipes. VISION is structured to allow up to 5 recycle passes. Therefore, all recycle fuels $(300 \mathrm{~s}, 400 \mathrm{~s}, 500 \mathrm{~s}, 600 \mathrm{~s}, 700 \mathrm{~s})$ are structured to have 5 columns of data. If one has data for only a single recycle pass, those data must be in the column for pass 1 , the other four columns left blank.

It is important to remember that VISION tracks core-averaged compositions. So, a strategy in which a mixture of MOX pins and UOX pins are used requires a single recipe that averages over the sets of pins.

Similarly, a complex blending of multiple fuel sources is invisible to VISION, the core-averaged recipe must be input. This is the strategy used in the multi-recycle recipes on this worksheet.[Youinou2009]

\subsection{0 - IMF Recipes}

This worksheet page contains the IMF recipes. VISION is structured to allow up to 5 recycle passes. Therefore, all recycle fuels $(300 \mathrm{~s}, 400 \mathrm{~s}, 500 \mathrm{~s}, 600 \mathrm{~s}, 700 \mathrm{~s})$ are structured to have 5 columns of data. If one has data for only a single recycle pass, those data must be in the column for pass 1 , the other four columns left blank. 
It is important to remember that VISION tracks core-averaged compositions. So, a strategy in which a mixture of IMF pins and UOX pins are used requires a single recipe that averages over the sets of pins. This is what is used in the multi-recycle recipes on this worksheet.[Pope2009]

\subsection{0 - Other Thermal Recycle Recipes}

This worksheet page is reserved for recycle fuels other than MOX or IMF. There is one draft recipe for the DUPIC fuel composition (direct use of uranium and plutonium in CANDUs).

\subsection{0 - Metal-Cooled Fast Reactor Recipes}

This page contains the fast reactor fuel recipes. Recall that as an alternative to selecting one of there recipes, the user can input a value from 0.00 to 1.00 , which VISION will interpret as a value of fast reactor TRU conversion ratio. If positive, oxide-fueled metal-cooled. If negative, , metal-cooled. The FR TRU CR correlations are on Interpolation FR-metal CR and Interpolation FR-oxide CR worksheets. The burner fast reactor data come from [Hoffman2006, Hoffman2007]. The correlation approach is described in [Yacout2008].

VISION is structured to allow up to 5 recycle passes. Therefore, all recycle fuels $(300 \mathrm{~s}, 400 \mathrm{~s}, 500 \mathrm{~s}, 600 \mathrm{~s}$, 700 s) are structured to have 5 columns of data. If one has data for only a single recycle pass, those data must be in the column for pass 1, the other four columns left blank. Currently in the AFCI program, we have only recipes for the first (startup) and equilibrium recycle pass, in which case the startup composition is entered into recycle pass 1 and the equilibrium composition is entered into recycle pass 5 .

Recipes 601 and 602 are special cases as they use the FR TRU CR correlations. In these cases, the user must specify the burnup in cell E2 (metal) or K2 (oxide).

\subsection{0 - Other-Cooled Fast Reactor Recipes}

This worksheet page is reserved for fast reactor recipes other than metal-cooled. It is currently blank but you can input recipes if you wish.

\subsection{Other Worksheets}

The other worksheets in this file should not be changed by the user.

\subsubsection{Interpolation Burnup Worksheet}

This worksheet shows how a burnup of 51 can then be changed to anything else specified by the user and have the correct recipes produced for the different burnups.[Yacout2008]

Caution: Nothing on this page should be changed by the user.

\subsubsection{Interpolation FR-metal CR Worksheet}

This worksheet contains correlations for modifying recipes as a function of TRU conversion ratio. The methodology is described in [Yacout2008] but those correlations have been updated by extracting more details from [Hoffman2007] for isotopes that are tracked by VISION 3.4 that were not tracked by VISION 2.2.

Caution: Nothing on this page should be changed by the user. 
VISION User Guide, Rev 3.4

June 2011

\subsubsection{Interpolation FR-oxide CR Worksheet}

This worksheet contains correlations for modifying recipes as a function of TRU conversion ratio. The methodology is described in [Yacout2008] but those correlations have been updated by extracting more details from [Hoffman2007] for isotopes that are tracked by VISION 3.4 that were not tracked by VISION 2.2.

Caution: Nothing on this page should be changed by the user.

\subsubsection{Worksheets Named Yellow, Blue, Green, Nu, VISION k-infinity}

These worksheets are for a new submodel in VISION, which is not yet operational. 


\section{VISION OUTPUTS}

VISION provides outputs embedded graphs and data tables within the Powersim model itself and by dumping data to Excel2007 files. The former is very helpful when changing or debugging the model, but it is not suitable for saving results of simulations as neither graphs nor data tables in Powersim are easy to transfer to other files. Therefore, there are embedded graphs and data tables that no longer serve useful functions and we have not updated them. If you wish to change or edit them, be sure "design mode" is on in Powersim.

So, use the embedded graphs only to watch if a simulation appears correct and when it is finished. Otherwise, use the output transferred to Excel. There are two types of output Excel2007 files, those that contain data dumps directly from the VISION Powersim model and those intended to organize and graph those data for user analysis.

The Powersim portion of VISION will store data for up to five runs in the Excel file output data-1.xlsm, which is typically at least $20 \mathrm{MB}$. The user can directly access and analyze those data. However, output data-1.xlsm will have a varying number of columns of data as the number of reactor types, fuel types, and separation types varies. And, if you leave your data in output data-1.xlsm, the next time you run VISION, Powersim will overwrite whatever is in output data-1.xlsm.

Instead, we recommend a two-step process that will provide the user with various graphs and a macro to help you produce other graphs of the data. The first step uses output data-2.xls, which copies data from output data-1.xlsm and puts it into a standard format of 10 reactors types, 10 separation types, and 10 fuel types - many of which will be blank. This allows other graphing files to reliably link to output data2; several such files are described in following subsections.

output_checks.xlsm - assists the user in checking the validity of the simulations just run

output_fuel_masses_by_class.xlsm - graphs fuel masses by class, e.g., mass of TRU

output_fuel_masses.xlsm - graphs fuel masses (summed over all classes)

output_reactors.xlsm - graphs reactor information

output_separations.xlsm - graphs separation information

output_uranium xlsm - graphs information on uranium resources and use

output_used_fuel_masses.xlsm - graphs information used fuel

output waste.xls - not included with VISION 3.4

The existing output files are large, but still only include a fraction of the data calculated within the Powersim portion of VISION. The user may, of course, create new variables and/or output more data than what is described below. If so, we recommend the following:

- Do not alter the existing outputs.

- Study Powersim software for how to create datasets and dataset connections. After a creating a dataset and selecting the variables you wish to dump exist, you drag the variable icon to the dataset icon and then (without letting up on the mouse) to the dataset connection at the top of the screen. You can either set the connection to place the data within output data-1.xlsm or a new Excel file you wish to you.

- If you inadvertently create an inconsistency in where you tell Powersim to dump data, the data will not dump. A good way to create an inconsistency is forgetting to tell Powersim to dump data 
only every year, instead of every time step, if you dumping data to files with numbers of rows arranged for the number of years of a simulation.

- Inventories ("stocks") are straightforward variables to dump.

- Flows are generally not straightforward variables to dump because some things in VISION are done every year and some every time step. If you dump a flow variable and set it to dump every year, you are actually getting the first time step of the year. This could be misleading. So, all flow variables we dump in VISION 3.4 are now "sliding averages". To see an example, go to US Reactor Park and use control-G to find any variable starting with SA, which denotes "sliding average", which is a function built into Powersim.

\section{Cautions:}

21. The output data-2.xIsm expects output data-1.xIsm to be in the same folder. If it is not, the macro in output data-2.xIsm that copies data from output data-1.xIsm will not function.

22. Data are not transferred automatically from output data-1.xIsm to output data-2.xIsm, you must either run the macro in output data-2.x/s or copy data manually.

23. The other output files expect output data-2.xIsm and base case settings ver3.x/s to be in the same folder. If not, you will have to update the "link" from those file to the output file in question. And, the Graph Builder macro in the other output files will not function.

24. The macros in the output files will work faster if the files are not "minimized" in Windows.

25. Data are generally automatically transferred from output data-2.xIsm to other output files. Due to quirks in Excel, sometimes you have to manually update links. Go to "Edit" then "Links" and manually update the links.

26. After running up to five cases, the user should make a copy of base case settings ver3.xIs, output data-2.xIsm, and other output file of interest.

27. Until you have saved the files and broken links, all input Excel files must remain in Office2003 format (extension xls); they cannot be Office2007 format (extension $\mathrm{x} / \mathrm{s} \mathrm{x}$ ).

\subsection{Output data-1.xIsm}

The vision model dumps directly to this file for up to five runs which corresponds to the tabs. The tabs will be numbered according to which runs they correspond with. This information will be used in the savable output files.

This file is not intended for direct user use, nonetheless, the user may find need to go to the raw data and hence this guide will provide an overview of the file and how it is organized.

The worksheets all have names of the form XXXX-n, where $n$ is the number of the run from 1 to 5 . All "1" worksheets appear before all "2" worksheets, etc. The order of the set of " $n$ " worksheets is kept the same. The top two or three rows of each worksheet may have labels indicating the variable name in VISION and the unit. All other rows proceed from 1/1/2000 to 1/1/2100, showing yearly data. 
Note that some cells may not contain data, only \#Num!, which means that the Powersim model is not currently dumping appropriate data to those cells. This typically arises from one of the following:

- The simulation was abnormally terminated, e.g., you stopped execution.

- A dataset connection in Powersim has lost its connection to output data-1.xlsm. This can occur if the variable to be dumped no longer exists or was somehow stopped from executing.

- Your computer was too busy when Powersim reached the end of the simulation and tried to dump data to output data-1.xlsm.

Each worksheet in output data-1.xlsm corresponds to a particular page in the Powersim model to make it easier to trace backward. The worksheets in output data-1.xlsm (and output data-2.xlsm) are as follows:

- Future Demand Prediction (YELLOW) - contains information on total and nuclear electricity predictions.

- Enrichment Capacity (YELLOW) - contains the cumulative SWUs (by fuel type) and total SWUs.

- U ore inventory (YELLOW) - contains (by fuel type) the consumed U ore and consumed U.

- Fuel fabrication Facilities (PURPLE) - contains the number of fuel fabrication facilities at the stages of design and license, construction, ready to operate, working (operating), new retirement, or retirement. Each stage has as many columns as there are fuel fabrication facility types.

- US Reactor Park (PINK) - contains the number (not capacity and not electricity generated) of reactors that are legacy reactors, legacy reactors near retirement, legacy reactor near shutdown, retired legacy reactors, reactors during licensing license, reactors during construction, reactors during construction needing fuel, ready reactors, fresh reactors, reactors near retirement, reactors near shutdown, retired reactors, and operating reactors. Each of those parameters is divided by reactor type. It also contains the total number of operating reactors, summed over all reactor types, the capacity (by reactor type), and the total capacity.

Note: these worksheets have 2 sets of rows of data, do not overlook the data in rows 221-424.

- Fuel Cycle (WHITE) - contains several mass flow parameters, notably the mined ore, accumulated depleted uranium, and how much fuel is in enrichment, fuel fabrication, ready fuel, reactors, wet storage, dry storage, MRS.

Note: these worksheets have 3 sets of rows of data, do not overlook the data in rows beneath row 200 .

- Mass Calcs (GREY) - contains the mass of fuel by chemical element by stage of the fuel cycle (fuel fabrication, ready fuel, fuel in reactors, wet storage, dry storage, MRS, retrievable repository, permanent repository). Each has as many columns as there are fuel types.

Note: these worksheets have 13 sets of rows of data, do not overlook the data in rows beneath row 200

- Separations Facilities (BLUE) - contains the number of separation facilities at the stages of design and license, construction, ready to operate, working (operating), new retirement, or retirement. Each stage has as many columns as there are separation facility types. 
- Fuel Makeup from Separations (BLUE) - contains information on the mass of material in the buffers between separations and fuel fabrication.

- Separation Capacity (BLUE) - contains information on how much fuel is flowing into separation, separation capacity and percent of separation capacity in use.

- Waste Mass (BLUE) - mass of waste, mass of wasteforms, and volumes of waste forms.

Note: these worksheets have 9 sets of rows of data.

- LTDose (DARK GREY) - The long-term dose (LTD) from a repository with the same characteristics as Yucca Mtn, crudely estimated by linearly scaling from early 2000s Yucca Mtn isotope-specific results. Time periods are 1e 4, 2e 4, 5e 4, 1e 5, 2e 5, 5e 5, 8e 5, 1 e6 years.

- AN-N-G Dose (GREY BLUE) - The dose, linearly scaled by isotope, from a PWR fuel assembly. Eventually, there will be three types of output, as follows, but at present only the first is implemented because we lack too much of the input data for the other two. And, we currently have only partial data for it, therefore this output must be considered experimental and partial.

○ Gamma dose, Sv/hr

- Spontaneous neutron dose, $\mathrm{Sv} / \mathrm{hr}$

- Alpha-n neutron dose, $\mathrm{Sv} / \mathrm{hr}$

There are four geometries in the vision heatdosetox ver3.xls input file, but only three of these are in use:

0.0 meters from midplane of fuel assembly

0.5 meters

1.0 meters

3.0 meters

Note: these worksheets have 2 sets of rows of data.

This worksheet and the next four have the same sequence of output variables, as follows:

1. Fuel fabrication

2. Ready fuel

3. Fuel in reactor

4. Wet storage

5. Dry storage

6. MRS

7. Separations

8. Separated material buffer box

9. Separated recovered uranium (not provided for AN-N-G dose)

10. LLW class $\mathrm{A} / \mathrm{B} / \mathrm{C}$

11. LLW GTCC

12. Decay storage

13. TRU waste

14. HLW

15. Retrievable repository 
16. Permanent repository

17. Depleted uranium (not provided for Heat rate or LTHeat)

- Gamma Neutron Emission (GREY BLUE) - Whereas dose is geometry and design dependent, the gamma and neutron emission from an inventory of radioactive material is not. Of course the emission $(\mathrm{W} / \mathrm{kg}$ ) does not itself indicate dose, but it is a parameter for relative comparison. NOTE: the neutron emission energy is currently estimated by the number of neutrons/second times an assumed $1 \mathrm{MeV} /$ neutron average energy.

- Heat rate (GREY BLUE) - The heat given off by the inventory in various parts of the fuel cycle in GW-thermal. At present, only heat-rate-1 is used; the other three "heat rates" are for future expansion, e.g., potentially use a heat rate at some time into the future instead of the then-current heat rate.

- LTHeat (BLUE) - The long-term heat (LTH) commitment from the inventory in various parts of the fuel cycle in joules. This is the heat that will be released, integrated over a particular time period. The three time periods provided are 50 to 1500 years, 100 to 1500 years, and 300 to 1500 years.[Piet2006] The start of each time period reflects the assumption that waste will be externally cooled through that time; the end of the time period reflects the assumption in the Yucca era that the in-between drift temperatures will have reached their peak.

Toxicity (GREY BLUE) - the ingestion radiotoxicity of the inventory in various parts of the fuel cycle. The time periods provided are $1 \mathrm{e} 1,1 \mathrm{e} 2,1 \mathrm{e} 3,1 \mathrm{e} 4,1 \mathrm{e} 5,1 \mathrm{e} 6$, and $1 \mathrm{e} 7$ years into the future. (1e8 is also listed but is not in use.)

Note: these worksheets have 2 sets of rows of data.

- Repository (BLUE) - contains the mass of fuel (by fuel type) in permanent and retrievable repository.

- Isotope (GREY BLUE) - The isotope-specific inventory in four parts of the fuel cycle - wet storage, dry storage, retrievable repository, permanent repository. Of course, isotope data for other parts of the fuel cycle could also be output by changing the output connections in the model.

\subsection{Output Data-2.xIsm}

Output data-2.xlsm has the same data in the same order as output data-1.xlsm, except we have not bothered to copy data from the Isotope worksheet in output data-1.xlsm. The difference between data-1 and data-2 is that data- 1 is directly connected to Powersim and therefore at risk of being overridden the next time you run the VISION model and it has the numbers of reactor types, separation types, and fuel types in the last simulations you ran.

Start on the START HERE worksheet, which will guide you through use of this spreadsheet file. This spreadsheet translates the raw VISION output file (output data-1.xIsm) into a common format with 10 reactor types, 10 separation types, and 10 fuel types, which is more suitable for graphing purposes. It reads and copies from output data-1.xlsm and pastes information into itself. Therefore, output data2.xls does not have an automatic link back to output data-1.xlsm.

First, open the input (base case settings ver3.xls) and output (output data-1.xlsm) files, or whatever you may have renamed them. The macros in output data-2.xls will not work unless those two files are open.

Second, if appropriate, clear the data in output data-2.xls. There are buttons to clear a specific run or clear all runs. Remember, data cleared are data gone! You do not have to clear previous data to bring in 
replacement data from output data-1.xlsm; however, we recommend doing so because your new data may have fewer numbers of reactors, fuels, and separation types. Note that the "clear run" feature allows you to run various simulations and decide to keep only some of the runs, clearing the other ones.

Third, set the input and output file names for the macros to use. The files must be in the same folder as output data-2.xls and must include the extension .xls. The defaults names are base case settings ver3.xls and output data-1.xlsm.

Fourth, load data from the input and output files. There are buttons to load a specific run or all the runs. Note that the "load run" feature allows you to replace just one of the runs you've previously calculated with a new data set. It is not possible to load new run X, however, into anything other than run X.

Fifth, open the graphic output files of interest.

\section{Cautions:}

28. Do not alter the output data-2.xIsm worksheets in any way - names, order, format, etc.

\subsection{Output Files with Graphs}

Other than output data-1.xlsm and output data-2.xlsm, all output files have the same format and same macros.

All require output data-2.xlsm and base case settings ver3.xls to be properly populated. You can have the output files read some a file with a name different that output data-2.xlsm but its format must be the same. If you chose to read from a differently named file you have to correct the connections from output data-2.xls to that output file, which means editing the links from output data-2.xlsm and base case settings ver3.xls by going to "Edit" on the Excel menu, then "Links".

All output files have multiple worksheets.

- START HERE - guides you through that output file.

- By run - a worksheet that sums all of the parameters in question over reactor types, fuel types, separation types, whatever is appropriate

- Parameter Run1 through Run5 - worksheets with more detail, one for each simulation run.

- Other worksheets going into yet more detail if appropriate.

Each output file has several pre-defined graphs. For each type of graph, there is one pre-set for a 100year simulation and one pre-set for a 200 -year simulation.

There are two macros in each output file, accessible via buttons or by "control" shortcuts.

- Graph Viewer (control-shift-E) - allows you to view thumbnails of all graphs in that currently active worksheet, in sets of 9. Click of a thumbnail to go directly to it. Once there you can view it or alter it as with any Excel graph.

- Graph Builder (control U) - guides you through the process of making a new graph from data in output data-2.xlsm. You can, of course, make graphs manually if you are adequately familiar with Excel graphs and linking data between Excel files. 


\subsubsection{Output_checks.xlsm}

If the file does not open in the START HERE worksheet, please go to it. "START HERE" is the left most worksheet. This file helps the answer the following questions:

- Are the names you gave to each run what you intended?

- Are the runs that actually ran what you intended?

- Is the Reactor Order Case what you intended?

- Is the Separation Order Case what you intended?

- Does the sum of disposition paths for each isotope in each of the Separation Efficiency Matrices $=100 \%$ ?

- Did you tell VISION to create enough legacy reactors to generate the nuclear electricity you wanted at the start of the simulation?

- Did you tell VISION to retire all the legacy reactors you created?

- Is the nuclear electricity that VISION calculated sufficiently close to what you intended?

- Is the number of "ready reactors" acceptable throughout the simulation?

\subsubsection{Output_reactors.xIsm}

If the file does not open in the START HERE worksheet, please go to it. "START HERE" is the left most worksheet. Verify the labels for reactor types. The spreadsheet is designed so that reactor types with a non-blank name will show data.

The worksheets in this file graph electricity generated per year (GWe-FPY/CY), operating capacity (GWe), capacity added each year (GWe/calendar year), capacity retired each year (GWe/calendar year). The first data worksheet has these data for all reactors for each run. The next five worksheets have these data by reactor type for each run.

There is also an ungraphed set of calculations that perform a "balance" check on the reactor capacity of each reactor type for each run. After the first year, the delta in capacity (new year - last year) should equal the capacity addition minus the capacity retired.

\subsubsection{Output_separations.xlsm}

If the file does not open in the START HERE worksheet, please go to it. "START HERE" is the left most worksheet.

This file pulls the data for the following parameters:

Separation capacity (tonnes/CY) requested by the user

Separation capacity (tonnes/CY) actually built

Separation flow (tonnes/CY) into separations from used fuel

Separation flow (tonnes/CY) from separations into buffer boxes 


\subsubsection{Output_fuel_masses.xlsm}

If the file does not open in the START HERE worksheet, please go to it. "START HERE" is the left most worksheet.

This worksheet examines the mass and flow of fuel throughout the system. This worksheet does not differentiate by chemical element or isotope.

There are three sets of worksheets.

- By run (all fuels) - total mass of fuel (all locations) for each run.

○ By fuel (all loc) runs 1 through 5 - mass of fuel (all locations) by fuel type for each run.

○ By loc by fuel runs 1 through 5 - mass of fuel, by location, by fuel type, for each run.

Even the last five worksheets group certain locations together to enable the graphs to be readable. The grouping is as follows:

○ Uranium location $=$ uranium conversion + uranium enrichment

- Fab location $=$ fuel fabrication + ready fuel

Reactor location $=$ fuel in reactors

○ Storage location $=$ wet storage + dry storage + MRS

○ Separations $=$ separations processes + buffer between separations and fuel fabrication

○ $\quad$ Repository $=$ retrievable repository + permanent repository

The more detailed location breakdown can be found directly in output data-1.xlsm or output data-2.xls.

The last five worksheets also provide (ungraphed) the rate of reactor fuel input and reactor fuel output, by fuel type (not by reactor type).

\subsubsection{Output_fuel_masses_by_class.xIsm}

If the file does not open in the START HERE worksheet, please go to it. "START HERE" is the left most worksheet. The worksheet is similar to "Fuel Masses" with two key differences. It provides more detailed information in that the total mass is divided into uranium, individual TRU elements, and sum of fission products.

Similar to Fuel Masses, there are three sets of worksheets.

- By run (all fuels) - total mass of fuel (all locations) for each run.

○ By fuel (all loc) runs 1 through 5 - mass of fuel (all locations) by fuel type for each run.

○ By loc by fuel runs 1 through 5 - mass of fuel, by location, by fuel type, for each run.

Even the last five worksheets group certain locations together to enable the graphs to be readable. The grouping is as follows:

○ Depleted uranium

○ Uranium location $=$ uranium conversion + uranium enrichment 
- Fab location $=$ fuel fabrication + ready fuel

- Reactor location $=$ fuel in reactors

○ Storage location $=$ wet storage + dry storage + MRS

○ Separations $=$ separations processes + buffer between separations and fuel fabrication

○ Repository $=$ retrievable repository + permanent repository

\subsubsection{Output_uranium.xIsm}

If the file does not open in the START HERE worksheet, please go to it. "START HERE" is the left most worksheet. This file contains information on uranium usage.

\subsubsection{Output_used_fuel_masses.xlsm}

If the file does not open in the START HERE worksheet, please go to it. "START HERE" is the left most worksheet. This file contains information on used fuel masses. 


\section{REFERENCES}

Dixon2009 B. W. Dixon, INPRO GAINS Activities, System Analysis Working Group Meeting, July 7, 2009.

DOE EIA2002 Department of Energy, Energy Information Administration, U.S. DOE EIA data, Form RW-859, "Nuclear Fuel Data," 2002.

DOE EIA2006a Department of Energy, Energy Information Administration, Annual Energy Review 2006, Report No. DOE/EIA-0384(2006), June, 2007, Table 8.1 Electricity Overview, 1949-2006.

DOE EIA 2006b Department of Energy, Energy Information Administration, Annual Energy Review 2006, Report No. DOE/EIA-0384(2006), June, 2007, Table 8.2a Electricity Net Generation: Total (All Sectors), 1949-2006.

Hoffman2006

E. A. Hoffman, W. S. Yang, R. N. Hill, Preliminary Core Design Studies for the Advanced Burner Reactor over a Wide Range of Conversion Ratios, ANL-AFCI177, September 29, 2006.

Hoffman2007

E. A. Hoffman, Updated Design Studies for the Advanced Burner Reactor over a Wide Range of Conversion Ratios, ANL-AFCI-189, May 31, 2007.

Piet2006

S. J. Piet et al, Fuel Cycle Scenario Definition, Evaluation, and Trade-offs, INL/EXT-06-11683, August 2006.

Piet2009 S. J. Piet, Selection of Isotopes and Elements for Fuel cycle Analysis, Advances in Nuclear Fuel Management IV, South Carolina, April 2009.

Piet 2010

Steven J. Piet, Samuel E. Bays, Edward A. Hoffman, "Description of Transmutation Library for Fuel Cycle System Analyses,” FCRD-SYSA-2010-000116, INL/EXT-1019545, August 4, 2010 - and updates thereof.

Pope2009 M. Pope, S. Bays, S. Piet, R. Ferrer, M. Asgari, B. Forget, “Transmutation Performance Analysis for Inert Matrix Fuels in Light Water Reactors and Computational Neutronics Methods Capabilities at INL," INL/EXT-07-12472, Rev. 1, May 1, 2009.

Smith2007 J. Smith et al, Benchmark and Verification Plan for the VISION Model, GNEPSYSA-AI-SS-PL-2008-000009, Rev 0, November 15, 2007.

Smith2008 J. Smith et al, VISION Dynamic Simulation Model Benchmark Comparison Report, February 14, 2008.

Stillman2004 J. A. Stillman, "Homogeneous Recycling Strategies in LWRs for Plutonium, Neptunium, and Americium Management," Argonne National Laboratory, ANLAFCI-124, August 2004.

Yacout2008 A. M. Yacout, T. A. Taiwo, Isotopic Vector Estimation Methods for System Dynamics Fuel Cycle Models, ANL-AFCI-240, August 30, 2008

Youinou2009 G. Youinou; S. Bays, Homogeneous recycling of Pu or Pu+M.A. in PWRs loaded with MOX-UE fuel (MOX with U-235 enriched U support), INL/EXT-09-16091, AFCI-SYSA-TRAN-SS-RT-2009-000055, June 2009. 
VISION User Guide, Rev 3.4

June 2011 
VISION User Guide, Rev 3.4

June 2011

\section{Appendix A}

\section{Pre-Defined Base Cases}


This appendix describes the pre-defined base cases, which have three purposes. First, we originally developed most of these cases for the Scenario Definition, Evaluation, and Trade-offs (SETS) study.[Piet2006] They therefore provide some of the benchmarking used upon subsequent model upgrades. Section A-3.7 describes newer benchmark cases. Second, user study of the base cases can help understand how to use VISION to model various types of situations. Third, running the pre-defined base cases can help the user understand fuel cycle system dynamics in general and VISION in particular.

\section{A-1. Phases}

In previous versions of VISION and its predecessor model, DYMOND, there were three phrases associated with reactor technology development and deployment. All of the SETS base cases have that structure. Separation and waste management technology is held constant but reactor technology can change twice: phase 0 is the initial condition and lasts until the beginning of phase 1 , and phases 1 and 2 are the second and third time periods.

Phase 0 is the initial time period; this phase starts in 2000 and always uses light water reactors without recycle, reflecting the current U.S. reactor fleet. The end of this phase is set by the start time for Phase 1. Under default conditions, the initial U.S. fleet in 2000 is assumed to have 103 light water reactors, of these, 86 reactors are assumed to be capable of only utilizing UOX fuel and are designated as LWRs in the model, while the remaining 17 reactors are assumed to be capable of utilizing UOX or MF fuel and are designated as LWR-MF.

Phase 1 is the second time period; this phase starts between 2000 and 2100 as defined in the different base cases. The value in the SETS base cases was either 2020 or 2025 . Phase 1 continues until the start of Phase 2 (the start of Phase 2 is defined by the user in manual mode by the slider bar). Phase 1 is and should be earlier than Phase 2.

Phase 2 is the last time period; this phase starts between 2000 and 2100, it was 2040 in the SETS base cases. The end of Phase 1 is specified by the start time for Phase 2. Phase 1 always precedes Phase 2 .

\section{A-2. Fuel and Reactor Types}

This subsection describes the different reactor and fuel types in the SETS base cases.

Many of the fuels which are listed below have specific transuranics listed such as $\mathrm{Pu}, \mathrm{Np}, \mathrm{Am}$, or $\mathrm{Cm}$. When these are included with the fuel type, only the transuranics specified are used within that fuel recipe. Each fuel recipe is very specific. This allows the user to track the use of the different transuranic elements.

\section{A-2.1 Once Thru - No Recycle}

This is uranium oxide (UOX) fuel that can be utilized in an LWR or LWR-MF reactors; there is no recycle material included. Selecting this option continues the fuel type from Phase 0 . This fuel requires thermal reactors for utilization; later in the set-up the relative proportion of LWR to LWR-MF reactors used can be varied. UOX is the only fuel that can be used by the LWRs.

\section{A-2.2 MOX-NpPu}

Note: originally we referred to this option as MOX-PuNp but later changed terminology so that the list of transuranic elements is always in Periodic Table order. This fuel is mixed oxide (MOX) fuel made with $\mathrm{Np}, \mathrm{Pu}$, and recovered $\mathrm{U}$ (uranium that has been through a reactor as fuel) that can be utilized by LWRMF reactors; recycling of fuel must be present for MOX to be produced. The MOX-NpPu recipe is a full 
core MOX or homogenous fuel assembly; it is intended to fill the entire core. The program is set-up to make as much MOX fuel as is requested and available; fuel requested but not available is made up by UOX fuel. This fuel requires LWR MF thermal reactors for utilization; later in the set-up the relative proportion of LWR to LWR MF reactors used can be varied. This base case uses the older MOX-NpPu recipe, which was for a single recycle. The vision recipe ver3.xls file now also contains multi-recycle options for MOX-Pu, MOX-NpPu, MOX-NpPuAm, and MOX-TRU option.[Youinou2009]

\section{A-2.3 MOX-NpPuAm}

Note: originally we referred to this option as MOX-PuNpAm but later changed terminology so that the list of transuranic elements is always in Periodic Table order. This is mixed oxide (MOX) fuel made with $\mathrm{Pu}, \mathrm{Np}, \mathrm{Am}$, and burned $\mathrm{U}$ (uranium that has been through a reactor as fuel) that can be utilized by LWR MF reactors; recycling of fuel (set later) must be present for MOX to be produced. The MOX PuNpAm recipe is a full core MOX; it is intended to fill the entire core. The program is set-up to make as much MOX fuel as is requested and available (this program carries an isotopic mass balance and uses the sum of elemental $\mathrm{Pu}$ as the determiner for the availability of MOX); fuel requested but not available is made up by UOX fuel. This fuel requires LWR-MF thermal reactors for utilization; later in the set-up the relative proportion of LWR to LWR-MF reactors used can be varied. MOX-NpPuAm fuel is user specified to have $1-5$ passes (recycles). The original base case used older multi-recycle data for MOXNpPuAm, which has been upgraded to higher quality data.[Youinou2009]

\section{A-2.4 IMF NpPu}

This is inert matrix fuel (IMF) made with $\mathrm{Np}$ and Pu and can be utilized by LWR MF reactors; recycling of fuel must be present for IMF to be produced. The IMF-NpPu recipe is a full core IMF; it is intended to fill the entire core. The program is set-up to make as much IMF fuel as is requested and available (this program carries an isotopic mass balance and uses the sum of elemental $\mathrm{Pu}$ as the determiner for the availability of IMF); fuel requested but not available is made up by UOX fuel. This fuel requires LWR MF thermal reactors for utilization; later in the set-up the relative proportion of LWR to LWR MF reactors used can be varied. This base case uses the older IMF-NpPu recipe, which was for a single recycle. The vision recipe ver3.xls file now also contains a multi-recycle IMF-NpPu option.[Pope2009]

\section{A-2.5 IMF-NpPuAm}

This is inert matrix fuel (IMF) made with $\mathrm{Np}, \mathrm{Pu}, \mathrm{Am}$, and depleted uranium (DU) and can be utilized by LWR MF reactors. Recycling of fuel must be present for IMF to be produced. The IMF-NpPuAm recipe is a blended core IMF, this means that in a single fuel assembly some of the pins will contain IMF and some will contain UOX made with DU. The program is set-up to make as much IMF fuel as is requested and available (this program carries an isotopic mass balance and uses the sum of elemental $\mathrm{Pu}$ as the determiner for the availability of IMF); fuel requested but not available is made up by UOX fuel. This fuel requires LWR MF thermal reactors for utilization; later in the set-up the relative proportion of LWR to LWR MF reactors used can be varied. IMF PuNpAm is user specified to have $1-5$ passes (recycles). The original base case used older multi-recycle data for IMF-NpPuAm, which has been upgraded to higher quality data.[Pope2009]

\section{A-2.6 IMF-PuNpAmCm}

This is inert matrix fuel (IMF) made with $\mathrm{Np}, \mathrm{Pu}, \mathrm{Am}$, and $\mathrm{Cm}$ can be utilized by LWR MF reactors. Recycling of fuel must be present for IMF to be produced. The IMF-NpPuAmCm recipe is a full core IMF; it is intended to fill the entire core. The program is set-up to make as much IMF fuel as is requested and available (this program carries an isotopic mass balance and uses the sum of elemental $\mathrm{Pu}$ as the 
determiner for the availability of IMF); fuel requested but not available is made up by UOX fuel. This fuel requires LWR MF thermal reactors for utilization; later in the set-up the relative proportion of LWR to LWR MF reactors used can be varied. This base case uses the older IMF-NpPuAmCm recipe, which was for a single recycle and stopped at $\mathrm{Cm} 246$. The vision recipe ver3.xls file now also contains a multirecycle IMF-TRU option, which covers the entire range of TRU elements $\mathrm{Np}, \mathrm{Pu}, \mathrm{Am}, \mathrm{Cm}, \mathrm{Bk}$ Cf.[Pope2009]

\section{A-2.7 FR-Burner}

This selects burner fast reactors, designated as FBR (the " $\mathrm{B}$ " stands for either breeder or burner) in the model. Recycling of fuel must be present for fast reactors to operate. Burner fast reactors are net consumers of transuranics. Later in the set-up the relative proportion of LWR, LWR MF, and FBR reactors used can be varied. New fast reactors are not brought online unless there is sufficient fast reactor fuel available (based on $\mathrm{Pu}$ ). Thermal reactors, LWR MF, are brought online to replace the capacity of fast reactors that cannot be brought online due to insufficient fuel. The LWRmf reactors use MOX or IMF fuel if that is part of the scenario; otherwise they use UOX if no thermal recycling is included in the scenario. The fast reactor is user specified to have 1- 5 passes (recycles). The original base case used older multi-recycle data for $\mathrm{CR}=0.25$ metal fuel fast reactors, whereas these data have been retained for this base case, higher quality data for a range of CR is now available.[Hoffman2006, Hoffman2007]

\section{A-2.8 FR-Breeder}

This selects breeder fast reactors, designated as FBR (the "B" stands for either breeder or burner) in the model. Recycling of fuel must be present for fast reactors to operate. Breeder fast reactors are net producers of transuranics. Later in the set-up the relative proportion of LWR, LWR MF, and FBR reactors used can be varied. New fast reactors are not brought online unless there is sufficient fast reactor fuel available (based on $\mathrm{Pu}$ ). Thermal reactors, LWR MF, are brought online to replace the capacity of fast reactors that cannot be brought online due to insufficient fuel. The LWR MF reactors use MOX or IMF fuel if that is part of the scenario; otherwise they use UOX if no thermal recycling is included in the scenario. The fast reactor is user specified to have 1- 5 passes (recycles). The original base case used older multi-recycle data for $\mathrm{CR}=1.07$ metal fuel fast reactors, whereas these data have been retained for this base case, higher quality data for a range of CR is now available.[Hoffman, in publication]

\section{A-3. Phase 1 - Phase 2 Box}

Within the "phase 1 phase 2" box, is listed the entire selection of base cases from which the user may choose. At the end of the list are "User Defined" base cases which can be set by the user. In order to run one of the base cases, click the base case you want to run and hit the play button on the tool bar. All of the base cases listed before the "1-tier" cases start phase 1 in 2025 and phase 2 in 2040.

These descriptions are grouped according to what fuel/reactor is chosen for phase 1 among the base cases. This extensive set of base cases were developed to survey the fuel cycle options in 2005-2007 studies as well as test the behavior of the model under diverse conditions. There are six groupings from the SETS report [Piet2006] discussed in sections 3.1 through 3.6, as follows:

Phase $1=$ once-through, i.e., recycling is delayed to phase 2.

Phase 1 = IMF-NpPuAm, i.e., multiple passes of blended, heterogeneous core IMF is used in Phase 1

Phase $1=$ MOX-NpPu, i.e., a single pass of MOX-NpPu is used in Phase 1

Phase $1=$ MOX-NpPuAm, i.e., multiple passes of blended MOX is used in Phase 1

Phase $1=$ FR burner with TRU conversion ratio of 0.25 
Phase $1=$ FR breeder with TRU conversion ratio of 1.07

The six groups include an explanation of why such a base case exists as well as the reasons for the differing phase 2 options given the same phase 1 option. Not all of the fuel types with all the different transuranic combinations are listed below.

\section{A-3.1 Once-Through}

The purpose of using UOX fuel in phase 1 is to see the affects of delaying recycling until 2040. In 2040 phase 2 begins and there are six options listed. The six options listed for phase 2 allow for further exploration within the nuclear fuel cycle.

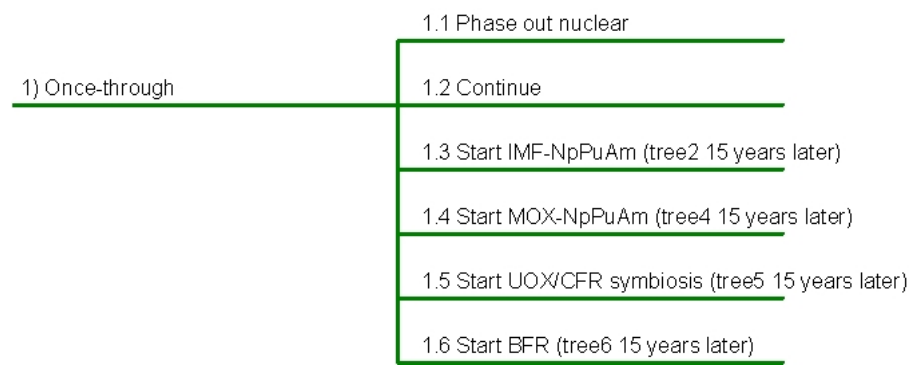

\section{A-3.2 IMF-NpPuAm}

The purpose of using IMF-NpPuAm (which uses blended IMF/UOX cores) in phase 1 is to attempt the fastest possible reduction in LTH, LTD, and LTR using thermal reactors and UREX+ separation technology. Assumes n-pass IMF fuels and their separation are practical. This IMF approach uses blended fuel assemblies, with $3 / 4$ UOX and $1 / 4$ IMF, with the TRU in used fuel UOX and IMF in one generation making the IMF in the next generation. Other n-pass IMF approaches require analysis, including increasing the IMF/UOX ratio to further accelerate benefits or require fewer reactors to use the blend. 3 $\mathrm{kt} / \mathrm{yr}$ separation plant starts in 2025. All fuel that can be made from that separation plant is assumed to be used in the growing TR fleet. The six options listed for phase 2 allow for further exploration within the nuclear fuel cycle.

\begin{tabular}{l|l} 
& \multicolumn{2}{c}{2.1 Phase out nuclear } \\
\cline { 2 - 2 } 2) IMF-NpPuAm & 2.2 Phase out recycling \\
\cline { 2 - 2 } $\begin{array}{l}\text { Hot cell fuel fab } \\
\text { Recycle youngest fuel first }\end{array}$ & 2.3 Continue \\
\cline { 2 - 2 } & 2.4 Shift to MOX-NpPuAm \\
\cline { 2 - 2 } & 2.5 Shift to IMF-NpPu/CFR symbiosis \\
\hline & 2.6 Shift to BFR, phase out TR \\
\hline
\end{tabular}

\section{A-3.3 MOX-NpPu}

The purpose of using MOX-NpPu in phase 1 is the fact that this option most accurately resembles the current international practice and current technology, while avoiding separation of $\mathrm{Pu}$. It is restricted to 1- 
recycling pass in current analyses. The six options listed for phase 2 allow for further exploration within the nuclear fuel cycle.

\begin{tabular}{|c|c|}
\hline & 3.1 Phase out nuclear \\
\hline \multirow[b]{2}{*}{ 3) MOX-NpPu (1-pass) } & 3.2 Phase out recycling \\
\hline & 3.3 Continue \\
\hline $\begin{array}{l}\text { Least "gap" per technology maturity levels } \\
\text { Closest to international practice } \\
\text { Glovebox fuel fabrication } \\
\text { Recycle oldest fuel first }\end{array}$ & 3.4 Shift to MOX-NpPuAm (n-pass) \\
\hline \multirow{2}{*}{$\begin{array}{l}\text { FY05 calculations: restrict to 1-pass (not } \\
\text { n-pass) }\end{array}$} & 3.5 Shift to MOX-NpPu/CFR symbiosis \\
\hline & 3.6 Shift to BFR, phase out TR \\
\hline
\end{tabular}

\section{A-3.4 MOX-NpPuAm}

The purpose of using MOX-NpPuAm in phase 1 is to attempt modest repository benefits using thermal reactors, UREX+ technology, and fuels relatively similar to current UOX and MOX-Pu.

Assumes RU is the uranium component in MOX; the $\mathrm{Pu} / \mathrm{U}$ ratio increases each cycle to keep the cores critical. Other n-pass MOX approaches require analysis, including keeping the core critical by increasing the uranium enrichment instead of the $\mathrm{Pu} / \mathrm{U}$ ratio. The six options listed for phase 2 allow for further exploration within the nuclear fuel cycle.

\begin{tabular}{l|l}
\cline { 2 - 2 } & \multicolumn{1}{l}{4.1 Phase out nuclear } \\
\cline { 2 - 2 } 4) MOX-NpPuAm & 4.2 Phase out recycling \\
\cline { 2 - 2 } $\begin{array}{l}\text { Hot cell fuelfab } \\
\text { Recycle youngest fuel first }\end{array}$ & 4.3 Continue \\
\hline & 4.4 Shift to IMF-NpPuAm \\
\cline { 2 - 2 } & 4.5 Shift to MOX-NpPu/CFR symbiosis \\
\cline { 2 - 2 } & 4.6 Shift to BFR, stop building TR \\
\hline
\end{tabular}

\section{A-3.5 FR Burner}

The purpose of using FR burner fuel in phase 1 allows for the exploration of the different pros and cons of FR burner reactors. The early FR experience would set the stage for BFR when uranium resources warrant. Balancing all the components of this type of system is not straightforward. FR deployment is limited by the amount of Pu available for FR fuel, existing FR's have $1^{\text {st }}$ priority on fuel over new FR's, if insufficient fuel is available for FR's to start, the missing capacity is met by starting thermal reactors. The six options listed for phase 2 allow for further exploration within the nuclear fuel cycle.

In DYMOND and versions of VISION prior to 2.2, it was possible to start fast reactors and then phase out fast reactors with fuel in the fast reactor loop (separation, fuel fab, reactor) moving back to LWRs.

Version 2.2 did not have this capability so that options 5.2, 5.3, and 5.4 could not be simulated. Version 3.4 now allows these options and we are rebuilding those base cases. 


\begin{tabular}{l|l}
\cline { 2 - 2 } & \multicolumn{1}{c}{5.1 Phase out nuclear } \\
\cline { 2 - 2 } 5.2 Phase out FR, keep once-thru TR \\
\cline { 2 - 2 } 5) UOXCFR symbiosis & 5.3 Phase out FR, start MOX-NpPuAm \\
\cline { 2 - 2 } & 5.3 Phase out FR, start IMF-NPPUAm \\
\cline { 2 - 2 } i.e., deploy first FR in 2025 & 5.5 Continue \\
\hline
\end{tabular}

\section{A-3.6 FR Breeder}

Start breeder FR in 2025 and moves into FR, skipping recycling in TR. It aims to accommodate a hypothetical combination of limited uranium resources and high nuclear growth. It is unique among the options in that BFR uses depleted uranium.

In DYMOND and versions of VISION prior to 2.2, it was possible to start fast reactors and then phase out fast reactors with fuel in the fast reactor loop (separation, fuel fab, reactor) moving back to LWRs.

Version 2.2 did not have this capability so that options $6.2,6.3,6.4$ could not be simulated. Version 3.4 now allows these options and we are rebuilding those base cases.

\begin{tabular}{|c|c|}
\hline & 6.1 Phase out nuclear \\
\hline & 6.2 Phase out BFR, keep once-thru TR \\
\hline & 6.3 Phase out BFR, start MOX-NpPuAm \\
\hline & 6.4 Phase out BFR, start IMF-NpPuAm \\
\hline 6) Build a few BFR & 6.5 Continue \\
\hline & 6.6 Accelerate BFR, phase out TR \\
\hline
\end{tabular}

\section{A-3.7 Recent Pre-Defined Base Cases}

The VISION benchmark and verification plan [Smith2007] identified 5 cases to use when testing new major releases of the model, see Table A-1. Three of those cases are among the SETS pre-defined base cases noted above. The last two use $\mathrm{CR}=0.50$ fast reactors with and without a single recycle of $\mathrm{MOX}$ between UOX and fast reactors. We have defined five additional cases to exercise new capabilities in VISION 3.4, also in Table A-1. 
Table A-1. Benchmark Cases

\begin{tabular}{|c|c|c|c|}
\hline Case (Reactor Specifications) & Source of Data & Why Include & Comments \\
\hline $1=\mathrm{UOX}$ at 50 burnup & \multirow{3}{*}{$\begin{array}{l}\text { SETS report } \\
\text { [Piet2006 } \\
\text { VISION benchmark } \\
\text { [Smith2008] }\end{array}$} & \multirow{5}{*}{$\begin{array}{l}\text { VISION B\&V } \\
\text { plan } \\
\text { [Smith2007] }\end{array}$} & Tests front-end capabilities \\
\hline $\begin{array}{l}1=\mathrm{UOX}-51 \\
2=\text { Single-mass MOX-NpPu }\end{array}$ & & & Tests thermal recycle \\
\hline $\begin{array}{l}1=\text { UOX-51 } \\
2=\text { Multipass IMF-NpPuAm }\end{array}$ & & & $\begin{array}{l}\text { Tests use of EU for the blended } \\
\text { heterogeneous IMF } \\
\text { Tests multipass recycling in } \\
\text { thermal reactors }\end{array}$ \\
\hline $\begin{array}{l}1=\mathrm{UOX}-50 \\
3=\mathrm{CR}=0.50 \text { fast reactor }\end{array}$ & \multirow[t]{2}{*}{$\begin{array}{l}\text { VISION benchmark } \\
\text { [Smith2008] }\end{array}$} & & $\begin{array}{l}\text { Exercise 1-tier capabilities } \\
\text { Exercise external Pu supply }\end{array}$ \\
\hline $\begin{array}{l}1=\mathrm{UOX}-50 \\
2=\mathrm{MOX} \\
3=\mathrm{CR}=0.50 \text { fast reactor }\end{array}$ & & & $\begin{array}{l}\text { Tests multi-tier dynamic } \\
\text { transition case to demonstrate } \\
\text { most complex situation }\end{array}$ \\
\hline $1 \mathrm{LWR}$ per reactor slot & Self-generated & \multicolumn{2}{|c|}{$\begin{array}{l}\text { Tests } 10 \text { reactor slots } \\
\text { Tests LWR BU correlation } \\
\text { Tests legacy reactor retirement with } 10 \text { reactor slots }\end{array}$} \\
\hline $\begin{array}{l}1=\mathrm{LWR} \\
2=\mathrm{HWR}\end{array}$ & $\begin{array}{l}\text { Modification of } \\
\text { INPRO GAINS } \\
\text { benchmark (LWR } \\
\text { and HWR business as } \\
\text { usual) }\end{array}$ & \multicolumn{2}{|c|}{$\begin{array}{l}\text { Tests HWR capability } \\
\text { Tests third method of growth specification }\end{array}$} \\
\hline $\begin{array}{l}1=\mathrm{LWR}-\mathrm{UOX} \\
2=\mathrm{LWR}-\mathrm{MF} \\
3=\mathrm{FR} \\
4=\mathrm{LWR}-\mathrm{UOX} \\
5=\mathrm{HWR} \\
6=\mathrm{LWR}-\mathrm{UOX} \\
7=\mathrm{HWR}\end{array}$ & $\begin{array}{l}\text { Modification of } \\
\text { INPRO GAINS } \\
\text { benchmark ( } 3 \text { non- } \\
\text { geographical regions) }\end{array}$ & \multicolumn{2}{|c|}{$\begin{array}{l}\text { Test partial multi-region capability } \\
\text { Test having } 4 \text { reactor technologies }\end{array}$} \\
\hline $\begin{array}{l}\text { Use all } 10 \text { slots } \\
1=\text { LWR-UOX } \\
2=\text { LWR MF } \\
3=\text { FR-burner-metal } \\
4=\text { FR-burner oxide } \\
5=\text { FR-breeder metal } \\
6=\text { HWR-UOX (no sep) } \\
7=\text { HWR-DUPIC (new recipe) } \\
8=\text { VHTR } \\
9=\text { LWR-UOX region2 (no sep) } \\
10=\text { blank (multiregion sep) }\end{array}$ & Self-generated & \multicolumn{2}{|c|}{$\begin{array}{l}\text { Tests } 10 \text { slots for reactor, separation, fuels. } \\
\text { Tests wide range of reactor and fuel types } \\
\text { concurrently. } \\
\text { Tests fully automatic ordering of reactors, fuels, } \\
\text { and separation capacity Tests draft ORNL HWR- } \\
\text { DUPIC recipe }\end{array}$} \\
\hline $\begin{array}{l}\text { 1=LWR UOX } \\
2=\text { LWR MOX } \\
3=\text { FR } \\
\text { Separation/fuel/reactor changes }\end{array}$ & Self-generated & \multicolumn{2}{|c|}{$\begin{array}{l}\text { Tests change of separation strategy } \\
\text { Tests } 4 \text { phases } \\
\text { Tests concurrent separation/fuel changes } \\
\text { Tests phase out of thermal recycling }\end{array}$} \\
\hline
\end{tabular}

\section{A-3.7.1 One LWR per Reactor Type}

This is a new case, designed to test 10 reactor slots, each has a single LWR in 2000. One LWR retires every 2 years starting in 2020, so that reactor- 1 should retire first, then reactor-2, etc.

The fuels, however, differ among the 10 reactor slots, allowing test of the LWR burnup correlation feature, see Table A-2. 
VISION User Guide, Rev 3.4

June 2011

Table A-2. Reactor, Fuel, and Separation Specifications for One LWR per Reactor Type

\begin{tabular}{|l|l|l|c|l|l|}
\hline$\#$ & Reactor & \multicolumn{1}{|c|}{ Fuel } & Fuel \# & \multicolumn{1}{|c|}{ Separations } & \multicolumn{1}{|c|}{ Separation \# } \\
\hline 1 & LWR & UOX 51 burnup & 103 & None & None \\
\hline 2 & LWR & UOX 51 burnup & 51 & None & None \\
\hline 3 & LWR & UOX 50 burnup & 50 & None & None \\
\hline 4 & LWR & UOX 33 burnup & 102 & None & None \\
\hline 5 & LWR & UOX 33 burnup & 33 & None & None \\
\hline 6 & LWR & UOX 51 burnup & 103 & None & None \\
\hline 7 & LWR & UOX 51 burnup & 51 & None & None \\
\hline 8 & LWR & UOX 50 burnup & 50 & None & None \\
\hline 9 & LWR & UOX 33 burnup & 102 & None & None \\
\hline 10 & LWR & UOX 33 burnup & 33 & None & None \\
\hline
\end{tabular}

\section{A-3.7.2 UOX-51 to $\mathrm{CR}=0.50$ Fast Reactor}

The 2007/2008 benchmark had the following basic parameters.

Table A-3. Reactor, Fuel, and Separation Specifications for Early 1-Tier Benchmark

\begin{tabular}{|c|c|l|c|c|c|}
\hline$\#$ & Reactor & Fuel & Fuel \# & Separations & Separation \# \\
\hline 1 & LWR & UOX & 103 & UREX+1 & 2 \\
\hline 2 & & & & & 21 \\
\hline 3 & FR & Metal CR $=0.50$ & 605 & Electrochemical & \\
\hline
\end{tabular}

\section{A-3.7.3 UOX-51 to 1-pass MOX-Pu to CR=0.50 Fast Reactor}

The 2007/2008 benchmark had the following basic parameters.

Table A-4. Reactor, Fuel, and Separation Specifications for early 2-Tier Benchmark

\begin{tabular}{|c|l|l|c|l|c|}
\hline$\#$ & Reactor & \multicolumn{1}{|c|}{ Fuel } & Fuel \# & Separations & Separation \# \\
\hline 1 & LWR & UOX & 103 & UREX+3 & 11 \\
\hline 2 & LWR MF & MOX-NpPu & 308 & UREX+1 & 2 \\
\hline 3 & FR & Metal CR $=0.50$ & 605 & Electrochemical & 21 \\
\hline
\end{tabular}

\section{A-3.7.4 LWR and HWR Once Through}

A new test case was developed from an INPRO GAINS benchmark described elsewhere.[Dixon2009] Key points of the scenario are as follows:

- Two types of reactors (LWRs and HWRs) in a once-through fuel cycle. Each $1 \mathrm{GWe}$ capacity/reactor, $80 \%$ capacity factor, $33 \%$ thermal efficiency, and 40 -year lifetime.

- 5000 GWe-year in 2100, 4700 for LWRs, 300 for HWRs

- Uses historic reactor capacities through 2008, then 6\% HWRs thereafter

- Growth is based on fixed output at 2030, 2050, 2100 with linear growth between points. No additional growth after 2100 .

- No growth after 2100 . 
The scenario is modeled using the third method of growth specification, namely set the target electricity production in 2100 and the percent of that target yearly from 2000 to 2100 . Key specifications are in Table A-5.

Table A-5. Reactor, Fuel, and Separation Specifications for LWR and HWR Once-Through

\begin{tabular}{|l|l|l|c|l|l|}
\hline$\#$ & Reactor & Fuel & Fuel \# & Separations & \multicolumn{1}{c|}{ Separation \# } \\
\hline 1 & LWR & UOX (45 burnup) & 108 & None & None \\
\hline 2 & HWR & Oxide (7 burnup) & 203 & None & None \\
\hline
\end{tabular}

\section{A-3.7.5 Approximation of Three Regions}

A new test case was developed from an INPRO GAINS benchmark described elsewhere.[Dixon2009] Key points of the scenario as they specified it are as follows:

- Region 1 = mature infrastructure, including recycling with fast burner reactors after $2040 ; 45 \%$ of historic growth, high future growth.

- $\quad$ Region 2 = mature infrastructure with both LWRs and HWRs, once-through fuel cycle with indefinite dry storage; $30 \%$ of historic growth moderate future growth.

- $\quad$ Region 3 = limited infrastructure with both LWRs and HWRs; $25 \%$ of historic growth, very high future growth.

- Independent case - once-fuel fuel cycle, dry storage

- Synergistic case - gets fresh LWR fuel from other regions $\left(2 / 3^{\text {rd }}\right.$ from Region $1,1 / 3^{\text {rd }}$ from Region 2), returns SNF -No conversion or enrichment capabilities

VISION 3.4 was not designed for full multi-region capability. However, it can model many dynamics of multiple regions, including the mix of reactor and fuel types and most routing among reactor fleets. There are four ways in which it cannot directly model the above specification.

First, it cannot model enrichment or uranium mining segregated by region or reactor type or fuel type. In the real world, uranium enrichment and uranium mining are international commodities and VISION merely calculates the required flows for each of the 10 reactor fleets. A user trying to directly model the above specification would have to manually add the specified mining, conversion, enrichment, and UOX fuel fabrication flows from region 3 to region 1 and region 2 .

Second, it cannot directly model the above growth specification. Recall that users can specify reactor growth in three ways:

- Specify growth for the combined nuclear reactor fleets on Growth Rate worksheet, specify the percent of that total allocated (by year) for each of the reactor types on the Reactor $\%$ s worksheet.

- Specify the precise number of reactors for each reactor types, by year, on the Reactor \#'s worksheet.

- Specify the year-2100 electricity generated for each reactor type on the Reactor Facility worksheet, then specify (by reactor type), the percent of the year-2100 value for each reactor type by year on the Reactor Growth \% of Final worksheet. 
The first method treats the entire simulation as a single "region" in the sense that there is a single nuclear energy growth specification; the third method treats each reactor type as its own "region" in the sense that it has its own energy growth specification independent of other reactor types (other regions). The INPRO GAINS specification lies between these, with reactors 1-3, 4-5, 6-7 having 3 growth specifications. This would be modeled by VISION by any of the three methods if external calculations were done to translate the specifications. This of course loses some hypothetical dynamics of multi-region scenarios in that VISION would not have reactors 1-2-3, 4-5, 6-7 interacting with regard to growth among themselves. For example, if region 1 was as specified and region 2 had LWR and FR (instead of LWR and HWR once through), then a true multi-region scenario would require algorithms for deciding FR/LWR interaction in regions 1 and 2 either independent or dependent on each other. Alternatively, if region 2 had LWR and HWR but the HWR used the DUPIC fuel option (using used LWR fuel), then there would be an intraregion interaction between HWR and LWR. In the current specification; however, there is no intra-region interaction between 4-5 and between 6-7.

Third, VISION cannot directly model the fuel routing from region 3 back to regions 1 and 2 . The INPRO GAINS specification is that $2 / 3$ goes to region 1 and $1 / 3$ goes to region 2 . This is a "push/percent" routing approach, whereas VISION uses a "pull/priority" routing from reactor to separations. For VISION 3.4 testing, we merely want to test having mass flows among reactor and separation types. Region 2 (reactors 4-5) do not make or receive fuel from region 3. Region 3 (reactors 6-7) do.

Fourth and final, VISION does not have the ability to specify legacy reactor retirement by reactor type; instead it retires reactor-1 first, then reactor-2, etc. A more exact simulation of the INPRO GAINS case would be simulated by starting before 2000 so that there were no legacy reactors.

The total fleet is assumed to start at $100 \mathrm{GWe-FPY/calendar} \mathrm{year,} \mathrm{which} \mathrm{is} \mathrm{assumed} \mathrm{to} \mathrm{be} 15 \%$ of total electricity. With all initial reactors assumed to be $1 \mathrm{GWe}$ capacity operating at $90 \%$ capacity factor, there must be 111 reactors in 2000, allocated as in Table A-6.

Table A-6. Reactor, Fuel, and Separation Specifications for Approximation of Three Regions

\begin{tabular}{|c|l|l|l|l|l|c|}
\hline$\#$ & Reactor & \multicolumn{1}{|c|}{ Percent } & \multicolumn{1}{|c|}{ Fuel } & Fuel \# & \multicolumn{1}{|c|}{ Separations } & Separation \# \\
\hline 1 & LWR & $\begin{array}{c}22.5 \% \text { in } 2000 \\
0 \% \text { in } 2100\end{array}$ & UOX (45 burnup) & 108 & UREX+3 & 11 \\
\hline 2 & LWR & $\begin{array}{c}22.5 \% \text { in } 2000 \\
0 \% \text { in } 2100\end{array}$ & MOX-NpPu & 308 & UERX+1 & 2 \\
\hline 3 & FR & $\begin{array}{c}0 \% \text { in } 2000 \\
45 \% \text { in } 2100\end{array}$ & $\begin{array}{l}\text { Metal fuel with } \\
\text { CR=0.50 }\end{array}$ & 605 & Electrochemical & 21 \\
\hline 4 & LWR & $15 \%$ & UOX (45 burnup) & 108 & None & 40 \\
\hline 5 & HWR & $15 \%$ & HWR-UOX & 203 & None & 40 \\
\hline 6 & LWR & $12.5 \%$ & UOX (45 burnup) & 108 & None & 40 \\
\hline 7 & HWR & $12.5 \%$ & HWR-UOX & 203 & None & 40 \\
\hline
\end{tabular}

\section{A-3.7.6 10 Reactor and Fuel Types}

We created this test case to exercise all 10 reactor-separation-fuel-fab trains with a wide range of reactor types concurrently. It also gave us a chance to test a new fuel recipe supplied by ORNL for the DUPIC fuel cycle. 
Table A-7. Reactor, Fuel, and Separation Specifications for the 10 reactor and fuel case

\begin{tabular}{|c|c|c|c|c|c|}
\hline \# & Reactor & Fuel & Fuel \# & Separations & Separation \# \\
\hline 1 & LWR & UOX & 103 & UREX+3 & 11 \\
\hline 2 & LWR MF & $\mathrm{MOX}-\mathrm{Pu}$ & 301 & UREX+1 & 2 \\
\hline 3 & FR & Metal $\mathrm{CR}=0.50$ & 605 & Electrochemical & 21 \\
\hline 4 & FR & Oxide $\mathrm{CR}=0.50$ & 610 & Electrochemical & $\begin{array}{l}23 \text { (mod of } 21 \text { but send to } \\
\text { fuel-4 instead of } 3 \text { ) }\end{array}$ \\
\hline 5 & FR & Metal $\mathrm{CR}=1.07$ & 614 & Electrochemical & $\begin{array}{c}24 \text { (mod of } 21 \text { but send to } \\
\text { fuel-5 instead of } 3)\end{array}$ \\
\hline 6 & HWR & Oxide & 203 & None & None \\
\hline 7 & HWR & DUPIC & 204 & None & None \\
\hline 8 & VHTR & Oxide & 201 & None & None \\
\hline 9 & LWR & UOX & 103 & None & None \\
\hline 10 & None & None & None & Into DUPIC fuel & $\begin{array}{l}33 \text { (modification of } 32 \text { but } \\
\text { send fuel to } 7 \text { instead of } 3 \text { ) }\end{array}$ \\
\hline
\end{tabular}

\section{A-3.7.7 Separation Technology Change}

We created this scenario to test multiple concurrent reactor/fuel/separation technology changes. There are effectively four phases:

$$
\begin{aligned}
& \text { a - once through } \\
& \text { b - recycle used UOX via COEX, make MOX-Pu, start fast reactors } \\
& \text { c - recycle used UOX via UREX+4, make MOX-NpPuAm, continue fast reactors } \\
& \text { d - recycle used UOX via UREX+1, phase out thermal reactor recycling }
\end{aligned}
$$

The transition from 1 to 2 tests the change in separation technology from not recovering the so-called minor actinides $(\mathrm{Np}, \mathrm{Am}, \mathrm{Cm}, \mathrm{Bk}, \mathrm{Cf})$ to recovering them. We modeled this by changing from COEX (separation matrix 16) to UREX+4 (separation matrix 11) for the separation-1 type. Note that the specifications for reactor-2/fuel-2 do change (deliberately) in this example from early/middle from MOX$\mathrm{Pu}$ (fed by COEX) to MOX-NpPuAm (fed by UREX+4).

The third phase tests phase out of thermal reactor use of recycled material. This means that separation-1 changes (from UREX+4 to UREX+1) and fuel-2 changes (from MOX-NpPuAm back to UOX).

This scenario tests the model (and user's) ability to coordinate changes as follows:

- Reactor Fuel Type worksheet

- Recycle Strategy Option worksheet from once-through (matrix 15) to 2-tier recycling (matrix 7) for both "b" and "c" phases to phase out thermal recycling (matrix 13).

- Separation worksheets 
VISION User Guide, Rev 3.4

June 2011

Table A-8. Reactor, Fuel, and Separation Specifications for Technology Change Case

\begin{tabular}{|l|l|l|c|l|c|}
\hline$\#$ & Reactor & \multicolumn{1}{|c|}{ Fuel } & Fuel \# & Separations & Separation \# \\
\hline $1-\mathrm{a}$ & LWR & UOX & 103 & None & None \\
\hline $1-\mathrm{b}$ & LWR & UOX & 103 & COEX & 16 \\
\hline $1-\mathrm{c}$ & LWR & UOX & 103 & UREX+4 & 11 \\
\hline $1-\mathrm{d}$ & LWR & UOX & 103 & UREX+1 & None \\
\hline $2-\mathrm{a}$ & LWR MF & UOX & 103 & None & 2 \\
\hline $2-\mathrm{b}$ & LWR MF & MOX-Pu & 301 & UREX+1 & 2 \\
\hline $2-\mathrm{c}$ & LWR MF & MOX-NpPuAm & 306 & UREX+1 & 2 \\
\hline $2-\mathrm{d}$ & LWR MF & UOX & 103 & UREX+1 & 21 \\
\hline 3 & FR & Metal CR $=0.50$ & 605 & Electrochemical & \\
\hline
\end{tabular}

